\title{
A COMPENDIUM OF RADIOCARBON AND OXIDIZABLE CARBON RATIO DATES FROM ARCHAEOLOGICAL SITES IN EAST TEXAS, WITH A DISCUSSION OF THE AGE AND DATING OF SELECT COMPONENTS AND PHASES
}

\section{TIMOTHY K. PERTTULA}

\author{
Frontera Archaeology, 10101 Woodhaven Drive, Austin, Texas 78753-4346 USA
}

\begin{abstract}
This paper presents a compilation of the $>520$ radiocarbon and oxidizable carbon ratio dates obtained since the early 1950s from archaeological sites in East Texas. Many of the dates are from difficult-to-obtain sources, such as archaeological sites investigated during the course of cultural resource management projects. An analysis of the age ranges in the dates indicate that most pertain to prehistoric and protohistoric Caddoan Indian occupations, particularly the Early (AD 10001200 ) and Middle Caddoan (AD 1200-1400) periods when prehistoric Caddoan settlements were widely distributed throughout the region.
\end{abstract}

\section{INTRODUCTION}

More than 520 radiocarbon and oxidizable carbon ratio (OCR) dates have been obtained from archaeological sites in East Texas in the last 40 years or so (the OCR dates have only been obtained since 1996, however). This constitutes a large and important chronological database on prehistoric and historic Native American occupations in the region, but it has been difficult to use because much of the information on the dates, and the archaeological sites from which the dates were obtained, has not been widely accessible until now. In this paper, I present a compendium of all available ${ }^{14} \mathrm{C}$ and OCR dates from East Texas, current as of July 1, 1997 (Tables 1 and 2, Appendix).

This compendium is based on both published and unpublished information from East Texas archaeological investigations, particularly cultural resource management excavations conducted under the auspices of the Antiquities Code of Texas and Section 106 of the National Historic Preservation Act. Dee Ann Story's (1990a) published compilation was the one key resource utilized to build the database presented here, along with the extensive ${ }^{14} \mathrm{C}$ database from investigations at Cooper Lake in the Sulphur River basin (Fields et al. 1997: Appendix B). The results of the many additional samples included here were gathered from draft and final archaeological technical reports on file at the Division of Archeology at the Texas Historical Commission (Austin, Texas), or provided by researchers working in East Texas (see Acknowledgments).

Data on the ${ }^{14} \mathrm{C}$ assays are included in Table 1 , namely the assay number, the provenience, the raw ${ }^{14} \mathrm{C}$ age, the $\delta^{13} \mathrm{C}$ values, the corrected ${ }^{14} \mathrm{C}$ age, the calibrated age range, and the relative area under the probability distribution for $1-\sigma$ calibrated ages. The ${ }^{14} \mathrm{C}$ assays are uniformly corrected (for isotopic fractionation) and calibrated at a 20 -yr interval scale for calendric dates using CALIB 3.03c, Test 10 (Stuiver and Reimer 1993a, 1993b). With a few exceptions noted in Table 1, assays that lacked ${ }^{13} \mathrm{C}$ values use the value estimates for fractionation correction suggested by Stuiver and Reimer (1993b: Table 1): $-25 \%$ for nutshells and charcoal, and $-10 \%$ for charred maize.

As of the writing of this paper, only five archaeological sites in East Texas have OCR dates: 41BW553, Knight's Bluff (41CS14), 41TT670, Tom Moore (41PN149), and Camp Joy Mound (41UR144) (Largent et al. 1997; Perttula et al. 1997a, 1997b; Mark Walters, personal communication 1997). OCR dating is a new dating procedure developed by the Archaeology Consulting Team, Inc. (Essex Junction, Vermont) for obtaining absolute dates on charcoal and soil humic materials from features. The procedure measures the relationship between the total carbon and the readily oxidizable carbon in a soil sample, with the ratio between the two-the oxidizable carbon ratio-apparently following a linear progression through time. Frink (1992, 1994, 1995; see also Kindall 1997) 
discusses the OCR dating procedure in detail. Table 2 provides data on the 23 available OCR dates in East Texas, with information on assay number, the provenience, the calculated OCR date in years before present, the confidence interval, and the final, rounded date as suggested by Frink (1996 personal communication). As OCR dating is a new dating method, its reliability and validity (in the sense of Ramenofsky and Steffen 1998: 8-10) as an absolute estimate of time has not been fully established, and more OCR samples are warranted (particularly from contexts where ${ }^{14} \mathrm{C}$ dates have also been obtained) to assess how the factors of sample depth, mean temperature, average annual rainfall, mean soil texture, soil acidity, and percent of carbon (Frink 1994) are influencing the OCR dates from East Texas.

\section{DATABASE}

Currently, there are $503{ }^{14} \mathrm{C}$ dates and 23 OCR dates from 102 prehistoric archaeological sites in 22 East Texas counties (Table 3). However, most of the archaeological sites only have between one and three dates (Tables 1 and 2), with very few of the sites having more than a total of $1{ }^{14} \mathrm{C}$ and/or OCR assays. The latter sites include George C. Davis (41CE19, $n=130$; Story 1990a, 1997, 1998; Story and Valastro 1977); Spider Knoll (41DT11, n=23; Fields et al. 1994a); Arnold (41HP102, $\mathrm{n}=18$; Doehner and Larson 1978); Hurricane Hill (41HP106, $\mathrm{n}=18$; Perttula 1998); and Mockingbird (41TT550, $\mathrm{n}=17$; Perttula et al. 1998); three of the sites are in the Cooper Lake project area in Delta and Hopkins counties (Fields et al. 1997).

TABLE 3. County Statistics on Sites with Dates and Number of Dates

\begin{tabular}{lcccc}
\hline County & $\begin{array}{c}\text { No. of sites } \\
\text { with }{ }^{14} \mathrm{C} \\
\text { dates }\end{array}$ & $\begin{array}{c}\text { No. of }{ }^{14} \mathrm{C} \\
\text { dates }\end{array}$ & $\begin{array}{c}\text { No. of sites } \\
\text { with OCR } \\
\text { dates }\end{array}$ & $\begin{array}{c}\text { No. of } \\
\text { OCR dates }\end{array}$ \\
\hline Anderson & 3 & 5 & -- & -- \\
Bowie & 3 & 10 & 1 & - \\
Camp & 2 & 3 & -- & -- \\
Cass & 5 & 12 & 1 & 3 \\
Cherokee & 1 & 130 & -- & -- \\
Delta & 15 & 84 & -- & -- \\
Harrison & 3 & 6 & -- & -- \\
Henderson & 4 & 11 & -- & -- \\
Hopkins & 10 & 65 & -- & -- \\
Jasper & 1 & 3 & -- & -- \\
Lamar & 2 & 20 & -- & -- \\
Morris & 1 & 5 & -- & -- \\
Nacogdoches & 3 & 15 & -- & -- \\
Panola & -- & -- & 1 & 2 \\
Red River & 5 & 23 & -- & -- \\
Rusk & 4 & 15 & -- & -- \\
Sabine & 2 & 2 & -- & -- \\
Shelby & 3 & 6 & -- & -- \\
Smith & 1 & 1 & -- & -- \\
Titus & 13 & 48 & 1 & 7 \\
Upshur & 8 & 17 & 1 & 2 \\
Wood & 9 & 22 & -- & -- \\
\hline
\end{tabular}


The counties with the highest numbers of sites with ${ }^{14} \mathrm{C}$ dates (Delta, Titus and Hopkins) all have been the scene of intensive cultural resource management-related archaeological investigations in the 1980s and 1990s. The same situation basically exists for the counties with the highest numbers of ${ }^{14} \mathrm{C}$ (and OCR) dates, with the exception of Cherokee County, where the 130 dates from the George C. Davis site were obtained principally from intensive investigations of mound and village areas in 1968-1970 (Story 1997, 1998).

The great majority of the East Texas ${ }^{14} \mathrm{C}$ dates have been obtained from Late Archaic, Woodland, and Formative-Late Caddoan period sites (Fig. 1). Less than $1.5 \%$ of the dates are associated with either Paleoindian (ca. 10,000-6000 BC) or Early/Middle Archaic (ca. 6000-2000 BC) period occupations, and $<0.5 \%$ may be associated with the post-AD 1680 Caddoan occupation of the region. The largest number of ${ }^{14} \mathrm{C}$ dates $(\mathrm{n}=128)$ fall in the Middle Caddoan period (ca. $\left.\mathrm{AD} 1200-1400\right)$, followed by the Early Caddoan period ( $c a$. AD 1000-1200) (n=101; Fig. 1).

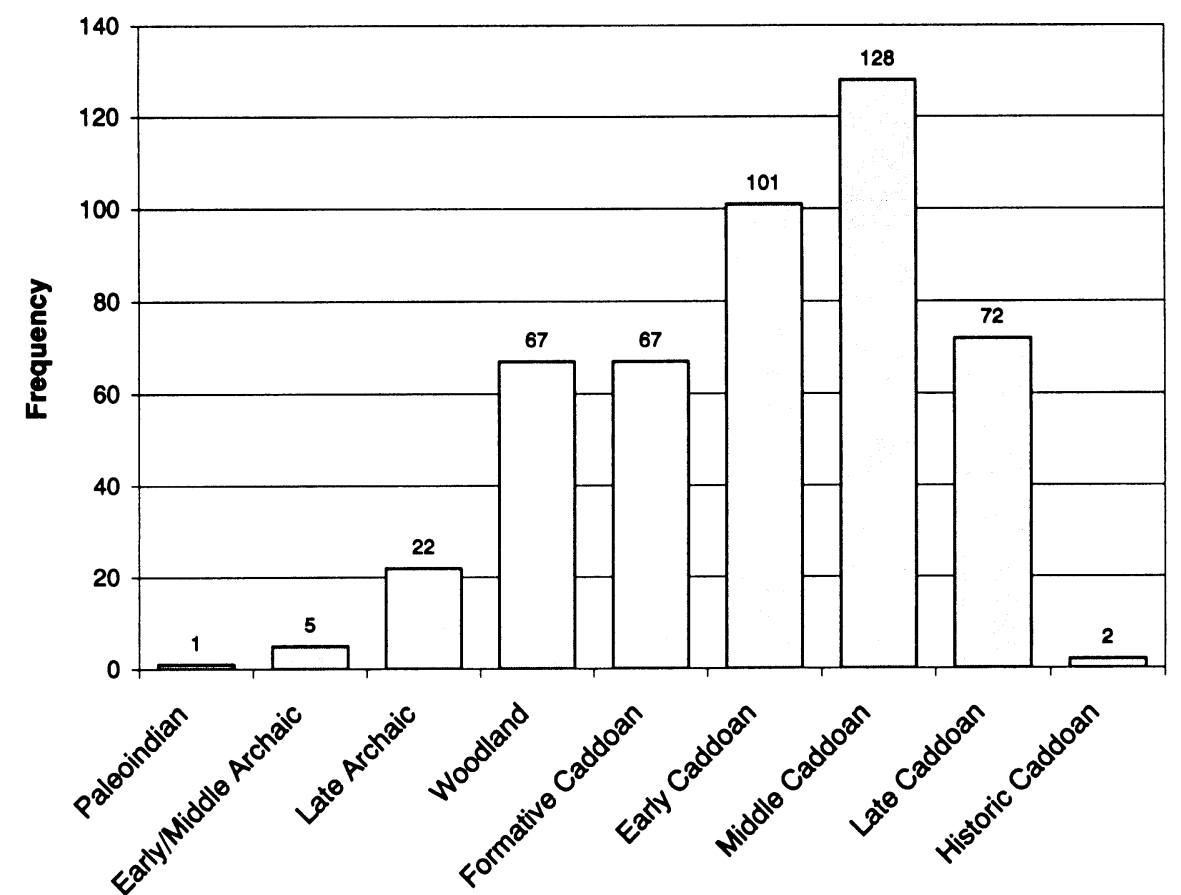

Fig. 1. Number of ${ }^{14} \mathrm{C}$ dates for the Paleoindian, Early/Middle Archaic, Late Archaic, Woodland, Formative Caddoan, Early Caddoan, Middle Caddoan, Late Caddoan and Historic Caddoan periods

Almost $80 \%$ of the ${ }^{14} \mathrm{C}$ dates pertain to occupations at prehistoric and protohistoric Caddoan sites in East Texas (Fig. 1). Relative to the 200-yr periods defined by Story (1990b: 334) for the Caddoan tradition, ${ }^{14} \mathrm{C}$ dates associated with the Early and Middle Caddoan periods comprise $62 \%$ of the total ${ }^{14} \mathrm{C}$ date sample, followed by those falling in the Late Caddoan (AD 1400-1680) (19.5\%) and Formative Caddoan ( $\mathrm{AD} 800-1000)$ (18.1\%) periods (Fig. 2).

At a slightly finer scale, using calibrated ages and age mid-points of 1- $\sigma$ calibrated age ranges, the largest number of Caddoan ${ }^{14} \mathrm{C}$ dates fall within the $\mathrm{AD} 1201-1300$ interval (Fig. 3). While the number of dates in this period of time is probably inflated to some degree by the extensive series of dates from the George C. Davis site (Table 1), nevertheless it does appear to be the case that Middle Caddoan 
period occupations are rather commonplace throughout much of East Texas (Middlebrook and Perttula 1997). In fact, this period probably represents the major peak in the region's occupational history. As such, the available ${ }^{14} \mathrm{C}$ data support as a whole the broad findings of archaeological research from East Texas (Story 1990b; Middlebrook and Perttula 1997). Other 100-yr intervals with large numbers of ${ }^{14} \mathrm{C}$ dates are (in decreasing frequency) $\mathrm{AD} 1001-1100, \mathrm{AD} 1401-1500, \mathrm{AD} 901-1000$ and $\mathrm{AD}$ $1301-1400 .{ }^{14} \mathrm{C}$ dates are particularly rare for the $\mathrm{AD} 1601-1700$ and $\mathrm{AD} 1701-1800$ intervals.

Again using calibrated ages and mid-points of 1- $\sigma$ age ranges, but looking at 25-yr intervals, there are interesting fluctuations in the number of ${ }^{14} \mathrm{C}$ dates for the Caddoan period sites in East Texas (Fig. 4). The 25-yr intervals between $\mathrm{AD} 1201-1225$ and $\mathrm{AD}$ 1226-1250 - the early part of the Middle Caddoan period-have the most ${ }^{14} \mathrm{C}$ dates, followed by the interval between $\mathrm{AD} 1351-1375$ and the two 25-yr intervals between AD 1076-1125.

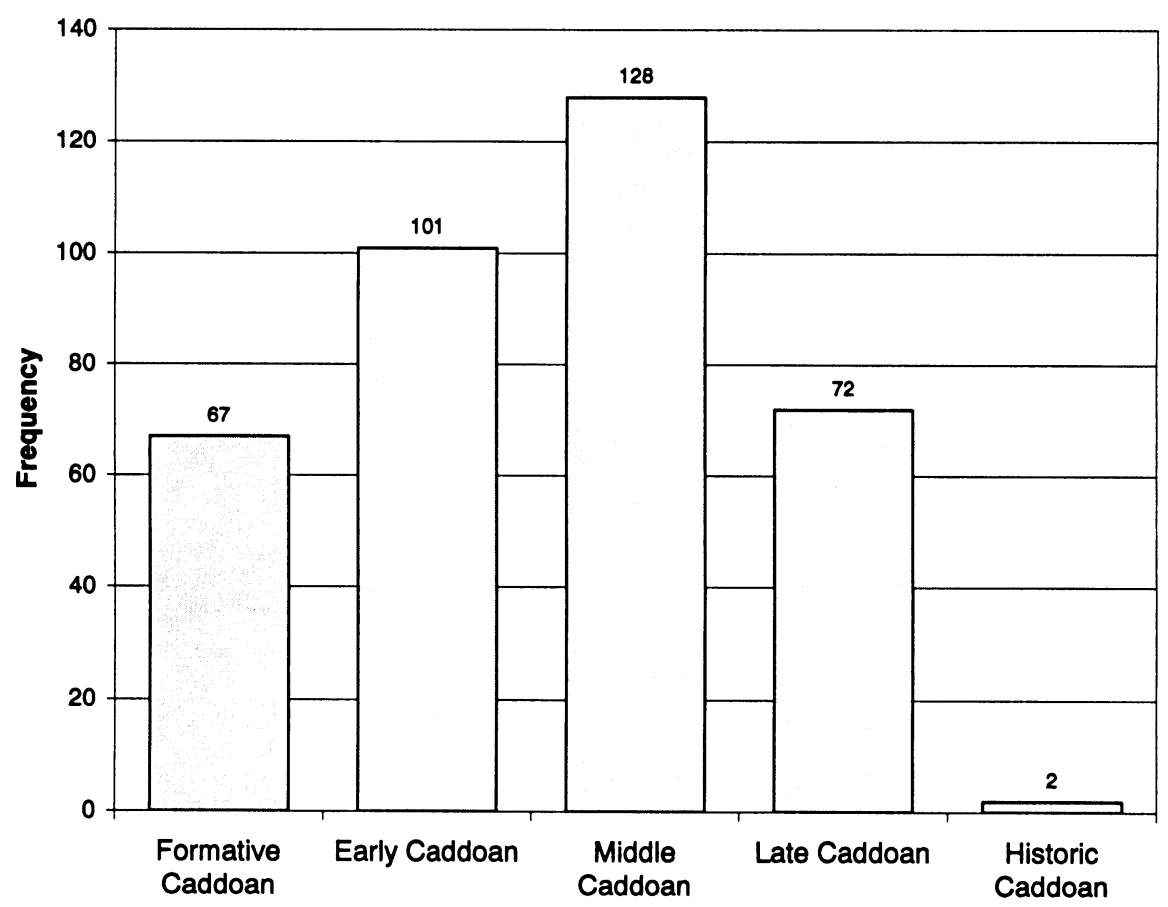

Fig. 2. Number of ${ }^{14} \mathrm{C}$ dates for the Formative Caddoan through Historic Caddoan periods

\section{Discussion}

The single possible ${ }^{14} \mathrm{C}$ date from a Paleoindian context in East Texas is from charcoal in a probable hearth buried in Late Pleistocene alluvium at the Delta Bone Quarry 5 (41DT86) on the North Sulphur River (Slaughter and Hoover 1963, 1965). While the context of the materials (including an antler tool) from the site are not unequivocal, the calibrated 1- $\sigma$ date of $8082-9170 \mathrm{BC}$ is broadly contemporaneous with Clovis, Folsom and Dalton complexes in the region.

Two sites in East Texas, both in the Sulphur River basin, have archaeological components dated by ${ }^{14} \mathrm{C}$ to pre-3000 BC contexts. A single burned rock feature at the Unionville site (41CS151) has a calibrated date of 4040-4161 BC (Cliff et al. 1996), while extensive excavations at the Finley Fan site (41HP159) exposed portions of two buried and stratigraphically discrete Middle Archaic components that date between 3152-4410 BC (Fields et al. 1997: 42). 


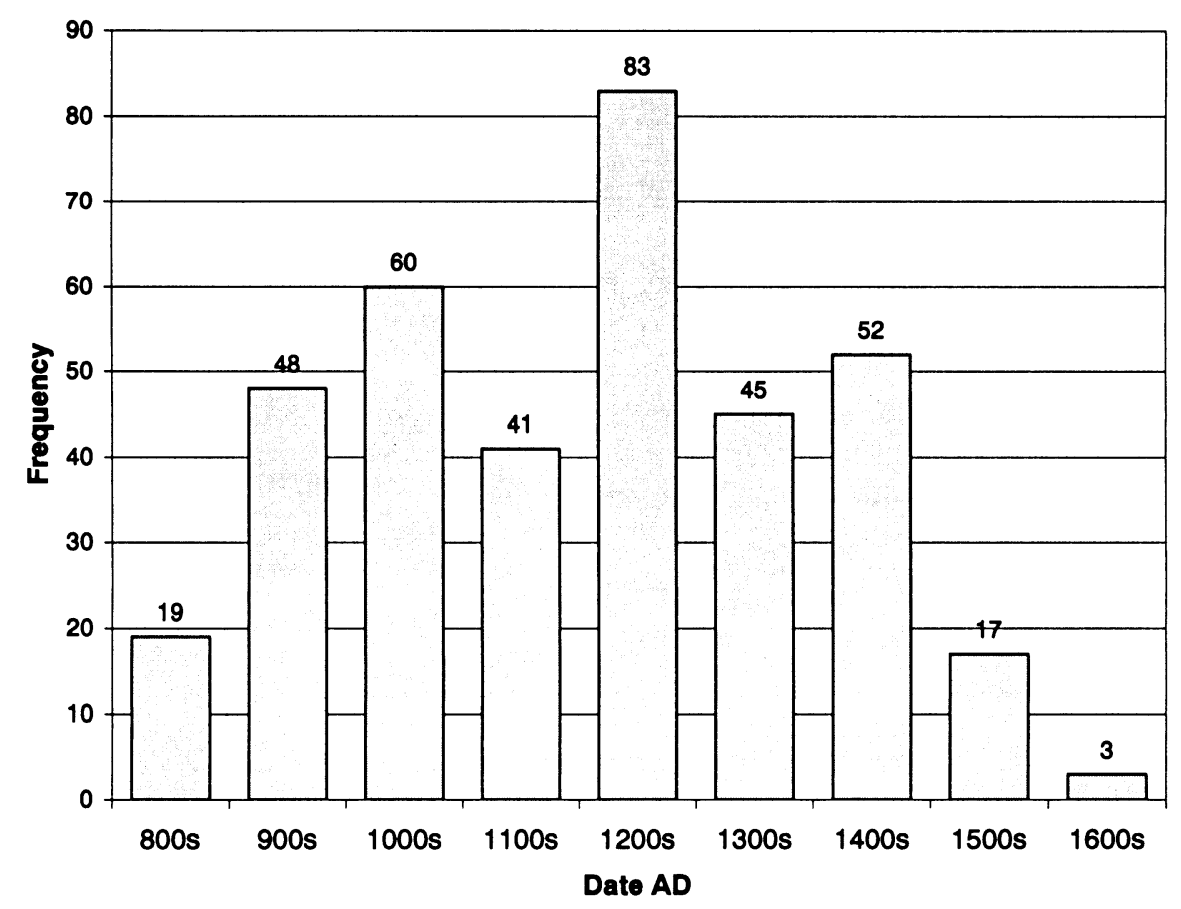

Fig. 3. Number of calibrated ${ }^{14} \mathrm{C}$ dates at 100 -yr intervals, $\mathrm{AD} 800-1750$

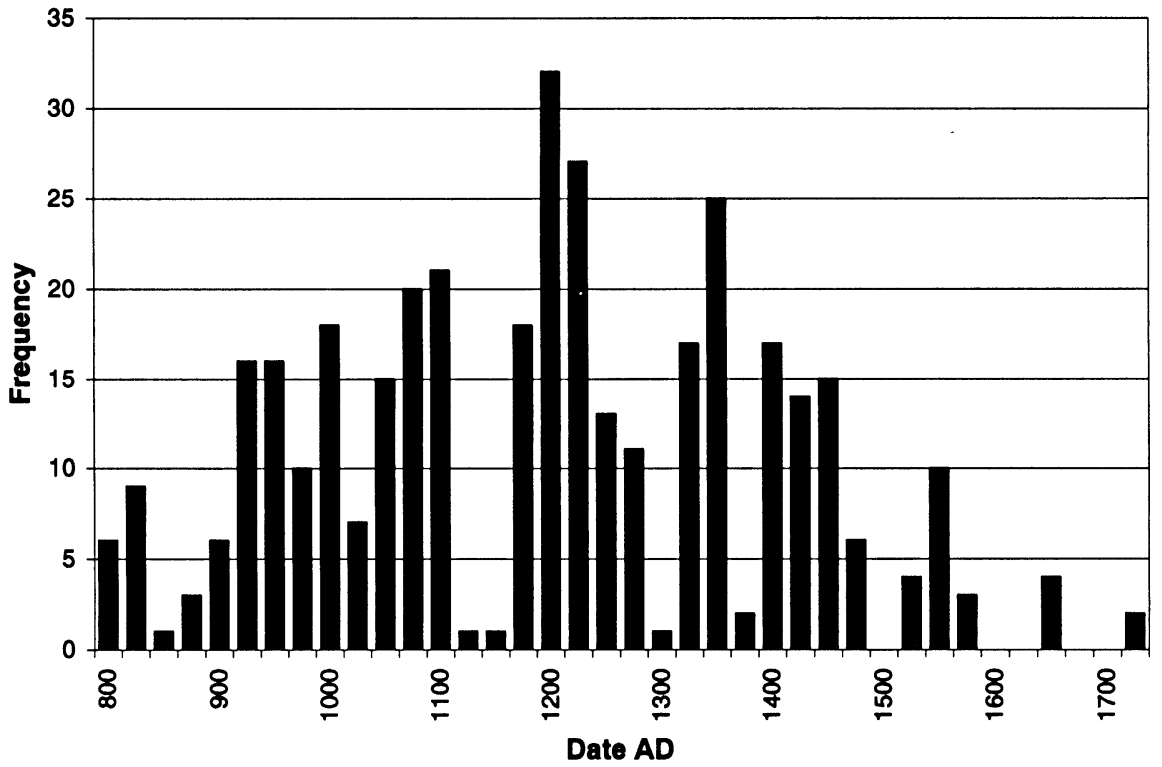

Fig. 4. Number of calibrated ${ }^{14} \mathrm{C}$ dates at 25 -yr intervals, $\mathrm{AD}$ 800-1675

For the Late Archaic period, there are still few well-dated archaeological components, although occupations of this period are apparently abundant throughout all East Texas river valleys and hinterland areas ( $c f$. Fields 1995; Perttula 1995). Fairly well-dated Late Archaic components include 
buried shell lens that date from 766 to $1084 \mathrm{BC}$ at the Winston site (41HE245) on the Trinity River (Richner and Bagot 1978); a buried scatter of burned rocks and lithic artifacts at the W. S. Long \#3 site (41HP118) in the South Sulphur River floodplain that dates from 924 to 1222 BC (McGregor and Martin 1997); and a small concentration of tools and burned rocks at the Mockingbird site (41TT550) that date between 408 and 828 BC (Table 1).

The best-dated Woodland period components in East Texas were investigated prior to the construction of Cooper Lake on the South Sulphur River (Fields et al. 1997). These include the Tick (41DT6), Spike (41DT16), Hurricane Hill (41HP106), and 41HP137 sites. The Tick and Spike sites have thick $(60-100 \mathrm{~cm})$ middens, with calibrated age spans for the Woodland occupations of $A D$ 192-896 and BC 195-AD 891, respectively (Table 1 ). The six calibrated dates from Woodland period contexts at Hurricane Hill range from $A D$ 59-449, and they are from features associated with a small midden and a cemetery of cremations and bundle burials (Perttula 1998). At 41HP137, the Woodland component dates from $\mathrm{BC} 122-\mathrm{AD} 652$, the ${ }^{14} \mathrm{C}$ dates being obtained from small pit features, one of which contained charred cultivated squash seeds (McGregor 1997).

Certainly the most thoroughly dated Formative and Early Caddoan period site in East Texas is the George C. Davis site (41CE19), a large village and mound center on the Neches River (Story 1997). Calibrated ${ }^{14} \mathrm{C}$ dates from village contexts establish that the site was occupied beginning in the ninth century $\mathrm{AD}$, and then continuously settled through the end of the 13th century $\mathrm{AD}$. A late series of calibrated dates from a few village contexts (such as Units 11, 43, and 109; Story 1998: Table 2-1) suggest that the site was inhabited to some degree as late as ca. AD 1350 (Table 1). While there are fewer dates from the three mounds at George C. Davis, and there are inconsistencies between several of the dates from the same general contexts, it does appear to be the case that Mound A (a large flat-topped platform) and Mound C (a burial mound) were built in the latter part of the Formative Caddoan period (Story 1997, 1998), and Mound B (flat-topped platform) was constructed $c a$. AD 1200 or slightly earlier.

There are several well-dated Early Caddoan period habitation sites at Cooper Lake, including the upper component at Spike, Doctors Creek (41DT124; Martin 1997), and 41DT63 (Fields et al. 1997). In the upper Sabine River basin, Early Caddoan habitation sites with consistent ${ }^{14} \mathrm{C}$ dates have been investigated at Taddlock (41WD482) and Spoonbill (41WD109) (Bruseth and Perttula 1981), as well as the Hudnall-Pirtle (41RK4) mound center and village in the middle stretches of the Sabine River basin (Bruseth 1991). Two calibrated dates from one of the eight mounds at HudnallPirtle range between AD 1152-1250. In the Red River, dated Early Caddoan period components are best known from the Roitsch or Sam Kaufman (41RR16) and Ray (41LR135) sites, both investigated during the 1991-1992 Texas Archeological Society field schools under the direction of Dr. James E. Bruseth. At Roitsch-Sam Kaufman, four calibrated dates from a structure near the East Mound (Skinner et al. 1969) range between AD 982 and 1250 (Table 1).

Two of the archaeological sites at Cooper Lake have fairly well-dated components that document settlements that extend from the Early Caddoan period into the Middle Caddoan period, Spider Knoll (41DT11) and Arnold (41HP102). At Spider Knoll, the many dates (Table 1) suggest the site was used a number of times over a period of $c a .400 \mathrm{yr}$ (Fields et al. 1997: 61), with the majority of the calibrated dates ranging from $A D$ 880-1287 (Table 1). With a few exceptions, the ${ }^{14} \mathrm{C}$ dates from the Arnold site fall into this same calibrated age range.

There are several Middle Caddoan period components in East Texas that appear to be well-dated by ${ }^{14} \mathrm{C}$ and/or OCR assays. At site 41TT670 (Largent et al. 1997) on White Oak Creek, one calibrated ${ }^{14} \mathrm{C}$ date and an OCR date (Table 2) suggest the Middle Caddoan component dates ca. AD 1150-1280, 
while two ${ }^{14} \mathrm{C}$ dates from Knight's Bluff (41CS14) pertain to a late Middle Caddoan phase that dates from $c a$. AD 1300 to 1400 (Cliff 1997: Table 1).

A residential Middle Caddoan period component at the Hurricane Hill site (41HP106) in the Cooper Lake area dates from a number of calibrated ${ }^{14} \mathrm{C}$ assays from features on the South rise to between AD 1248 and 1394 (Perttula 1998; Fields et al. 1997). An archeomagnetic date of AD $1300 \pm 50$ has also been obtained from this Middle Caddoan component.

In the middle and upper Sabine River basin, the best dated Middle Caddoan components include McKenzie (41WD55), a substructural mound site (Granberry 1995), the Oak Hill Village (41RK214), and Spoonbill (41WD109) (Table 1). The calibrated dates from the McKenzie mound range between $\mathrm{AD} 1298$ and 1470, while the three from Middle Caddoan features at the Spoonbill site are slightly earlier (AD 1228-1393). The available ${ }^{14} \mathrm{C}$ dates from the Oak Hill Village suggest the occupation there dates between $\mathrm{ca}$. AD $1150-1400$, but several other ${ }^{14} \mathrm{C}$ dates on structures now being obtained may alter estimates of the site's temporal range (Robert Rogers, personal communication 1997).

The Washington Square site (41NA49) in the Neches-Angelina River basin is another well-dated mound complex (Corbin and Hart 1998). Pooled ${ }^{14} \mathrm{C}$ dates on charcoal, hardwood nutshells, and charred corn range between cal AD 1268 and 1302 (Corbin and Hart 1998: 74 and Table 4). Finally, four calibrated ${ }^{14} \mathrm{C}$ assays from the Tyson site (41SY92) date this important Middle Caddoan period settlement in the Attoyac River basin (Middlebrook 1994) to between AD 1336 and 1490 (Table 1). One of the dates was on mussel shells included as grave goods with Feature 14, the burial of a 3- to 4-yr-old child accompanied by many grave goods (Middlebrook 1994: 16).

None of the Late Caddoan archaeological phases in East Texas (Story 1990b: Table 43) is well-dated by either ${ }^{14} \mathrm{C}$ or OCR methods. This is particularly the case for the Frankston and Allen phases, although several late 17th-early 18th century archeomagnetic dates have been obtained from the Allen phase component at the Deshazo site (Story 1995), and two ${ }^{14} \mathrm{C}$ dates from a midden deposit at the Alcoa No. 1 site (41AN87) date the Frankston phase occupation between AD 1386 and 1488 (Amick et al. 1991).

The Titus and McCurtain phases have become better dated by absolute means over the last few years (cf. Perttula et al. 1997a, 1998; Bruseth 1998). For the Titus phase, ${ }^{14} \mathrm{C}$ and OCR dates from sites such as Tuck Carpenter (41CP5), Sam Roberts (41CP8), 41TT182, Mockingbird (41TT550), 41UR118 and 41UR133 at proposed Lake Gilmer, the Camp Joy Mound (41UR144) at Lake O' the Pines, and Steck (41WD529) suggest that the Titus phase dates between $c a$. AD 1430 and 1680. Significantly, four OCR and ${ }^{14} \mathrm{C}$ dates from a burned house lens at the Camp Joy Mound (Tables 1 and 2) have convincingly documented the use of the platform mound at the site between $c a . \mathrm{AD} 1500$ and 1650 .

${ }^{14} \mathrm{C}$ dates from McCurtain phase contexts at the Roitsch-Sam Kaufman, Holdeman (41RR11; Perino 1995), and Rowland Clark (41RR77; Perino 1994) sites indicate that the McCurtain phase can be divided into early ( $c a$. AD 1300/1350-1500) and late ( $c$. AD 1500-1700) contexts ( $c f$. Bruseth 1998), with corresponding changes in ceramic decorative styles and the shape of arrow points. The early McCurtain phase features at the Holdeman site date to AD 1392-1478 at 1- $\sigma$ and AD 13321513 at Roitsch-Sam Kaufman (Table 1), while calibrated dates from ceramically later features at the Rowland Clark site range from $\mathrm{AD} 1502-1603$. Interestingly, calibrated ${ }^{14} \mathrm{C}$ dates from the Peerless Bottoms site (41HP175) in the upper Sulphur River basin, having virtually the same variety of Caddoan ceramics as early McCurtain phase sites on the Red River, range between $\mathrm{AD} 1330$ and 1524 (Fields et al. 1994b). 


\section{CONCLUSION}

Given the possibility of sampling biases (i.e., based on the selective collection of samples from the better preserved sedentary Caddoan occupation of the region, and the highly concentrated nature of cultural resource management excavation projects in East Texas; see the discussion in Bruseth (1998:49)), and calibration curve effects (e.g., Miller 1996: 55-69) on such a series of calibrated ${ }^{14} \mathrm{C}$ dates, there are clear peaks and valleys in the number of ${ }^{14} \mathrm{C}$ dates from prehistoric archaeological sites in East Texas (Figs. 1 and 2). Most notably, the analysis of the age ranges in the calibrated dates indicate that most pertain to prehistoric and protohistoric Caddoan Indian occupations, particularly the Early (AD 1000-1200) and Middle Caddoan (AD 1200-1400) periods when prehistoric Caddoan settlements were widely distributed throughout the region. Surely, future analyses of age trends based on a much larger and spatially expansive ${ }^{14} \mathrm{C}$ and OCR database will help to clarify and enrich these findings.

\section{ACKNOWLEDGMENTS}

I would like to thank the following individuals for providing me with unpublished information on ${ }^{14} \mathrm{C}$ assays from East Texas sites: Maynard Cliff, J. Brett Cruse, Ross C. Fields, Wayne Glanders, Darden Hood, Tom Middlebrook, Robert Rogers, Eric Schroeder, Mark Walters and James E. Bruseth. Thanks also to Douglas S. Frink for conducting the analyses of the OCR samples. I am also grateful to Myles Miller for the interesting discussions of ${ }^{14} \mathrm{C}$ dating and calibration curve effects, and to David Sewell and Austin Long for review comments on the paper.

\section{REFERENCES}

Amick, C., Furman, E., Perttula, T. K., Bruseth, J. E. and Yates, B. C. 1991 ALCOA \#1 (41AN87): A Frankston phase settlement along Mound Prairie Creek, Anderson County, Texas. Caddoan Archeological Newsletter II (2): 11-15.

Bruseth, J. E. 1991 Hudnall-Pirtle site (41RK4): An Early Caddoan mound complex in northeast Texas. Caddoan Archeology Newsletter II (3): 9-15.

1998 The development of Caddoan Polities along the middle Red River Valley of Eastern Texas and Oklahoma. In Perttula, T. K. and Bruseth, J. E., eds., The Native History of the Caddo: Their Place in Southeastern Archeology and Ethnohistory. Texas Archeological Research Laboratory, The University of Texas at Austin. Studies in Archeology 30: 47-68.

Bruseth, J. E. and Perttula, T. K. 1981 Prehistoric Settlement Patterns at Lake Fork Reservoir. Texas Antiquities Permit Series, Report No. 2. Texas Antiquities Committee, Austin, and Southern Methodist University, Dallas.

Cliff, M. B. 1997 The Middle Caddoan Period in the Lower Sulphur River Area. Journal of Northeast Texas Archaeology 9: 9-16.

Cliff, M. B., Green, M. M., Hunt, S. M., Shanabrook, D. and Peter, D. E. 1996 Excavations in Area C of the Unionville Site (41CS151), White Oak Creek Mitigation Area (WOCMA), Cass County, Texas. Report of Investigations No. 4, White Oak Creek Mitigation Area Archeological Technical Series. Geo-Marine,
Inc., Plano.

Corbin, J. E. and Hart, J. P. 1998 The Washington Square Mound site: A Middle Caddo mound complex in South Central East Texas. Bulletin of the Texas Archeological Society 69: 47-78.

Doehner, K. and Larson, R. E. 1978 Archaeological Research at the Proposed Cooper Lake, Northeast Texas, 1974-1975. Research Report 108. Archaeology Research Program, Southern Methodist University, Dallas.

Fields, R. C. 1995 The Archeology of the Post Oak Savannah of East-Central Texas. Bulletin of the Texas Archeological Society 66: 301-330.

Fields, R. C., Gadus, E. F., Klement, L. W. and Gardner, K. M. 1994a Excavations at the Spider Knoll Site, Cooper Lake Project, Delta County, Texas. Reports of Investigations No. 96. Prewitt and Associates, Inc., Austin.

Fields, R. C., Gadus, E. F. and Klement, L. W. 1994b The Peerless Bottoms site: A Late Caddoan component at Cooper Lake, Hopkins County, Texas. Bulletin of the Texas Archeological Society 65: 55-114.

Fields, R. C., Blake, M. E. and Kibler, K. W. 1997 Synthesis of the Prehistoric and Historic Archeology of Cooper Lake, Delta and Hopkins Counties, Texas. Reports of Investigations No. 104. Prewitt and Associates, Inc., Austin.

Frink, D. S. 1992 The chemical variability of carbonized organic matter through time. Archaeology of Eastern 
North America 20: 67-79.

1994 The oxidizable carbon ratio (OCR): A proposed solution to some of the problems encountered with radiocarbon data. North American Archaeologist 15(1): 17-29.

1995 Application of the oxidizable carbon ratio dating procedure and its implications for pedogenic research. In Pedological Perspectives in Archaeological Research. SSSA Special Publication 44. Soil Science Society of America, Madison, Wisconsin: 95-106.

Granberry, D. 1995 William T. McKenzie Mound. The Record 46(1): 1-18. Dallas Archeological Society, Dallas.

Kindall, S. 1997 The oxidizable carbon ratio (OCR) technique: A new, low-cost dating method. The Steward, Collected Papers on Texas Archeology 4: 91-94. Office of the State Archeologist, Texas Historical Commission, Austin.

Kromer, B. and Becker, B. 1993 German oak and pine ${ }^{14} \mathrm{C}$ calibration, $7200-9439$ BC. In Stuiver, M., Long, A. and Kra, R. S., eds., Calibration 1993. Radiocarbon 35(1): 125-135.

Largent, F. B., Beene, D. L., Cliff, M. B. and Hunt, S. M. 1997 Cultural Resources Testing of Two Sites within the White Oak Creek Wildlife Management Area (WOCMA), Bowie and Titus Counties, Texas. White Oak Creek Wildlife Management Area Archeological Technical Series, Report of Investigations No. 6. GeoMarine, Inc., Plano.

Martin, W. A. 1997 Archaeological Investigations at 41DT124: The Doctors Creek site. In McGregor, D. E., Green, M. M., Jurney, D. H., Martin, W. A., Moir, R. W. and Saunders, J. W., Archaeological Investigations at Cooper Lake, Delivery Order Numbers 2, 3, \& 4, 1987: Cultural Resource Studies for Cooper Lake, Hopkins and Delta Counties, Texas. Archaeology Research Program, Department of Anthropology, Southern Methodist University, Dallas: 271-340.

McGregor, D. E. 1997 Archaeological investigations at 41HP137. In McGregor, D. E., Green, M. M., Jurney, D. H., Martin, W. A., Moir, R. W. and Saunders, J. W., Archaeological Investigations at Cooper Lake, Delivery Order Numbers 2, 3, \& 4, 1987: Cultural Resource Studies for Cooper Lake, Hopkins and Delta Counties, Texas. Archaeology Research Program, Department of Anthropology, Southern Methodist University, Dallas: $341-361$.

McGregor, D. E. and W. A. Martin 1997 Site descriptions of tested prehistoric sites. In McGregor, D. E., Green, M. M., Jurney, D. H., Martin, W. A., Moir, R. W. and Saunders, J. W., Archaeological Investigations at Cooper Lake, Delivery Order Numbers 2, 3, \& 4, 1987: Cultural Resource Studies for Cooper Lake, Hopkins and Delta Counties, Texas. Archaeology Research Program, Department of Anthropology, Southern Methodist University, Dallas: 31-126.

Middlebrook, T. 1994 An update of archaeological inves- tigations at the Tyson site (41SY92). Journal of Northeast Texas Archaeology 3: 1-36.

Middlebrook, T. and Perttula, T. K. 1997 The Middle Caddoan period in East Texas: A summary of the findings of the East Texas Caddoan Research Group. Journal of Northeast Texas Archaeology 9: 1-8.

Miller, M. R., III 1996 The Chronometric and Relative Chronology Project. Archaeological Technical Report No. 5. Anthropology Research Center, Department of Sociology and Anthropology, University of Texas at El Paso.

Perino, G. 1994 Archaeological research at the Rowland Clark site (41RR77), Red River County, Texas. Journal of Northeast Texas Archaeology 4: 3-42.

1995 The Dan Holdeman site (41RR11), Red River County, Texas. Journal of Northeast Texas Archaeology 6: 3-65.

Perttula, T. K. 1995 The Archeology of the Pineywoods and Post Oak Savanna of Northeast Texas. Bulletin of the Texas Archeological Society 66:331-359.

, ed. 1998 The Hurricane Hill Site (41HP106): The Archaeology of a Late Archaic/Early Ceramic and Early-Middle Caddoan Settlement in Northeast Texas. Special Publication No. 4. Friends of Northeast Texas Archaeology, Austin and Pittsburg. In preparation.

Perttula, T. K., Turner, M. and Nelson, B. 1997a Radiocarbon and oxidizable carbon ratio dates from the Camp Joy mound (41UR144) in Northeast Texas. Caddoan Archeology 7 (4): 10-16.

Perttula, T. K., Prikryl, D. J. and Nelson, B. 1997b Archeological Evaluation of a Proposed Sewer Line in the Knight's Bluff Campground at Atlanta State Park, and Delineation of the Knight's Bluff Site (41CS14) Cemetery/Midden Areas. Texas Archeological Research Laboratory, The University of Texas at Austin.

Perttula, T. K., Tate, M., Neff, H., Cogswell, J. W., Glasscock, M. D., Skokan, E., Mulholland, S., Rogers, R. and Nelson, B. 1998 Analysis of the Titus Phase Mortuary Assemblage at the Mockingbird or "Kahbakayammaahin" Site (41TT550). Document No. 970849. Espey, Huston \& Associates, Inc., Austin.

Ramenofsky, A. F. and Steffen, A. 1998 Units as tools of measurement. In Ramenofsky, A. F. and Steffen, A., eds., Unit Issues in Archaeology: Measuring Time, Space, and Material. Salt Lake City, University of Utah Press: 3-17.

Richner, J. J. and Bagot, J. T. (assemblers) 1978 A Reconnaissance Survey of the Trinity River Basin, 19761977. Research Report 113. Archaeology Research Program, Southern Methodist University, Dallas.

Skinner, S. A., Harris, R. K. and Anderson, K. M., eds. 1969 Archaeological Investigations at the Sam Kaufman Site, Red River County, Texas. Contributions in Anthropology No. 5. Department of Anthropology, Southern Methodist University, Dallas.

Slaughter, B. H. and Hoover, B. R. 1963 Sulphur River formation and the Pleistocene mammals of the Ben 
Franklin local fauna. Journal of the Graduate Research Center 31(3): 132-148. Southern Methodist University, Dallas.

$1965 \mathrm{An}$ antler artifact from the Late Pleistocene of northeastern Texas. American Antiquity 30(3): 351352.

Story, D. A. 1990a Radiocarbon Assays. In Story, D. A., Guy, J. A., Burnett, B. A., Freeman, M. D., Rose, J. C., Steele, D. G., Olive, B. W. and Reinhard, K. J. The Archeology and Bioarcheology of the Gulf Coastal Plain. Research Series 38. Fayetteville, Arkansas Archeological Survey: 658-735.

1990b Cultural History of the Native Americans. In Story, D. A., Guy, J. A., Burnett, B. A., Freeman, M. D., Rose, J. C., Steele, D. G., Olive, B. W. and Reinhard, K. J. The Archeology and Bioarcheology of the Gulf Coastal Plain. Research Series 38. Fayetteville, Arkansas Archeological Survey: 163-366.

1995 General summary and synthesis. In Story, D. A., ed., The Deshazo Site, Nacogdoches County Texas. Volume 2. Artifacts of Native Manufacture. Studies in Archeology 21. Texas Archeological Re- search Laboratory, The University of Texas at Austin: 233-247.

$19971968-1970$ archeological investigations at the George C. Davis site, Cherokee County, Texas. Bulletin of the Texas Archeological Society 68: 1-110.

1998 The George C. Davis site mounds, structures, and burials: Glimpses into Early Caddoan symbolism and ideology. In Perttula, T. K. and Bruseth, J. E., eds., The Native History of the Caddo: Their Place in Southeastern Archeology and Ethnohistory. Studies in Archeology 30. Texas Archeological Research Laboratory, The University of Texas at Austin: 9-43.

Story, D. A. and Valastro, S. Jr. 1977 Radiocarbon dating and the George C. Davis site, Texas. Journal of Field Archaeology 4(1): 63-89.

Stuiver, M. and Reimer, P. J. 1993a Extended ${ }^{14} \mathrm{C}$ data base and revised CALIB $3.0{ }^{14} \mathrm{C}$ age calibration program. In Stuiver, M., Long, A. and Kra, R. S., eds., Calibration 1993. Radiocarbon 35(1): 215-230.

1993b CALIB User's Guide Rev 3.0.3A for Macintosh computers. Quaternary Research Center, University of Washington, Seattle.

\section{APPENDIX}

TABLE $1 .{ }^{14} \mathrm{C}$ Assays from Prehistoric Archaeological Sites in Eastern Texas

\begin{tabular}{|c|c|c|c|c|c|c|}
\hline Assay no. & Provenience & Raw age & $\delta^{13} \mathrm{C}$ & $\begin{array}{l}\text { Corrected } \\
{ }^{14} \mathrm{C} \text { age }\end{array}$ & $\begin{array}{l}\text { Calibrated } \\
\text { age range* }\end{array}$ & $\mathrm{RA} \dagger$ \\
\hline \multicolumn{7}{|c|}{ Ferguson (41AN67) } \\
\hline$T x-1275$ & $\begin{array}{l}\text { Post fragment } \\
\text { capped by midden }\end{array}$ & $230 \pm 70$ & -- & $230 \pm 81$ & $\begin{array}{l}\text { AD } 1722-1817 \\
\text { AD } 1630-1698\end{array}$ & $\begin{array}{l}.42 \\
.31 \\
.12\end{array}$ \\
\hline Tx-1276 & $\begin{array}{l}\text { Same sample } \\
\text { as Tx-1275 }\end{array}$ & $360 \pm 70$ & -- & $360 \pm 81$ & $\begin{array}{l}\text { AD } 1523-1563 \\
\text { AD } 1536-1635 \\
\text { AD } 1473-1530\end{array}$ & $\begin{array}{l}.12 \\
.63 \\
.37\end{array}$ \\
\hline \multicolumn{7}{|c|}{ Alcoa No. 1 (41AN87) } \\
\hline Beta-43537 & Unit lv. 4 & $490 \pm 60$ & -- & $490 \pm 72$ & $\begin{array}{l}\text { AD 1393-1488 } \\
A D 1321-1340\end{array}$ & $\begin{array}{l}.91 \\
.08\end{array}$ \\
\hline Beta-43538 & Unit 1, lv. 6 & $550 \pm 60$ & -- & $550 \pm 72$ & $\begin{array}{l}\text { AD } 1386-1438 \\
A D 1310-1353\end{array}$ & $\begin{array}{l}.60 \\
.40\end{array}$ \\
\hline $\begin{array}{l}\text { 41AN } 120 \\
\text { SMU-669 }\end{array}$ & $\begin{array}{l}\text { Mussel } \\
\text { shell lens \#1 }\end{array}$ & $1744 \pm 64$ & -- & $1744 \pm 76$ & AD $\quad 231-404$ & 1.00 \\
\hline \multicolumn{7}{|c|}{ Hatchel (41BW3) } \\
\hline Tx-1903 & Floor $\mathrm{K}$, mound & $1250 \pm 70$ & -. & $1250 \pm 81$ & $A D \quad 695-869$ & 1.00 \\
\hline Tx-1904 & Floor $\mathrm{H}$, mound & $810 \pm 40$ & -- & $810 \pm 57$ & AD 1193-1282 & 1.00 \\
\hline Tx-1905 & $\begin{array}{l}\text { Fea. 18, Floor } \mathrm{H} \text {, } \\
\text { mound }\end{array}$ & $1000 \pm 40$ & -- & $1000 \pm 57$ & $\begin{array}{l}\text { AD } 988-1055 \\
\text { AD } 1083-1122 \\
\text { AD } 1138-1157\end{array}$ & $\begin{array}{l}.59 \\
.28 \\
.13\end{array}$ \\
\hline Tx-1906 & $\begin{array}{l}\text { Fea. } 4 \text {, } \\
\text { Floor B, mound }\end{array}$ & $660 \pm 40$ & -- & $660 \pm 57$ & $\begin{array}{l}\text { AD 1342-1392 } \\
\text { AD 1291-1319 }\end{array}$ & $\begin{array}{l}.64 \\
.36\end{array}$ \\
\hline \multicolumn{7}{|c|}{ Cranfill (41BW171) } \\
\hline Beta-92920 & Midden, deer bone & $680 \pm 110$ & $-22.67 \% 0$ & $710 \pm 110$ & $\begin{array}{l}\text { AD } 1229-1328 \\
\text { AD } 1332-1396\end{array}$ & $\begin{array}{l}.62 \\
.38\end{array}$ \\
\hline
\end{tabular}


TABLE $1 .{ }^{14} \mathrm{C}$ Assays from Prehistoric Archaeological Sites in Eastern Texas (Continued)

\begin{tabular}{|c|c|c|c|c|c|c|}
\hline Assay no. & Provenience & Raw age & $\delta^{13} \mathrm{C}$ & $\begin{array}{l}\text { Corrected } \\
{ }^{14} \mathrm{C} \text { age }\end{array}$ & $\begin{array}{l}\text { Calibrated } \\
\text { age range* }\end{array}$ & $\mathrm{RA} \dagger$ \\
\hline Beta-92921 & $\begin{array}{l}\text { Midden, } \\
\text { charred nutshells }\end{array}$ & $510 \pm 50$ & $-25.9 \%$ & $490 \pm 50$ & AD 1405-1453 & 1.00 \\
\hline \multicolumn{7}{|l|}{ 41BW553 } \\
\hline Beta-94626 $\ddagger$ & $\begin{array}{l}\text { Midden, } \\
\text { below Fea. } 6\end{array}$ & $920 \pm 80$ & $-27.4 \%$ & $880 \pm 80$ & $\begin{array}{l}\text { AD } 1152-1230 \\
\text { AD } 1045-1100 \\
\text { AD } 1114-1146\end{array}$ & $\begin{array}{l}.50 \\
.32 \\
.18\end{array}$ \\
\hline Beta-94627 $\ddagger$ & Fea. 3 & $930 \pm 70$ & $-27.1 \% 0$ & $890 \pm 70$ & $\begin{array}{l}\text { AD } 1153-1222 \\
\text { AD } 1046-1098 \\
\text { AD } 1115-1145\end{array}$ & $\begin{array}{l}.47 \\
.34 \\
.19\end{array}$ \\
\hline Beta-94628 $\ddagger$ & Fea. 1 & $450 \pm 70$ & $-26.0 \% 0$ & $430 \pm 70$ & $\begin{array}{l}\text { AD } 1424-1517 \\
\text { AD } 1585-1623\end{array}$ & $\begin{array}{l}.76 \\
.24\end{array}$ \\
\hline Beta-94629 $\ddagger$ & Fea. 6 & $580 \pm 90$ & $-26.9 \%$ & $550 \pm 90$ & $\begin{array}{l}\text { AD } 1378-1441 \\
\text { AD } 1307-1361\end{array}$ & $\begin{array}{l}.57 \\
.43\end{array}$ \\
\hline \multicolumn{7}{|c|}{ George C. Davis (41CE19) } \\
\hline C-153 & $\begin{array}{l}\text { Md. A, Fea. } 31 \text { pit, } \\
\text { pre-mound } \\
\text { (maize) }\end{array}$ & $1553 \pm 175$ & $-\cdot$ & $1794 \pm 180$ & $\begin{array}{ll}\mathrm{AD} & 52-434 \\
\mathrm{AD} & 25-44\end{array}$ & $\begin{array}{l}.97 \\
.03\end{array}$ \\
\hline M-1168 & $\begin{array}{l}\text { Md. A, Fea. } 31 \text { pit, } \\
\text { pre-mound } \\
\text { (maize) }\end{array}$ & $655 \pm 75$ & -- & $896 \pm 85$ & $\begin{array}{l}\text { AD } 1151-1219 \\
\text { AD } 1044-1105 \\
\text { AD } 1112-1147\end{array}$ & $\begin{array}{l}.41 \\
.37 \\
.21\end{array}$ \\
\hline$T x-105$ & $\begin{array}{l}\text { Md. A, Fea. } 31 \text { pit, } \\
\text { pre-mound } \\
\text { (maize) }\end{array}$ & $1120 \pm 90$ & -- & $1361 \pm 99$ & AD $\quad 598-787$ & 1.00 \\
\hline Tx-674 & $\begin{array}{l}\text { Md. B, Fea. 108, } \\
\text { under md. }\end{array}$ & $1420 \pm 100$ & -- & $1396 \pm 108$ & $\begin{array}{ll}\text { AD } & 552-727 \\
\text { AD } & 733-772\end{array}$ & $\begin{array}{l}.85 \\
.15\end{array}$ \\
\hline Tx-675 & $\begin{array}{l}\text { Md. B, midden } \\
\text { under md. }\end{array}$ & $1010 \pm 80$ & -- & $986 \pm 90$ & $\mathrm{AD} \quad 986-1166$ & 1.00 \\
\hline Tx-676 & $\begin{array}{l}\text { Md. B, midden } \\
\text { under md., } \\
\text { probably below } \\
\text { Fea. } 112 \text { floor }\end{array}$ & $1120 \pm 80$ & -- & $1096 \pm 90$ & $\begin{array}{ll}\mathrm{AD} & 860-1028 \\
\mathrm{AD} & 822-839\end{array}$ & $\begin{array}{l}.94 \\
.06\end{array}$ \\
\hline Tx-677 & $\begin{array}{l}\text { Md. B, midden un- } \\
\text { der md., west of } \\
\text { F112 and upper } \\
\text { part of Zone } 1\end{array}$ & $1070 \pm 70$ & -- & $1046 \pm 81$ & $\begin{array}{l}A D \quad 890-1046 \\
A D 1098-1115\end{array}$ & $\begin{array}{l}.91 \\
.06\end{array}$ \\
\hline $\mathrm{Tx}-678$ & Unit 4 , midden & $1430 \pm 160$ & -- & $1406 \pm 165$ & AD $\quad 444-789$ & 1.00 \\
\hline Tx-905 & $\begin{array}{l}\text { Md. B, Fea. 111, } \\
\text { pre-mound struc- } \\
\text { ture }\end{array}$ & $850 \pm 100$ & -- & $826 \pm 108$ & $\begin{array}{l}\text { AD } 1155-1288 \\
\text { AD } 1050-1087 \\
\text { AD } 1120-1140\end{array}$ & $\begin{array}{l}.76 \\
.15 \\
.09\end{array}$ \\
\hline Tx-906a & $\begin{array}{l}\text { Unit 6, Fea. 110-1 } \\
\text { (maize) }\end{array}$ & $710 \pm 60$ & -- & $951 \pm 72$ & AD 1023-1164 & 1.00 \\
\hline Tx-906b & Unit 6, Fea. 110-1 & $1130 \pm 160$ & -- & $1106 \pm 165$ & $\begin{array}{l}\text { AD } 768-1049 \\
\text { AD } 1089-1119 \\
\text { AD } 721-738\end{array}$ & $\begin{array}{l}.87 \\
.06 \\
.04\end{array}$ \\
\hline Tx-907 & Unit 6, Fea. 110-2 & $960 \pm 70$ & -- & $936 \pm 81$ & AD 1024-1180 & 1.00 \\
\hline Tx-908 & $\begin{array}{l}\text { Unit 6, Feas. } 110-7 \\
\& 110-17\end{array}$ & $1230 \pm 100$ & -- & $1206 \pm 108$ & $\begin{array}{ll}\text { AD } & 757-897 \\
\text { AD } & 910-959 \\
\text { AD } & 712-745\end{array}$ & $\begin{array}{l}.67 \\
.20 \\
.13\end{array}$ \\
\hline Tx-909 & Unit 6, Fea. 110-7 & $1170 \pm 120$ & -- & $1146 \pm 127$ & AD $\quad 772-1017$ & .98 \\
\hline
\end{tabular}


$\underline{\text { TABLE } 1 .{ }^{14} \mathrm{C} \text { Assays from Prehistoric Archaeological Sites in Eastern Texas (Continued) }}$

\begin{tabular}{|c|c|c|c|c|c|c|}
\hline Assay no. & Provenience & Raw age & $\delta^{13} \mathrm{C}$ & $\begin{array}{l}\text { Corrected } \\
{ }^{14} \mathrm{C} \text { age }\end{array}$ & $\begin{array}{l}\text { Calibrated } \\
\text { age range* }\end{array}$ & $\mathrm{RA} \dagger$ \\
\hline Tx-910 & $\begin{array}{l}\text { Md. B, Fea. 114, } \\
\text { pre-mound pit or } \\
\text { post trench }\end{array}$ & $830 \pm 70$ & -- & $806 \pm 81$ & AD 1160-1294 & .99 \\
\hline Tx-911 & $\begin{array}{l}\text { Md. B, } \\
\text { Fea. 111-20 } \\
\text { post, pre-mound }\end{array}$ & $870 \pm 160$ & -- & $846 \pm 165$ & AD 1026-1292 & 1.00 \\
\hline Tx-912 & $\begin{array}{l}\text { Md. B, Fea. 111, } \\
\text { pre-mound struc- } \\
\text { ture beam }\end{array}$ & $870 \pm 70$ & -- & $846 \pm 81$ & $\begin{array}{l}\text { AD } 1157-1278 \\
\text { AD } 1058-1080 \\
\text { AD } 1124-1136\end{array}$ & $\begin{array}{l}.82 \\
.11 \\
.07\end{array}$ \\
\hline Tx-913 & $\begin{array}{l}\text { Md. C, Fea. 119, } \\
\text { Stage II }\end{array}$ & $1150 \pm 80$ & -- & $1126 \pm 90$ & $\begin{array}{ll}\mathrm{AD} & 855-1011 \\
\mathrm{AD} & 817-845\end{array}$ & $\begin{array}{l}.88 \\
.12\end{array}$ \\
\hline Tx-914a & $\begin{array}{l}\text { Md. B, } \\
\text { Fea. 120-2, struc- } \\
\text { ture under Md. } \\
\text { B wash (maize) }\end{array}$ & $790 \pm 70$ & -- & $1031 \pm 81$ & $\begin{array}{l}\text { AD } 951-1056 \\
\text { AD } 1082-1123 \\
\text { AD } 894-918 \\
\text { AD } 1137-1157\end{array}$ & $\begin{array}{l}.64 \\
.17 \\
.10 \\
.08\end{array}$ \\
\hline$T x-914 b$ & Md. B, Fea. 120-2 & $1060 \pm 60$ & -- & $1036 \pm 72$ & $\begin{array}{l}\text { AD } 947-1048 \\
\text { AD } 894-920 \\
\text { AD } 1091-1118\end{array}$ & $\begin{array}{l}.72 \\
.12 \\
.11\end{array}$ \\
\hline Tx-915 & $\begin{array}{l}\text { Md. B, Fea. } 118 \\
\text { midden above } \\
\text { floor of structure } \\
\text { under Md. B fill }\end{array}$ & $830 \pm 70$ & -- & $806 \pm 81$ & AD $1160-1294$ & .99 \\
\hline Tx-916 & $\begin{array}{l}\text { Md. B, Fea. } 108 \text {, } \\
\text { midden under } \mathrm{Md} \text {. } \\
\text { B wash }\end{array}$ & $900 \pm 70$ & -- & $876 \pm 81$ & $\begin{array}{l}\text { AD } 1153-1239 \\
\text { AD } 1046-1096 \\
\text { AD } 1115-1144\end{array}$ & $\begin{array}{l}.55 \\
.29 \\
.17\end{array}$ \\
\hline Tx-917 & $\begin{array}{l}\text { Md. B, Fea. 111-3 } \\
\text { posts, pre-mound } \\
\text { structure }\end{array}$ & $980 \pm 70$ & -- & $956 \pm 81$ & AD 1015-1169 & 1.00 \\
\hline Tx-918 & $\begin{array}{l}\text { Md. B, Fea. 111, } \\
\text { pre-mound struc- } \\
\text { ture beam }\end{array}$ & $810 \pm 70$ & -- & $786 \pm 81$ & AD 1168-1297 & 1.00 \\
\hline Tx-919 & $\begin{array}{l}\text { Md. B, Fea. 112- } \\
\text { 10, post, pre- } \\
\text { mound }\end{array}$ & $1310 \pm 80$ & -- & $1286 \pm 90$ & $\begin{array}{ll}\mathrm{AD} & 665-821 \\
\mathrm{AD} & 841-859\end{array}$ & $\begin{array}{l}.91 \\
.09\end{array}$ \\
\hline Tx-920 & $\begin{array}{l}\text { Md. B, Fea. } 115 \\
\text { midden under } \\
\text { floor, under mound } \\
\text { fill \& wash }\end{array}$ & $1150 \pm 70$ & -- & $1126 \pm 81$ & $\begin{array}{ll}\mathrm{AD} & 861-1010 \\
\mathrm{AD} & 822-839\end{array}$ & $\begin{array}{l}.93 \\
.07\end{array}$ \\
\hline $\mathrm{Tx}-921$ & $\begin{array}{l}\text { Md. B, Fea. 111, } \\
\text { pre-mound struc- } \\
\text { ture }\end{array}$ & $950 \pm 70$ & -- & $926 \pm 81$ & AD 1029-1185 & 1.00 \\
\hline Tx-922 & Unit 6, Fea. 110-2 & $1070 \pm 70$ & -- & $1046 \pm 81$ & $\begin{array}{l}\text { AD } 890-1046 \\
\text { AD } 1098-1115\end{array}$ & $\begin{array}{l}.91 \\
.06\end{array}$ \\
\hline Tx-923 & $\begin{array}{l}\text { Md. B, Fea. } 115 \\
\text { posts } 1-2, \text { under } \\
\text { Md. B fill \& wash }\end{array}$ & $1020 \pm 100$ & -- & $996 \pm 108$ & AD $964-1182$ & .99 \\
\hline Tx-924 & $\begin{array}{l}\text { Md. B, Fea. 112, } \\
\text { posts 5-13, pre- } \\
\text { mound structure }\end{array}$ & $940 \pm 70$ & -- & $916 \pm 81$ & AD 1036-1194 & 1.00 \\
\hline
\end{tabular}


TABLE $1 .{ }^{14} \mathrm{C}$ Assays from Prehistoric Archaeological Sites in Eastern Texas (Continued)

\begin{tabular}{|c|c|c|c|c|c|c|}
\hline Assay no. & Provenience & Raw age & $\delta^{13} \mathrm{C}$ & $\begin{array}{l}\text { Corrected } \\
{ }^{14} \mathrm{C} \text { age }\end{array}$ & $\begin{array}{l}\text { Calibrated } \\
\text { age range* }\end{array}$ & RA $\dagger$ \\
\hline$T x-925$ & $\begin{array}{l}\text { Md. B, Fea. } 120 \\
\text { posts } 1-6 \text {, under } \\
\text { Md. B wash }\end{array}$ & $1150 \pm 70$ & -- & $1126 \pm 81$ & $\begin{array}{ll}\text { AD } & 861-1010 \\
\text { AD } & 822-839\end{array}$ & $\begin{array}{l}.93 \\
.07\end{array}$ \\
\hline Tx-926 & Unit 6, Fea. 110-1 & $1000 \pm 60$ & -- & $976 \pm 72$ & $\begin{array}{l}\text { AD } 1012-1069 \\
\text { AD } 1071-1129 \\
\text { AD } 1131-1160\end{array}$ & $\begin{array}{l}.41 \\
.39 \\
.20\end{array}$ \\
\hline$T x-1201$ & $\begin{array}{l}\text { Unit 10, Fea. } 125- \\
1,3 \text { rd hearth }\end{array}$ & $920 \pm 80$ & -. & $896 \pm 90$ & $\begin{array}{l}\text { AD } 1151-1219 \\
\text { AD } 1043-1107 \\
\text { AD } 1111-1148\end{array}$ & $\begin{array}{l}.41 \\
.37 \\
.21\end{array}$ \\
\hline$T x-1202$ & $\begin{array}{l}\text { Unit 10, } \\
\text { Fea. 125-82 }\end{array}$ & $1080 \pm 80$ & -- & $1056 \pm 90$ & $\begin{array}{l}\text { AD } 884-1048 \\
\text { AD } 1093-1117\end{array}$ & $\begin{array}{l}.89 \\
.08\end{array}$ \\
\hline$T x-1203$ & $\begin{array}{l}\text { Md. C, fill of pre- } \\
\text { mound pit overlain } \\
\text { by Stage V fill }\end{array}$ & $910 \pm 80$ & -- & $886 \pm 90$ & $\begin{array}{l}\text { AD } 1151-1227 \\
\text { AD } 1044-1105 \\
\text { AD } 1112-1147\end{array}$ & $\begin{array}{l}.46 \\
.35 \\
.20\end{array}$ \\
\hline$T x-1204$ & $\begin{array}{l}\text { Unit 10, } \\
\text { Fea. 125-1 }\end{array}$ & $1110 \pm 80$ & -- & $1086 \pm 90$ & $\mathrm{AD} \quad 861-1035$ & .96 \\
\hline$T x-1206$ & $\begin{array}{l}\text { Md. C, Fea. 134, } \\
\text { Stage I, pre-mound } \\
\text { burial }\end{array}$ & $1010 \pm 80$ & -- & $986 \pm 90$ & AD $986-1166$ & 1.00 \\
\hline Tx-1207 & $\begin{array}{l}\text { Borrow pit, upper- } \\
\text { most stratum }\end{array}$ & $410 \pm 70$ & -. & $386 \pm 81$ & $\begin{array}{l}\text { AD } 1446-1524 \\
\text { AD } 1559-1631\end{array}$ & $\begin{array}{l}.54 \\
.46\end{array}$ \\
\hline Tx-1208 & $\begin{array}{l}\text { Unit 14, } \\
\text { Fea. 137-16B }\end{array}$ & $1070 \pm 70$ & -- & $1046 \pm 81$ & $\begin{array}{l}\text { AD } 890-1046 \\
\text { AD } 1098-1115\end{array}$ & $\begin{array}{l}.91 \\
.06\end{array}$ \\
\hline Tx-1209 & $\begin{array}{l}\text { Unit 14, } \\
\text { Fea. 137-15 }\end{array}$ & $860 \pm 80$ & -- & $836 \pm 90$ & $\begin{array}{l}\text { AD } 1157-1283 \\
\text { AD } 1057-1081\end{array}$ & $\begin{array}{l}.82 \\
.12\end{array}$ \\
\hline $\mathrm{Tx}-1210$ & $\begin{array}{l}\text { Unit 11, } \\
\text { Fea. 160-54 }\end{array}$ & $890 \pm 80$ & -- & $866 \pm 90$ & $\begin{array}{l}\text { AD } 1154-1257 \\
\text { AD } 1048-1092 \\
\text { AD } 1117-1143\end{array}$ & $\begin{array}{l}.63 \\
.24 \\
.13\end{array}$ \\
\hline$T x-1211$ & $\begin{array}{l}\text { Unit 11, } \\
\text { Fea. 139-21 }\end{array}$ & $860 \pm 80$ & -- & $836 \pm 90$ & $\begin{array}{l}\text { AD } 1157-1283 \\
\text { AD } 1057-1081\end{array}$ & $\begin{array}{l}.82 \\
.12\end{array}$ \\
\hline Tx-1212 & $\begin{array}{l}\text { Unit 11, } \\
\text { Fea. 139-1 }\end{array}$ & $1160 \pm 90$ & -. & $1136 \pm 99$ & $\mathrm{AD} \quad 673-1048$ & $.98 \S$ \\
\hline $\mathrm{Tx}-1213$ & $\begin{array}{l}\text { Unit 11, Fea. 139- } \\
83 \text {, post of Str. } \\
\text { F139 }\end{array}$ & $950 \pm 80$ & -- & $926 \pm 90$ & AD 1028-1195 & 1.00 \\
\hline $\mathrm{Tx}-1214$ & $\begin{array}{l}\text { Unit 13, } \\
\text { Fea. 126-2 }\end{array}$ & $790 \pm 80$ & -- & $766 \pm 90$ & $\begin{array}{l}\text { AD } 1168-1307 \\
\text { AD } 1362-1377\end{array}$ & $\begin{array}{l}.94 \\
.06\end{array}$ \\
\hline $\mathrm{Tx}-1215$ & $\begin{array}{l}\text { Unit 13, } \\
\text { Fea. 126-8 }\end{array}$ & $850 \pm 90$ & - & $826 \pm 99$ & $\begin{array}{l}\text { AD } 1157-1287 \\
\text { AD } 1055-1083 \\
\text { AD } 1122-1138\end{array}$ & $\begin{array}{l}.80 \\
.13 \\
.07\end{array}$ \\
\hline $\mathrm{Tx}-1216$ & $\begin{array}{l}\text { Unit 16S, } \\
\text { Fea. 165-1 }\end{array}$ & $780 \pm 70$ & -- & $756 \pm 81$ & $\begin{array}{l}\text { AD } 1192-1307 \\
\text { AD 1361-1378 }\end{array}$ & $\begin{array}{l}.92 \\
.08\end{array}$ \\
\hline $\mathrm{Tx}-1217$ & $\begin{array}{l}\text { Unit 16S, } \\
\text { Fea. } 165-63\end{array}$ & $1020 \pm 70$ & -- & $996 \pm 81$ & $\begin{array}{l}\text { AD } 986-1069 \\
\text { AD } 1071-1129 \\
\text { AD } 1131-1160\end{array}$ & $\begin{array}{l}.51 \\
.33 \\
.16\end{array}$ \\
\hline$T x-1221$ & $\begin{array}{l}\text { Unit } 15 \text {, Fea. } 146- \\
69 \text { in structure } \\
\text { F146 }\end{array}$ & $1000 \pm 80$ & -- & $976 \pm 90$ & AD $993-1169$ & 1.00 \\
\hline$T x-1222$ & $\begin{array}{l}\text { Unit 15, } \\
\text { Fea. 146-71 }\end{array}$ & $1100 \pm 80$ & -- & $1076 \pm 90$ & $\begin{array}{ll}\text { AD } & 865-1043 \\
\text { AD } & 827-833\end{array}$ & $\begin{array}{l}.96 \\
.02\end{array}$ \\
\hline
\end{tabular}


TABLE 1. ${ }^{14} \mathrm{C}$ Assays from Prehistoric Archaeological Sites in Eastern Texas (Continued)

\begin{tabular}{|c|c|c|c|c|c|c|}
\hline Assay no. & Provenience & Raw age & $\delta^{13} \mathrm{C}$ & $\begin{array}{l}\text { Corrected } \\
{ }^{14} \mathrm{C} \text { age }\end{array}$ & $\begin{array}{l}\text { Calibrated } \\
\text { age range* }\end{array}$ & RAt \\
\hline$T x-1223$ & $\begin{array}{l}\text { Unit 15, Fea. 146- } \\
\text { 164, interior post } \\
\text { in structure F146 }\end{array}$ & $1290 \pm 80$ & -- & $1266 \pm 90$ & $\begin{array}{ll}\mathrm{AD} & 678-827 \\
\mathrm{AD} & 833-865\end{array}$ & $\begin{array}{l}.84 \\
.16\end{array}$ \\
\hline$T x-1224$ & $\begin{array}{l}\text { Unit } 15, \\
\text { Fea. } 146-62\end{array}$ & $980 \pm 70$ & -- & $956 \pm 81$ & AD 1015-1169 & 1.00 \\
\hline$T x-1225$ & $\begin{array}{l}\text { Md. B, fill, earliest } \\
\text { construction phase }\end{array}$ & $910 \pm 140$ & -- & $886 \pm 146$ & AD 1027-1266 & 1.00 \\
\hline$T x-1226$ & $\begin{array}{l}\text { Md. B, fill, earliest } \\
\text { construction phase }\end{array}$ & $700 \pm 80$ & -- & $676 \pm 90$ & $\begin{array}{l}\text { AD 1331-1396 } \\
\text { AD 1281-1329 }\end{array}$ & $\begin{array}{l}.57 \\
.43\end{array}$ \\
\hline$T x-1227$ & $\begin{array}{l}\text { Same as Tx-1225 } \\
\& \mathrm{Tx}-1226\end{array}$ & $1100 \pm 70$ & -- & $1076 \pm 81$ & AD $879-1038$ & 1.00 \\
\hline $\mathrm{Tx}-1228$ & $\begin{array}{l}\text { Borrow pit, } \\
140-160 \mathrm{~cm}\end{array}$ & $850 \pm 60$ & -. & $826 \pm 72$ & AD $1160-1285$ & .98 \\
\hline Tx-1229 & $\begin{array}{l}\text { Borrow pit, } \\
140-160 \mathrm{~cm}\end{array}$ & $790 \pm 240$ & -- & $766 \pm 243$ & AD 1020-1419 & 1.00 \\
\hline$T x-1231$ & $\begin{array}{l}\text { Md. C, Fea. 118, } \\
\text { Stage IV burial }\end{array}$ & $770 \pm 80$ & -- & $746 \pm 90$ & $\begin{array}{l}\text { AD 1201-1313 } \\
\text { AD 1349-1389 }\end{array}$ & $\begin{array}{l}.81 \\
.19\end{array}$ \\
\hline Tx-1294 & $\begin{array}{l}\text { Md. C, Fea. 155, } \\
\text { Stage II burial }\end{array}$ & $1260 \pm 70$ & -- & $1236 \pm 81$ & $\begin{array}{ll}\text { AD } & 751-884 \\
\text { AD } & 704-749\end{array}$ & $\begin{array}{l}.76 \\
.24\end{array}$ \\
\hline Tx-1295 & $\begin{array}{l}\text { Md. C, Stage III } \\
\text { burial (Fea. 161) }\end{array}$ & $1240 \pm 100$ & -- & $1216 \pm 108$ & $\begin{array}{ll}\mathrm{AD} & 700-894 \\
\mathrm{AD} & 920-946\end{array}$ & $\begin{array}{l}.90 \\
.10\end{array}$ \\
\hline Tx-1307 & $\begin{array}{l}\text { Unit } 10, \text { Fea. } 125- \\
1, \text { same context } \\
\text { as } T x-1308\end{array}$ & $1030 \pm 70$ & -- & $1006 \pm 81$ & $\begin{array}{l}\text { AD } 976-1067 \\
A D 1073-1128 \\
A D 1132-1160\end{array}$ & $\begin{array}{l}.56 \\
.29 \\
.15\end{array}$ \\
\hline Tx-1308 & $\begin{array}{l}\text { Unit } 10 \text {, Fea. } 125- \\
1,2 \text { nd of } 3 \\
\text { superimposed } \\
\text { hearths (maize) }\end{array}$ & $800 \pm 70$ & -- & $1041 \pm 81$ & $\begin{array}{l}A D \quad 892-1047 \\
A D 1096-1116\end{array}$ & $\begin{array}{l}.88 \\
.08\end{array}$ \\
\hline$T x-1310$ & $\begin{array}{l}\text { Unit 11, } \\
\text { Fea. 139-62 (cane) }\end{array}$ & $670 \pm 90$ & -- & $911 \pm 99$ & AD 1036-1214 & 1.00 \\
\hline Tx-1311 & $\begin{array}{l}\text { Unit 11, } \\
\text { Fea. 136-13 }\end{array}$ & $880 \pm 80$ & -- & $856 \pm 90$ & $\begin{array}{l}\text { AD } 1156-1274 \\
\text { AD } 1052-1085 \\
\text { AD } 1121-1139\end{array}$ & $\begin{array}{l}.73 \\
.17 \\
.10\end{array}$ \\
\hline $\mathrm{Tx}-1312$ & $\begin{array}{l}\text { Unit 11, } \\
\text { Fea. 136-6 }\end{array}$ & $750 \pm 90$ & -- & $726 \pm 99$ & $\begin{array}{l}\text { AD } 1220-1322 \\
\text { AD } 1339-1393\end{array}$ & $\begin{array}{l}.69 \\
.31\end{array}$ \\
\hline$T x-1313$ & $\begin{array}{l}\text { Unit 11, } \\
\text { Fea. 139-62 }\end{array}$ & $850 \pm 70$ & -- & $826 \pm 81$ & $\begin{array}{l}\mathrm{AD} 1159-1286 \\
\mathrm{AD} 1064-1075\end{array}$ & $\begin{array}{l}.92 \\
.05\end{array}$ \\
\hline Tx-1314 & $\begin{array}{l}\text { Unit 11, } \\
\text { Fea. 139-84 }\end{array}$ & $700 \pm 70$ & -- & $676 \pm 81$ & $\begin{array}{l}\text { AD } 1335-1395 \\
\text { AD } 1282-1326\end{array}$ & $\begin{array}{l}.58 \\
.42\end{array}$ \\
\hline$T x-1315$ & $\begin{array}{l}\text { Unit } 11 \text {, Fea. } 139- \\
50 \text {, post or pit in- } \\
\text { side structure F139 }\end{array}$ & $910 \pm 60$ & -- & $886 \pm 72$ & $\begin{array}{l}\text { AD } 1153-1225 \\
\text { AD } 1046-1098 \\
\text { AD } 1115-1145\end{array}$ & $\begin{array}{l}.49 \\
.32 \\
.18\end{array}$ \\
\hline$T x-1316$ & $\begin{array}{l}\text { Unit 11, } \\
\text { Fea. 139-7 }\end{array}$ & $810 \pm 70$ & -- & $786 \pm 81$ & AD 1168-1297 & 1.00 \\
\hline Tx-1317 & $\begin{array}{l}\text { Unit 11, } \\
\text { Fea. 139-30 }\end{array}$ & $760 \pm 100$ & -- & $736 \pm 108$ & $\begin{array}{l}\text { AD } 1205-1325 \\
\text { AD 1336-1394 }\end{array}$ & $\begin{array}{l}.71 \\
.29\end{array}$ \\
\hline$T x-1318$ & $\begin{array}{l}\text { Unit 11, } \\
\text { Fea. 139-90 }\end{array}$ & $740 \pm 110$ & -- & $716 \pm 117$ & AD $1221-1398$ & 1.00 \\
\hline Tx-1319 & $\begin{array}{l}\text { Unit 11, } \\
\text { Fea. 139-3 }\end{array}$ & $690 \pm 70$ & -- & $666 \pm 81$ & $\begin{array}{l}\text { AD } 1335-1395 \\
A D 1286-1326\end{array}$ & $\begin{array}{l}.60 \\
.40\end{array}$ \\
\hline
\end{tabular}


TABLE $1 .{ }^{14} \mathrm{C}$ Assays from Prehistoric Archaeological Sites in Eastern Texas (Continued)

\begin{tabular}{|c|c|c|c|c|c|c|}
\hline Assay no. & Provenience & Raw age & $\delta^{13} \mathrm{C}$ & $\begin{array}{l}\text { Corrected } \\
{ }^{14} \mathrm{C} \text { age }\end{array}$ & $\begin{array}{l}\text { Calibrated } \\
\text { age range* }\end{array}$ & RAt \\
\hline$T x-1320$ & $\begin{array}{l}\text { Unit 11, } \\
\text { Fea. 160-52 }\end{array}$ & $740 \pm 60$ & -- & $716 \pm 72$ & $\begin{array}{l}\text { AD 1245-1314 } \\
\text { AD 1348-1389 }\end{array}$ & $\begin{array}{l}.67 \\
.33\end{array}$ \\
\hline Tx-1395 & $\begin{array}{l}\text { Md. A, Sec. 13, } \\
\text { apparently struc- } \\
\text { ture F. } 31 \text {, pre- } \\
\text { mound }\end{array}$ & $830 \pm 80$ & -- & $806 \pm 90$ & $\begin{array}{l}\text { AD } 1159-1295 \\
\text { AD } 1063-1076\end{array}$ & $\begin{array}{l}.92 \\
.05\end{array}$ \\
\hline Tx-1396 & $\begin{array}{l}\text { Md. A, Sec. } \\
\text { 17R13, } 21.2 \text {, } \\
\text { above Fea. } 9 \text { floor }\end{array}$ & $710 \pm 70$ & -- & $686 \pm 81$ & $\begin{array}{l}\text { AD } 1335-1395 \\
\text { AD } 1278-1326\end{array}$ & $\begin{array}{l}.54 \\
.46\end{array}$ \\
\hline Tx-1397 & $\begin{array}{l}\text { Md. A, Sec. } \\
\text { 20R13, } \\
26-39 \mathrm{~cm}, \text { Fea. } 9\end{array}$ & $890 \pm 60$ & -- & $866 \pm 72$ & $\begin{array}{l}\text { AD } 1155-1253 \\
\text { AD } 1050-1087 \\
\text { AD } 1120-1140\end{array}$ & $\begin{array}{l}.68 \\
.21 \\
.11\end{array}$ \\
\hline Tx-1398 & $\begin{array}{l}\text { Md. A, above } \\
\text { floor of Fea. } 35\end{array}$ & $1050 \pm 70$ & -- & $1026 \pm 81$ & $\begin{array}{l}\text { AD } 956-1059 \\
\text { AD } 1079-1124 \\
\text { AD } 1136-1158\end{array}$ & $\begin{array}{l}.63 \\
.20 \\
.10\end{array}$ \\
\hline Tx-1399 & $\begin{array}{l}\text { Md. A, Sec. 13, } \\
\text { Fea. 31, pre- } \\
\text { mound }\end{array}$ & $1130 \pm 60$ & -. & $1106 \pm 72$ & AD $882-1015$ & 1.00 \\
\hline$T x-1405$ & $\begin{array}{l}\text { Unit 11, } \\
\text { Fea. 139-30 (cane) }\end{array}$ & $570 \pm 80$ & -- & $811 \pm 90$ & $\begin{array}{l}\text { AD 1158-1293 } \\
\text { AD 1062-1077 }\end{array}$ & $\begin{array}{l}.91 \\
.06\end{array}$ \\
\hline Tx-3267 & $\begin{array}{l}\text { Unit } 43, \text { Fea. } 184- \\
3 \text { (maize) }\end{array}$ & $560 \pm 60$ & -- & $801 \pm 72$ & $\mathrm{AD} 1175-1288$ & 1.00 \\
\hline$T x-3268$ & $\begin{array}{l}\text { Unit } 45 \text {, } \\
\text { Fea. 185-4 }\end{array}$ & $1040 \pm 230$ & -- & $1016 \pm 233$ & $\mathrm{AD} \quad 811-1236$ & 1.00 \\
\hline Tx-3269 & $\begin{array}{l}\text { Unit } 44 \text {, } \\
\text { Fea. 186-1 }\end{array}$ & $740 \pm 70$ & -- & $716 \pm 81$ & $\begin{array}{l}A D 1238-1316 \\
A D 1346-1391\end{array}$ & $\begin{array}{l}.67 \\
.33\end{array}$ \\
\hline$T x-3270$ & $\begin{array}{l}\text { Unit } 44 \text {, } \\
\text { Fea. 186-1 } \\
\text { (maize) }\end{array}$ & $770 \pm 70$ & -- & $1011 \pm 81$ & $\begin{array}{l}\text { AD } 971-1066 \\
\text { AD } 1073-1128 \\
\text { AD } 1132-1160\end{array}$ & $\begin{array}{l}.59 \\
.28 \\
.14\end{array}$ \\
\hline Tx-3271 & $\begin{array}{l}\text { Unit } 46, \\
\text { Fea. } 187-3\end{array}$ & $790 \pm 80$ & $-26.94 \%$ & $759 \pm 90$ & $\begin{array}{l}\text { AD } 1175-1308 \\
A D 1359-1380\end{array}$ & $\begin{array}{l}.91 \\
.09\end{array}$ \\
\hline$T x-3272$ & $\begin{array}{l}\text { Unit } 46, \\
\text { Fea. } 187-5\end{array}$ & $780 \pm 100$ & $-25.17 \%$ & $777 \pm 108$ & $\begin{array}{l}\text { AD } 1159-1309 \\
\text { AD } 1356-1383 \\
\text { AD } 1064-1075\end{array}$ & $\begin{array}{l}.85 \\
.09 \\
.04\end{array}$ \\
\hline$T x-3273$ & $\begin{array}{l}\text { Unit } 48, \\
\text { Fea. 189-6 }\end{array}$ & $950 \pm 80$ & $-26.39 \%$ & $928 \pm 90$ & AD 1027-1194 & 1.00 \\
\hline Tx-3274 & $\begin{array}{l}\text { Unit } 48 \text {, } \\
\text { Fea. 189-6 } \\
\text { (maize) }\end{array}$ & $440 \pm 90$ & -- & $681 \pm 99$ & AD 1271-1401 & 1.00 \\
\hline$T x-3275$ & $\begin{array}{l}\text { Unit 45, } \\
\text { Fea. } 185-11\end{array}$ & $910 \pm 90$ & -- & $886 \pm 99$ & $\begin{array}{l}\text { AD } 1151-1227 \\
\text { AD } 1043-1108 \\
\text { AD } 1111-1149\end{array}$ & $\begin{array}{l}.44 \\
.35 \\
.21\end{array}$ \\
\hline Tx-3276 & $\begin{array}{l}\text { Unit } 45 \text {, } \\
\text { Fea. } 185-11 \\
\text { (maize) }\end{array}$ & $550 \pm 60$ & -- & $791 \pm 72$ & AD 1182-1291 & 1.00 \\
\hline Tx-3307 & $\begin{array}{l}\text { Unit } 48 \text {, } \\
\text { Fea. } 189-1 \text { (maize) }\end{array}$ & $880 \pm 110$ & -- & $1121 \pm 117$ & $\mathrm{AD} \quad 783-1021$ & 1.00 \\
\hline Tx-3308 & $\begin{array}{l}\text { Unit } 43 \text {, } \\
\text { Fea. } 184-4\end{array}$ & $620 \pm 100$ & $-25.64 \%$ & $610 \pm 108$ & $\mathrm{AD} 1294-1418$ & 1.00 \\
\hline
\end{tabular}


TABLE 1. ${ }^{14} \mathrm{C}$ Assays from Prehistoric Archaeological Sites in Eastern Texas (Continued)

\begin{tabular}{|c|c|c|c|c|c|c|}
\hline Assay no. & Provenience & Raw age & $\delta^{13} \mathrm{C}$ & $\begin{array}{l}\text { Corrected } \\
{ }^{14} \mathrm{C} \text { age }\end{array}$ & $\begin{array}{l}\text { Calibrated } \\
\text { age range* }\end{array}$ & RA $\dagger$ \\
\hline Tx-3309 & $\begin{array}{l}\text { Unit } 45, \\
\text { Fea. } 185-8\end{array}$ & $1170 \pm 100$ & $\cdots$ & $1170 \pm 108$ & AD 773-989 & .99 \\
\hline$T x-3310$ & $\begin{array}{l}\text { Unit } 45 \text {, } \\
\text { Fea. 185-1 } \\
\text { (maize) }\end{array}$ & $610 \pm 100$ & -- & $851 \pm 108$ & $\begin{array}{l}\text { AD } 1154-1278 \\
\text { AD } 1048-1090 \\
\text { AD } 1118-1142\end{array}$ & $\begin{array}{l}.69 \\
.20 \\
.11\end{array}$ \\
\hline Tx-3311 & $\begin{array}{l}\text { Unit 46, } \\
\text { Fea. 187-3 } \\
\text { (cane) }\end{array}$ & $1140 \pm 160$ & -- & $1381 \pm 165$ & $\mathrm{AD} \quad 536-875$ & 1.00 \\
\hline $\mathrm{Tx}-3312$ & $\begin{array}{l}\text { Unit } 43 \text {, } \\
\text { Fea. } 184-4 \text { (cane) }\end{array}$ & $1190 \pm 80$ & -- & $1431 \pm 90$ & $\mathrm{AD} \quad 536-699$ & 1.00 \\
\hline Tx-3399 & $\begin{array}{l}\text { Unit } 62 \text {, } \\
\text { Fea. 193-1, Zone } 4\end{array}$ & $990 \pm 60$ & -- & $966 \pm 72$ & $\begin{array}{l}\text { AD } 1017-1130 \\
\text { AD } 1130-1161\end{array}$ & $\begin{array}{l}.79 \\
.21\end{array}$ \\
\hline$T x-3400$ & $\begin{array}{l}\text { Unit } 62 \text {, Fea. } 193- \\
1 \text {, Zone } 5\end{array}$ & $1020 \pm 60$ & -- & $996 \pm 72$ & $\begin{array}{l}\text { AD } 988-1064 \\
\text { AD } 1075-1127 \\
\text { AD } 1133-1159\end{array}$ & $\begin{array}{l}.52 \\
.32 \\
.15\end{array}$ \\
\hline Tx-3401 & $\begin{array}{l}\text { Unit } 62 \text {, Fea. } 193- \\
1 \text {, Zone } 10\end{array}$ & $800 \pm 40$ & -- & $776 \pm 57$ & $\mathrm{AD} 1221-1290$ & 1.00 \\
\hline Tx-3692 & $\begin{array}{l}\text { Unit } 65 \text {, } \\
\text { Fea. 195-137 }\end{array}$ & $960 \pm 60$ & -- & $936 \pm 72$ & AD $1026-1170$ & 1.00 \\
\hline Tx-3693 & $\begin{array}{l}\text { Unit 65, Fea. 195- } \\
137 \text { (maize) }\end{array}$ & $1400 \pm 150$ & -- & $1641 \pm 155$ & $\begin{array}{ll}\mathrm{AD} & 311-566 \\
\mathrm{AD} & 251-308\end{array}$ & $\begin{array}{l}.81 \\
.16\end{array}$ \\
\hline Tx-3694 & $\begin{array}{l}\text { Unit } 65 \text {, } \\
\text { Fea. } 195-133 \\
\text { (maize) }\end{array}$ & $820 \pm 60$ & -- & $1061 \pm 72$ & $\mathrm{AD} \quad 891-1030$ & 1.00 \\
\hline Tx-3695 & $\begin{array}{l}\text { Unit } 65 \text {, Fea. } 195- \\
149 \text { (maize) }\end{array}$ & $1400 \pm 60$ & -- & $1641 \pm 72$ & $\begin{array}{l}\text { AD } 373-534 \\
A D \quad 346-362\end{array}$ & $\begin{array}{l}.92 \\
.08\end{array}$ \\
\hline Tx-3697 & $\begin{array}{l}\text { Unit } 65, \\
\text { Fea. } 195-128\end{array}$ & $820 \pm 60$ & -- & $796 \pm 72$ & AD 1178-1289 & 1.00 \\
\hline$T x-4185$ & $\begin{array}{l}\text { Unit 64, } \\
\text { Fea. 196-10 }\end{array}$ & $750 \pm 70$ & -- & $726 \pm 81$ & $\begin{array}{l}\text { AD 1226-1313 } \\
\text { AD 1349-1389 }\end{array}$ & $\begin{array}{l}.74 \\
.26\end{array}$ \\
\hline$T x-4186$ & $\begin{array}{l}\text { Unit 65, } \\
\text { Fea. 195-22 }\end{array}$ & $980 \pm 40$ & -- & $956 \pm 57$ & $\begin{array}{l}\text { AD } 1074-1127 \\
\text { AD } 1024-1065 \\
\text { AD } 1133-1159\end{array}$ & $\begin{array}{l}.44 \\
.34 \\
.22\end{array}$ \\
\hline$T x-4187$ & $\begin{array}{l}\text { Unit 65, Fea. } \\
\text { 195-145 }\end{array}$ & $990 \pm 40$ & -- & $966 \pm 57$ & $\begin{array}{l}\text { AD } 1075-1126 \\
\text { AD } 1019-1064 \\
\text { AD } 1134-1159\end{array}$ & $\begin{array}{l}.42 \\
.37 \\
.21\end{array}$ \\
\hline$T x-4188$ & $\begin{array}{l}\text { Unit } 65, \\
\text { Fea. } 195-166\end{array}$ & $1200 \pm 50$ & -- & $1176 \pm 64$ & $\begin{array}{ll}\mathrm{AD} & 787-896 \\
\mathrm{AD} & 912-957\end{array}$ & $\begin{array}{l}.72 \\
.28\end{array}$ \\
\hline Tx-4189 & $\begin{array}{l}\text { Unit } 65 \text {, } \\
\text { Fea. } 195-183\end{array}$ & $1220 \pm 60$ & -- & $1196 \pm 72$ & $\begin{array}{ll}\text { AD } & 773-897 \\
\text { AD } & 910-958\end{array}$ & $\begin{array}{l}.77 \\
.22\end{array}$ \\
\hline$T x-4190$ & $\begin{array}{l}\text { Unit } 65 \text {, } \\
\text { Fea. } 195-189\end{array}$ & $790 \pm 80$ & -- & $766 \pm 90$ & $\begin{array}{l}\text { AD } 1168-1306 \\
\text { AD } 1363-1377\end{array}$ & $\begin{array}{l}.94 \\
.06\end{array}$ \\
\hline Tx-4192 & $\begin{array}{l}\text { Unit 65, } \\
\text { Fea. } 195-190\end{array}$ & $860 \pm 90$ & -- & $836 \pm 99$ & $\begin{array}{l}\text { AD } 1156-1283 \\
\text { AD } 1053-1085 \\
\text { AD } 1121-1139\end{array}$ & $\begin{array}{l}.77 \\
.15 \\
.08\end{array}$ \\
\hline Tx-4193 & $\begin{array}{l}\text { Unit 65, } \\
\text { Fea. 195-191 }\end{array}$ & $930 \pm 70$ & -- & $906 \pm 81$ & $\begin{array}{l}\text { AD } 1043-1108 \\
\text { AD } 1151-1208 \\
\text { AD } 1111-1148\end{array}$ & $\begin{array}{l}.41 \\
.36 \\
.23\end{array}$ \\
\hline
\end{tabular}


TABLE $1 .{ }^{14} \mathrm{C}$ Assays from Prehistoric Archaeological Sites in Eastern Texas (Continued)

\begin{tabular}{|c|c|c|c|c|c|c|}
\hline Assay no. & Provenience & Raw age & $\delta^{13} \mathrm{C}$ & $\begin{array}{l}\text { Corrected } \\
{ }^{14} \mathrm{C} \text { age }\end{array}$ & $\begin{array}{l}\text { Calibrated } \\
\text { age range* }\end{array}$ & RA $†$ \\
\hline Tx-4194 & $\begin{array}{l}\text { Unit } 65, \\
\text { Fea. } 195-196\end{array}$ & $1030 \pm 70$ & -- & $1006 \pm 81$ & $\begin{array}{l}\text { AD } 976-1067 \\
\text { AD } 1073-1128 \\
\text { AD } 1132-1160\end{array}$ & $\begin{array}{l}.56 \\
.29 \\
.15\end{array}$ \\
\hline Tx-4195 & $\begin{array}{l}\text { Unit } 109 \text {, } \\
\text { Fea. } 220-27\end{array}$ & $1270 \pm 70$ & -- & $1246 \pm 81$ & $\mathrm{AD} \quad 700-875$ & 1.00 \\
\hline Tx-4196 & $\begin{array}{l}\text { Unit 109, } \\
\text { Fea. 220-42 }\end{array}$ & $1020 \pm 80$ & -- & $996 \pm 90$ & $\mathrm{AD} \quad 979-1164$ & 1.00 \\
\hline Tx-4197 & $\begin{array}{l}\text { Unit } 109 \\
\text { Fea. } 220-25\end{array}$ & $760 \pm 80$ & -- & $736 \pm 90$ & $\begin{array}{l}\text { AD 1216-1316 } \\
\text { AD 1346-1391 }\end{array}$ & $\begin{array}{l}.75 \\
.25\end{array}$ \\
\hline Tx-4198 & $\begin{array}{l}\text { Unit 109, } \\
\text { Fea. } 220-23\end{array}$ & $1030 \pm 70$ & -- & $1006 \pm 81$ & $\begin{array}{l}\text { AD } 976-1067 \\
A D 1073-1128 \\
A D \quad 1132-1160\end{array}$ & $\begin{array}{l}.56 \\
.29 \\
.15\end{array}$ \\
\hline Tx-4199 & $\begin{array}{l}\text { Unit } 65 \text {, } \\
\text { Fea. } 195-197\end{array}$ & $830 \pm 110$ & -- & $806 \pm 117$ & $\begin{array}{l}\text { AD } 1155-1298 \\
\text { AD } 1049-1089 \\
\text { AD } 1119-1141\end{array}$ & $\begin{array}{l}.77 \\
.14 \\
.09\end{array}$ \\
\hline$T x-4200$ & $\begin{array}{l}\text { Unit } 65 \text {, } \\
\text { Fea. } 195-198\end{array}$ & $1240 \pm 90$ & -- & $1216 \pm 99$ & $\begin{array}{ll}\mathrm{AD} & 750-894 \\
\mathrm{AD} & 701-750 \\
\mathrm{AD} & 927-944\end{array}$ & $\begin{array}{l}.72 \\
.21 \\
.07\end{array}$ \\
\hline$T x-4201$ & $\begin{array}{l}\text { Unit 64, } \\
\text { Fea. 196-11 }\end{array}$ & $1020 \pm 110$ & -- & $996 \pm 117$ & $\mathrm{AD} \quad 961-1191$ & .97 \\
\hline Tx-4340 & $\begin{array}{l}\text { Unit 65, } \\
\text { Fea. 195-191 } \\
\text { (maize) }\end{array}$ & $520 \pm 90$ & -- & $761 \pm 99$ & $\begin{array}{l}\text { AD } 1168-1309 \\
\text { AD } 1355-1384\end{array}$ & $\begin{array}{l}.88 \\
.12\end{array}$ \\
\hline Tx-4616 & $\begin{array}{l}\text { Unit 109, } \\
\text { Fea. } 220-30\end{array}$ & $780 \pm 50$ & -- & $756 \pm 64$ & AD 1218-1302 & 1.00 \\
\hline Tx-4617 & $\begin{array}{l}\text { Unit 109, } \\
\text { Fea. } 220-59\end{array}$ & $560 \pm 120$ & -- & $536 \pm 127$ & AD 1293-1485 & 1.00 \\
\hline $\mathrm{Tx}-4618$ & $\begin{array}{l}\text { Unit 109, } \\
\text { Fea. } 220-56\end{array}$ & $880 \pm 60$ & -- & $856 \pm 72$ & $\begin{array}{l}\text { AD } 1157-1269 \\
\text { AD } 1056-1082 \\
\text { AD } 1123-1137\end{array}$ & $\begin{array}{l}.79 \\
.14 \\
.08\end{array}$ \\
\hline Tx-4619 & $\begin{array}{l}\text { Unit 109, } \\
\text { Fea. } 220-62\end{array}$ & $770 \pm 130$ & -- & $746 \pm 136$ & $\begin{array}{l}\text { AD } 1167-1329 \\
\text { AD } 1332-1396\end{array}$ & $\begin{array}{l}.74 \\
.26\end{array}$ \\
\hline$T x-4620$ & $\begin{array}{l}\text { Unit 109, } \\
\text { Fea. 220-61 }\end{array}$ & $750 \pm 220$ & -- & $726 \pm 224$ & $\begin{array}{l}\text { AD } 1151-1427 \\
\text { AD } 1044-1105 \\
\text { AD } 1112-1147\end{array}$ & $\begin{array}{l}.79 \\
.14 \\
.08\end{array}$ \\
\hline $\mathrm{Tx}-4621$ & $\begin{array}{l}\text { Unit 109, } \\
\text { Fea. 220-79 }\end{array}$ & $730 \pm 150$ & -. & $706 \pm 155$ & AD 1174-1414 & 1.00 \\
\hline$T x-4622$ & $\begin{array}{l}\text { Unit 109, } \\
\text { Fea. 220-97 }\end{array}$ & $930 \pm 70$ & -- & $906 \pm 81$ & $\begin{array}{l}\text { AD 1043-1108 } \\
\text { AD } 1151-1208 \\
\text { AD } 1111-1148\end{array}$ & $\begin{array}{l}.41 \\
.36 \\
.23\end{array}$ \\
\hline$T x-4623$ & $\begin{array}{l}\text { Unit 109, } \\
\text { Fea. 220-64 }\end{array}$ & $1020 \pm 60$ & -- & $996 \pm 72$ & $\begin{array}{l}\text { AD } 988-1064 \\
\text { AD } 1075-1127 \\
\text { AD } 1133-1159\end{array}$ & $\begin{array}{l}.52 \\
.32 \\
.15\end{array}$ \\
\hline$T x-4624$ & $\begin{array}{l}\text { Unit 109, Fea. } \\
\text { 220-30 (maize) }\end{array}$ & $1010 \pm 60$ & -- & $1251 \pm 72$ & $\begin{array}{ll}\mathrm{AD} & 697-828 \\
\mathrm{AD} & 833-865\end{array}$ & $\begin{array}{l}.81 \\
.19\end{array}$ \\
\hline$T x-4625$ & $\begin{array}{l}\text { Unit 109, } \\
\text { Fea. 220-113 }\end{array}$ & $1000 \pm 170$ & -- & $976 \pm 175$ & $\begin{array}{ll}\text { AD } & 944-1237 \\
\text { AD } & 894-927\end{array}$ & $\begin{array}{l}.92 \\
.08\end{array}$ \\
\hline \multicolumn{7}{|c|}{ Tuck Carpenter (41CP5) } \\
\hline $\mathrm{Tx}-666$ & Burial 10 & $360 \pm 70$ & -- & $360 \pm 81$ & $\begin{array}{l}\text { AD } 1536-1635 \\
\text { AD } 1473-1530\end{array}$ & $\begin{array}{l}.63 \\
.37\end{array}$ \\
\hline
\end{tabular}


TABLE $1 .{ }^{14} \mathrm{C}$ Assays from Prehistoric Archaeological Sites in Eastern Texas (Continued)

\begin{tabular}{|c|c|c|c|c|c|c|}
\hline Assay no. & Provenience & Raw age & $\delta^{13} \mathrm{C}$ & $\begin{array}{l}\text { Corrected } \\
{ }^{14} \mathrm{C} \text { age }\end{array}$ & $\begin{array}{l}\text { Calibrated } \\
\text { age range* }\end{array}$ & RA $\dagger$ \\
\hline \multicolumn{7}{|c|}{ Sam Roberts (41CP8) } \\
\hline Tx-199 & $\begin{array}{l}\text { Md., elev., } \\
101.5 \mathrm{ft} ., \text { N30W10 }\end{array}$ & $320 \pm 60$ & -. & $320 \pm 72$ & $\begin{array}{l}\text { AD } 1490-1605 \\
\text { AD } 1613-1649\end{array}$ & $\begin{array}{l}.76 \\
.24\end{array}$ \\
\hline Tx-202 & $\begin{array}{l}\text { Md., elev. } \\
101.7 \mathrm{ft} . \\
\text { N36W8.9 }\end{array}$ & $240 \pm 90$ & -- & $240 \pm 99$ & $\begin{array}{l}\text { AD 1724-1816 } \\
\text { AD } 1621-1696 \\
\text { AD } 1515-1592\end{array}$ & $\begin{array}{l}.34 \\
.29 \\
.24\end{array}$ \\
\hline \multicolumn{7}{|c|}{ Coker Mound (41CS1) } \\
\hline Beta-92919 $\ddagger$ & Burial layer & $410 \pm 50$ & $-14.6 \% 0$ & $570 \pm 50$ & $\begin{array}{l}\text { AD } 1388-1423 \\
\text { AD 1312-1350 }\end{array}$ & $\begin{array}{l}.51 \\
.49\end{array}$ \\
\hline \multicolumn{7}{|c|}{ Knight's Bluff (41CS14) } \\
\hline Tx-242 & Burial 5 fill & $550 \pm 90$ & -- & $550 \pm 99$ & $\begin{array}{l}\text { AD } 1373-1443 \\
\text { AD } 1305-1367\end{array}$ & $\begin{array}{l}.56 \\
.44\end{array}$ \\
\hline Tx-243 & $\begin{array}{l}\text { Unit E120 } \\
\mathrm{N} 5,46 \mathrm{~cm}\end{array}$ & $680 \pm 70$ & -- & $680 \pm 81$ & $\begin{array}{l}\text { AD } 1335-1395 \\
\text { AD } 1280-1326\end{array}$ & $\begin{array}{l}.57 \\
.43\end{array}$ \\
\hline \multicolumn{7}{|l|}{$41 \mathrm{CS} 150$} \\
\hline Beta-76607 & Fea. 2 & $630 \pm 60$ & $-26.8 \%$ & $600 \pm 60$ & $\begin{array}{l}\text { AD } 1307-1361 \\
\text { AD } 1378-1405\end{array}$ & $\begin{array}{l}.67 \\
.33\end{array}$ \\
\hline \multicolumn{7}{|l|}{$41 C S 151$} \\
\hline Beta-76608 $\ddagger$ & Fea. 1 & $2400 \pm 60$ & $-25.0 \% 0$ & $2400 \pm 60$ & $\begin{array}{l}531-394 \mathrm{BC} \\
752-704 \mathrm{BC}\end{array}$ & $\begin{array}{l}.80 \\
.20\end{array}$ \\
\hline Beta-76610 & Fea. 3 & $910 \pm 60$ & $-26.5 \%$ & $890 \pm 60$ & $\begin{array}{l}\text { AD } 1153-1221 \\
\text { AD } 1047-1095 \\
\text { AD } 1116-1144\end{array}$ & $\begin{array}{l}.50 \\
.32 \\
.18\end{array}$ \\
\hline Beta-81672 & Fea. 9 & $460 \pm 60$ & $-24.8 \%$ & $460 \pm 60$ & $\begin{array}{l}A D 1406-1491 \\
A D 1605-1613\end{array}$ & $\begin{array}{l}.96 \\
.04\end{array}$ \\
\hline Beta-81674 & Fea. 23 & $5300 \pm 60$ & $-25.4 \%$ & $5300 \pm 60$ & $\begin{array}{l}\text { BC } 4161-4040 \\
\text { BC } 4225-4184\end{array}$ & $\begin{array}{l}.74 \\
.24\end{array}$ \\
\hline Beta-82167 $\ddagger$ & Fea. 9 & $470 \pm 60$ & $-27.2 \%$ & $430 \pm 60$ & $\begin{array}{l}\mathrm{AD} 1427-1514 \\
\mathrm{AD} 1594-1620\end{array}$ & $\begin{array}{l}.82 \\
.18\end{array}$ \\
\hline Beta-82168 $\ddagger$ & Fea. 21 & $210 \pm 60$ & $-28.2 \%$ & $160 \pm 60$ & $\begin{array}{l}\text { AD } 1716-1782 \\
\text { AD } 1671-1704 \\
\text { AD } 1795-1820 \\
\text { AD } 1840-1867\end{array}$ & $\begin{array}{l}.37 \\
.18 \\
.14 \\
.13\end{array}$ \\
\hline Beta-82169 $\ddagger$ & Fea. 29 & $1140 \pm 60$ & $-28.6 \%$ & $1090 \pm 60$ & $\begin{array}{ll}\mathrm{AD} & 943-1010 \\
\mathrm{AD} & 894-931\end{array}$ & $\begin{array}{l}.66 \\
.34\end{array}$ \\
\hline \multicolumn{7}{|l|}{$41 \mathrm{CS} 155$} \\
\hline Beta-76611 $\ddagger$ & Fea. 1 & $700 \pm 60$ & $-23.7 \%$ & $720 \pm 60$ & $\begin{array}{l}\text { AD } 1247-1309 \\
\text { AD } 1356-1383\end{array}$ & $\begin{array}{l}.76 \\
.24\end{array}$ \\
\hline \multicolumn{7}{|l|}{ Tick (41DT6) } \\
\hline SMU-349 & $\begin{array}{l}\text { Unit } 10, \\
30-35 \mathrm{~cm}\end{array}$ & $1320 \pm 190$ & -- & $1320 \pm 194$ & $\begin{array}{ll}\mathrm{AD} & 560-896 \\
\mathrm{AD} & 912-957\end{array}$ & $\begin{array}{l}.91 \\
.09\end{array}$ \\
\hline Beta-51364 & $\begin{array}{l}\text { Flotation } \\
\text { Column } 1 \text {, } \\
\text { lv. } 2\end{array}$ & $1270 \pm 60$ & $-26.2 \%$ & $1250 \pm 60$ & $\begin{array}{ll}\mathrm{AD} & 752-826 \\
\mathrm{AD} & 705-749 \\
\mathrm{AD} & 834-864\end{array}$ & $\begin{array}{l}.51 \\
.30 \\
.18\end{array}$ \\
\hline Beta-51365 & $\begin{array}{l}\text { Flotation } \\
\text { Column 1, lv. } 4\end{array}$ & $1790 \pm 100$ & $-26.1 \%$ & $1770 \pm 100$ & $\begin{array}{ll}\text { AD } & 192-389 \\
\text { AD } & 146-181\end{array}$ & $\begin{array}{l}.87 \\
.13\end{array}$ \\
\hline
\end{tabular}


TABLE $1 .{ }^{14} \mathrm{C}$ Assays from Prehistoric Archaeological Sites in Eastern Texas (Continued)

\begin{tabular}{|c|c|c|c|c|c|c|}
\hline Assay no. & Provenience & Raw age & $\delta^{13} \mathrm{C}$ & $\begin{array}{l}\text { Corrected } \\
{ }^{14} \mathrm{C} \text { age }\end{array}$ & $\begin{array}{l}\text { Calibrated } \\
\text { age range* }\end{array}$ & RA $†$ \\
\hline Beta-51366 & $\begin{array}{l}\text { Flotation } \\
\text { Column 2, lv. } 2\end{array}$ & $1300 \pm 80$ & $-25.0 \%$ & $1300 \pm 80$ & $\mathrm{AD} \quad 658-813$ & 1.00 \\
\hline Beta-51367 & $\begin{array}{l}\text { Flotation } \\
\text { Column 2, lv. } 3\end{array}$ & $1370 \pm 80$ & $-25.5 \%$ & $1370 \pm 80$ & $\begin{array}{ll}\mathrm{AD} & 613-724 \\
\mathrm{AD} & 735-771\end{array}$ & $\begin{array}{l}.80 \\
.20\end{array}$ \\
\hline Beta-51368 & $\begin{array}{l}\text { Flotation } \\
\text { Column 2, lv. } 4\end{array}$ & $1470 \pm 80$ & $-25.8 \% 0$ & $1460 \pm 80$ & $\mathrm{AD} \quad 536-667$ & 1.00 \\
\hline Beta-52240 & $\begin{array}{l}\text { Units } 6 \text { and } \\
12-14, \text { lv. } 5\end{array}$ & $1120 \pm 70$ & $-25.8 \% 0$ & $1110 \pm 70$ & AD $882-1012$ & 1.00 \\
\hline \multicolumn{7}{|c|}{ Spider Knoll (41DT11) } \\
\hline Beta-46858 & Unit 10, lv. 8 & $1030 \pm 60$ & $-24.8 \%$ & $1040 \pm 60$ & $\begin{array}{ll}\text { AD } & 952-1044 \\
\text { AD } & 894-918\end{array}$ & $\begin{array}{l}.83 \\
.12\end{array}$ \\
\hline Beta-46859 & Unit 10, lv. 5 & $840 \pm 60$ & $-26.4 \% 0$ & $810 \pm 60$ & AD 1189-1282 & 1.00 \\
\hline Beta-46860 $\ddagger$ & Fea. 5 & - & -- & $960 \pm 50$ & $\begin{array}{l}\text { AD } 1077-1125 \\
\text { AD } 1023-1062 \\
\text { AD } 1134-1158\end{array}$ & $\begin{array}{l}.44 \\
.35 \\
.21\end{array}$ \\
\hline Beta- 48768 & Fea. 1 & $1060 \pm 80$ & $-26.5 \% 0$ & $1040 \pm 80$ & $\begin{array}{l}\text { AD } 893-1046 \\
\text { AD } 1097-1115\end{array}$ & $\begin{array}{l}.88 \\
.08\end{array}$ \\
\hline Beta-48769 & Fea. 2 & $1140 \pm 90$ & $-26.7 \%$ & $1120 \pm 90$ & $\begin{array}{ll}\mathrm{AD} & 856-1014 \\
\mathrm{AD} & 818-844\end{array}$ & $\begin{array}{l}.90 \\
.10\end{array}$ \\
\hline Beta- $63297 \ddagger$ & Unit 6, lv. 1 & -- & -- & $940 \pm 50$ & $\begin{array}{l}\text { AD } 1072-1128 \\
\text { AD } 1036-1067 \\
\text { AD } 1132-1160\end{array}$ & $\begin{array}{l}.49 \\
.27 \\
.24\end{array}$ \\
\hline Beta-63298 & Unit 9, lv. 5 & $590 \pm 80$ & $-25.6 \%$ & $580 \pm 80$ & $\begin{array}{l}\text { AD } 1307-1362 \\
\text { AD } 1377-1422\end{array}$ & $\begin{array}{l}.56 \\
.44\end{array}$ \\
\hline Beta-63299 & Unit 9, lv. 9 & -- & -- & $770 \pm 50$ & $\mathrm{AD} 1231-1288$ & 1.00 \\
\hline Beta-63300‡ & Unit 13, lv. 1 & -- & -- & $925 \pm 50$ & $\begin{array}{l}\text { AD } 1042-1110 \\
\text { AD } 1110-1149 \\
\text { AD } 1150-1165\end{array}$ & $\begin{array}{l}.56 \\
.32 \\
.11\end{array}$ \\
\hline Beta-63301 & $\begin{array}{l}\text { Unit 13, } \\
\text { lv. } 4\end{array}$ & $1020 \pm 60$ & $-25.5 \%$ & $1010 \pm 60$ & $\begin{array}{l}\text { AD } 978-1054 \\
\text { AD } 1084-1122 \\
\text { AD } 1138-1156\end{array}$ & $\begin{array}{l}.66 \\
.23 \\
.11\end{array}$ \\
\hline Beta- $63302 \ddagger$ & Unit 14, lv. 9 & -- & -- & $920 \pm 55$ & AD 1040-1169 & 1.00 \\
\hline Beta- 63303 & Fea. 135 & $930 \pm 50$ & $-25.2 \% 0$ & $930 \pm 50$ & $\begin{array}{l}\text { AD } 1042-1149 \\
\text { AD } 1150-1162\end{array}$ & $\begin{array}{l}.91 \\
.09\end{array}$ \\
\hline Beta-63304 & Fea. 136 & $850 \pm 70$ & $-26.1 \%$ & $830 \pm 70$ & $\mathrm{AD} 1160-1283$ & .98 \\
\hline Beta-63305 & Fea. 147 & $1010 \pm 70$ & $-24.9 \%$ & $1010 \pm 70$ & $\begin{array}{l}\text { AD } 975-1060 \\
\text { AD } 1078-1125 \\
\text { AD } 1135-1158\end{array}$ & $\begin{array}{l}.61 \\
.26 \\
.13\end{array}$ \\
\hline Beta-65796‡ & Fea. 129 & $1080 \pm 55$ & $-24.1 \%$ & $1095 \pm 55$ & $\begin{array}{l}\text { AD } 943-1003 \\
\text { AD } 894-931\end{array}$ & $\begin{array}{l}.63 \\
.37\end{array}$ \\
\hline Beta- $65797 \ddagger$ & Fea. 51 & $725 \pm 55$ & $-20.9 \%$ & $790 \pm 55$ & AD 1216-1287 & 1.00 \\
\hline Beta-65798 $\ddagger$ & Fea. 73 & $985 \pm 55$ & $-19.8 \%$ & $1065 \pm 55$ & $\begin{array}{l}\text { AD } 952-1024 \\
\text { AD } 894-918\end{array}$ & $\begin{array}{l}.81 \\
.19\end{array}$ \\
\hline Beta-65799 & Fea. 117 & $1095 \pm 55$ & $-24.7 \%$ & $1100 \pm 55$ & $\begin{array}{l}\text { AD } 941-996 \\
\text { AD } 893-937\end{array}$ & $\begin{array}{l}.57 \\
.43\end{array}$ \\
\hline Beta- 65800 & Fea. 22 & $1400 \pm 170$ & $-26.5 \% 0$ & $1380 \pm 170$ & AD $533-882$ & 1.00 \\
\hline Beta- 65801 & Fea. 35 & $880 \pm 90$ & $-26.4 \%$ & $850 \pm 90$ & $\begin{array}{l}\text { AD } 1156-1277 \\
\text { AD } 1053-1084 \\
\text { AD } 1121-1138\end{array}$ & $\begin{array}{l}.76 \\
.16 \\
.09\end{array}$ \\
\hline
\end{tabular}


$\underline{\text { TABLE } 1 .{ }^{14} \mathrm{C} \text { Assays from Prehistoric Archaeological Sites in Eastern Texas (Continued) }}$

\begin{tabular}{|c|c|c|c|c|c|c|}
\hline Assay no. & Provenience & Raw age & $\delta^{13} \mathrm{C}$ & $\begin{array}{l}\text { Corrected } \\
{ }^{14} \mathrm{C} \text { age }\end{array}$ & $\begin{array}{l}\text { Calibrated } \\
\text { age range* }\end{array}$ & RA $\dagger$ \\
\hline Beta-65802 & Fea. 75 & $890 \pm 55$ & $-23.9 \%$ & $910 \pm 55$ & $\begin{array}{l}\text { AD } 1043-1106 \\
\text { AD } 1112-1148 \\
\text { AD } 1151-1186\end{array}$ & $\begin{array}{l}.47 \\
.27 \\
.26\end{array}$ \\
\hline Beta-65803 & Fea. 125 & $1120 \pm 80$ & $-27.4 \%$ & $1080 \pm 80$ & AD $880-1033$ & 1.00 \\
\hline Beta- 65804 & Fea. 137 & $850 \pm 80$ & $-26.4 \%$ & $830 \pm 80$ & $\begin{array}{l}\text { AD } 1159-1284 \\
\text { AD } 1063-1076\end{array}$ & $\begin{array}{l}.91 \\
.06\end{array}$ \\
\hline \multicolumn{7}{|c|}{ Spike (41DT16) } \\
\hline SMU-398 & $\begin{array}{l}\text { Unit } 14, \\
45-50 \mathrm{~cm}\end{array}$ & $200 \pm 80$ & - & $200 \pm 90$ & $\begin{array}{l}\text { AD } 1715-1820 \\
\text { AD } 1646-1705 \\
\text { AD } 1915-1955^{*} \\
\text { AD } 1839-1870\end{array}$ & $\begin{array}{l}.47 \\
.25 \\
.17 \\
.10\end{array}$ \\
\hline SMU-401 & $\begin{array}{l}\text { Unit } 10 \text {, } \\
45-50 \mathrm{~cm}\end{array}$ & $1060 \pm 70$ & -- & $1060 \pm 81$ & $\begin{array}{l}\text { AD } 885-1043 \\
\text { AD } 1106-1112\end{array}$ & $\begin{array}{l}.97 \\
.02\end{array}$ \\
\hline Beta-51369 & Fea. 3 & $1060 \pm 90$ & $-25.2 \% 0$ & $1060 \pm 90$ & $\begin{array}{l}\text { AD } 883-1047 \\
\text { AD } 1094-1116\end{array}$ & $\begin{array}{l}.90 \\
.07\end{array}$ \\
\hline Beta-51370 & Fea. 8 & $1140 \pm 70$ & $-25.9 \%$ & $1130 \pm 70$ & $\begin{array}{l}\text { AD } 864-1002 \\
\text { AD } 826-834\end{array}$ & $\begin{array}{l}.96 \\
.04\end{array}$ \\
\hline Beta-51371 & Fea. 17 & $2090 \pm 90$ & $-25.7 \%$ & $2080 \pm 90$ & BC 195-AD 24 & .99 \\
\hline Beta-51372 & Unit 9, lv. 6 & $1300 \pm 80$ & $-26.0 \% 0$ & $1290 \pm 80$ & $\mathrm{AD} \quad 664-815$ & .97 \\
\hline Beta-51373 & Unit 13 , lv. 3 & $800 \pm 70$ & $-26.8 \% 0$ & $770 \pm 70$ & AD 1199-1300 & 1.00 \\
\hline Beta-51374 & Unit 25, lv. 6 & $1090 \pm 70$ & $-26.5 \%$ & $1070 \pm 70$ & $\begin{array}{ll}\mathrm{AD} & 940-1022 \\
\mathrm{AD} & 893-939\end{array}$ & $\begin{array}{l}.69 \\
.31\end{array}$ \\
\hline Beta-51375 & Unit 28, lv. 3 & $930 \pm 80$ & $-25.5 \%$ & $930 \pm 80$ & AD 1027-1182 & 1.00 \\
\hline Beta-52241 & Units $8 \& 9$, lv. 8 & $1300 \pm 60$ & $-25.5 \%$ & $1290 \pm 60$ & $\mathrm{AD} \quad 667-787$ & 1.00 \\
\hline Beta-52242 & Units $13 \& 19$, lv. 8 & $1330 \pm 70$ & $-25.9 \%$ & $1310 \pm 70$ & $\mathrm{AD} \quad 658-785$ & 1.00 \\
\hline Beta-52243 & Units $17 \& 18$, lv. 9 & $1230 \pm 80$ & $-25.7 \%$ & $1220 \pm 80$ & 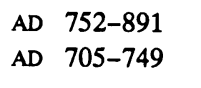 & $\begin{array}{l}.80 \\
.20\end{array}$ \\
\hline Beta-52244 & $\begin{array}{l}\text { Units } 19 \& 26 \text {, } \\
\text { lv. } 10\end{array}$ & $1550 \pm 90$ & $-24.8 \%$ & $1560 \pm 90$ & AD $\quad 425-598$ & 1.00 \\
\hline Beta-52245 & Units $26 \& 27$, lv. 8 & $1520 \pm 60$ & $-24.8 \%$ & $1530 \pm 60$ & $\begin{array}{ll}\mathrm{AD} & 530-606 \\
\mathrm{AD} & 450-484 \\
\mathrm{AD} & 500-525\end{array}$ & $\begin{array}{l}.63 \\
.22 \\
.16\end{array}$ \\
\hline \multicolumn{7}{|c|}{ L. O. Ray (41DT21) } \\
\hline Beta-46861 & Fea. 2 & $1320 \pm 80$ & $-27.6 \%$ & $1270 \pm 80$ & $\begin{array}{ll}\mathrm{AD} & 676-821 \\
\mathrm{AD} & 840-860\end{array}$ & $\begin{array}{l}.89 \\
.11\end{array}$ \\
\hline Beta-46862 & Unit 6, lv. 4 & -- & -- & $1045 \pm 50$ & $\begin{array}{ll}\text { AD } & 960-1033 \\
\text { AD } & 898-908\end{array}$ & $\begin{array}{l}.93 \\
.07\end{array}$ \\
\hline Beta-46863‡ & Unit 8, lv. 3 & -- & -- & $170 \pm 50$ & $\begin{array}{l}\text { AD } 1719-1789 \\
\text { AD } 1667-1701 \\
\text { AD } 1918-1951 \\
\text { AD } 1790-1818\end{array}$ & $\begin{array}{l}.43 \\
.20 \\
.19 \\
.17\end{array}$ \\
\hline \multicolumn{7}{|c|}{ Ranger (41DT37) } \\
\hline SMU-363 & Unit $46,10-15 \mathrm{~cm}$ & $270 \pm 60$ & -- & $270 \pm 72$ & $\begin{array}{l}\text { AD } 1510-1602 \\
\text { AD } 1615-1678 \\
\text { AD } 1771-1802\end{array}$ & $\begin{array}{l}.43 \\
.36 \\
.14\end{array}$ \\
\hline 41DT42 & & & & & & \\
\hline SMU-477 & Unit $7,20-25 \mathrm{~cm}$ & $1060 \pm 120$ & -- & $1060 \pm 127$ & $\begin{array}{l}\text { AD } 868-1068 \\
\text { AD } 1072-1128 \\
A D 1132-1160\end{array}$ & $\begin{array}{l}.76 \\
.16 \\
.08\end{array}$ \\
\hline
\end{tabular}


TABLE $1 .{ }^{14} \mathrm{C}$ Assays from Prehistoric Archaeological Sites in Eastern Texas (Continued)

\begin{tabular}{|c|c|c|c|c|c|c|}
\hline Assay no. & Provenience & Raw age & $\delta^{13} \mathrm{C}$ & $\begin{array}{l}\text { Corrected } \\
{ }^{14} \mathrm{C} \text { age }\end{array}$ & $\begin{array}{l}\text { Calibrated } \\
\text { age range* }\end{array}$ & RA $†$ \\
\hline \multicolumn{7}{|l|}{ 41DT50 } \\
\hline Beta-46857 & Unit 1 & $660 \pm 80$ & $-26.2 \%$ & $640 \pm 80$ & $\begin{array}{l}\text { AD } 1332-1396 \\
\text { AD } 1297-1328\end{array}$ & $\begin{array}{l}.68 \\
.32\end{array}$ \\
\hline \multicolumn{7}{|c|}{ Luna (41DT52) } \\
\hline SMU-396 & Fea. $21 \mathrm{~A}$ & $920 \pm 40$ & -- & $920 \pm 57$ & AD 1039-1170 & 1.00 \\
\hline SMU-404 & Unit $30,30-40 \mathrm{~cm}$ & $660 \pm 70$ & -- & $660 \pm 81$ & $\begin{array}{l}\text { AD } 1334-1395 \\
\text { AD } 1289-1326\end{array}$ & $\begin{array}{l}.62 \\
.38\end{array}$ \\
\hline SMU-417 & Fea. 31A & $160 \pm 45$ & -- & $160 \pm 60$ & $\begin{array}{l}\text { AD } 1716-1782 \\
\text { AD } 1671-1704 \\
\text { AD } 1916-1947 \\
\text { AD } 1795-1820\end{array}$ & $\begin{array}{l}.37 \\
.18 \\
.17 \\
.14\end{array}$ \\
\hline SMU-471 & Unit $19,20-30 \mathrm{~cm}$ & $280 \pm 70$ & -- & $280 \pm 81$ & $\begin{array}{l}\text { AD } 1489-1607 \\
\text { AD } 1612-1674 \\
\text { AD } 1778-1797\end{array}$ & $\begin{array}{l}.55 \\
.33 \\
.08\end{array}$ \\
\hline SMU-476 & Fea. $15 \mathrm{~A}$ & $1300 \pm 150$ & -- & $1300 \pm 155$ & $\begin{array}{ll}\mathrm{AD} & 616-894 \\
\mathrm{AD} & 927-944\end{array}$ & $\begin{array}{l}.96 \\
.04\end{array}$ \\
\hline \multicolumn{7}{|l|}{ 41DT59 } \\
\hline Beta-81670 & Unit 31, lv. 5 & $2660 \pm 50$ & $-26.2 \%$ & $2640 \pm 50$ & $839-782 \mathrm{BC}$ & 1.00 \\
\hline \multicolumn{7}{|c|}{ Johns Creek (41DT62) } \\
\hline Beta-51379 & Unit 9, lv. 3 & $1790 \pm 140$ & $-25.2 \%$ & $1790 \pm 140$ & $\begin{array}{lr}\text { AD } & 113-408 \\
\text { AD } & 86-102\end{array}$ & $\begin{array}{l}.96 \\
.04\end{array}$ \\
\hline Beta-52602 & $\begin{array}{l}\text { Units } 2,5-7,11 \\
\text { and } 14,1 \mathrm{lv} .7\end{array}$ & $1240 \pm 70$ & $-25.9 \% 0$ & $1220 \pm 70$ & $\begin{array}{l}\text { AD } 757-890 \\
\text { AD } 712-745\end{array}$ & $\begin{array}{l}.84 \\
.16\end{array}$ \\
\hline Beta-52603 & $\begin{array}{l}\text { Units } 7,8,11,15 \text {, } \\
17 \text { and } 19,1 \text { lv. } 5\end{array}$ & $1020 \pm 80$ & $-26.0 \%$ & $1000 \pm 80$ & $\begin{array}{l}\text { AD } 982-1068 \\
\text { AD } 1072-1128 \\
\text { AD } 1132-1160\end{array}$ & $\begin{array}{l}.53 \\
.31 \\
.16\end{array}$ \\
\hline Beta-52604 & $\begin{array}{l}\text { Units } 7,8 \text { and } 20 \text {, } \\
\text { lv. } 4\end{array}$ & $870 \pm 130$ & $-27.3 \%$ & $830 \pm 130$ & $\begin{array}{l}\text { AD } 1153-1288 \\
\text { AD } 1046-1098 \\
\text { AD } 1115-1145\end{array}$ & $\begin{array}{l}.67 \\
.21 \\
.12\end{array}$ \\
\hline Beta-52605 & $\begin{array}{l}\text { Units } 2,7,12 \text { and } \\
13 \text {, lvs. } 6-7\end{array}$ & $1370 \pm 110$ & $-24.8 \% 0$ & $1380 \pm 110$ & $\begin{array}{lr}\mathrm{AD} & 590-780 \\
\mathrm{AD} & 561-589\end{array}$ & $\begin{array}{l}.91 \\
.09\end{array}$ \\
\hline \multicolumn{7}{|l|}{$41 D T 63$} \\
\hline Beta-46864 & Unit 1, lv. 5 & $1080 \pm 100$ & $-24.1 \% 0$ & $1090 \pm 100$ & $\begin{array}{ll}\mathrm{AD} & 852-1034 \\
\mathrm{AD} & 815-848\end{array}$ & $\begin{array}{l}.90 \\
.10\end{array}$ \\
\hline Beta-46865 & Unit 2, lv. 4 & $1020 \pm 90$ & $-25.2 \%$ & $1010 \pm 90$ & $\mathrm{AD} \quad 967-1162$ & 1.00 \\
\hline Beta-46866 & Unit 2, lv. 7 & $940 \pm 60$ & $-25.6 \%$ & $930 \pm 60$ & $\mathrm{AD} 1036-1166$ & 1.00 \\
\hline \multicolumn{7}{|c|}{ Thomas (41DT80) } \\
\hline SMU-1903 & Fea. 2 & -- & $-25.8 \%$ & $920 \pm 30$ & $\begin{array}{l}\text { AD } 1046-1099 \\
\text { AD } 1115-1145 \\
\text { AD } 1153-1165\end{array}$ & $\begin{array}{l}.56 \\
.31 \\
.13\end{array}$ \\
\hline SMU-1959 & Fea. 48 & -- & $-25.0 \%$ & $960 \pm 4$ & $\begin{array}{l}\text { AD } 1030-1043 \\
\text { AD } 1106-1112 \\
\text { AD } 1148-1151\end{array}$ & $\begin{array}{l}.70 \\
.16 \\
.13\end{array}$ \\
\hline SMU-1967 & Fea. 3 & -- & $-25.3 \% 0$ & $1020 \pm 60$ & $\begin{array}{l}\text { AD } 968-1051 \\
\text { AD } 1086-1120 \\
\text { AD } 1139-1156\end{array}$ & $\begin{array}{l}.73 \\
.18 \\
.09\end{array}$ \\
\hline SMU-1968 & Fea. 12 & -- & $-25.7 \%$ & $920 \pm 110$ & AD 1025-1218 & 1.00 \\
\hline SMU-2025 & Fea. 23 & -- & -- & $860 \pm 30$ & $\mathrm{AD} 1166-1227$ & 1.00 \\
\hline
\end{tabular}


TABLE $1 .{ }^{14} \mathrm{C}$ Assays from Prehistoric Archaeological Sites in Eastern Texas (Continued)

\begin{tabular}{|c|c|c|c|c|c|c|}
\hline Assay no. & Provenience & Raw age & $\delta^{13} \mathrm{C}$ & $\begin{array}{c}\text { Corrected } \\
{ }^{14} \mathrm{C} \text { age }\end{array}$ & $\begin{array}{l}\text { Calibrated } \\
\text { age range* }\end{array}$ & RA $†$ \\
\hline Tx-1958 & Unit $88,25-30 \mathrm{~cm}$ & $1220 \pm 350$ & -- & $1220 \pm 352$ & AD $534-1198$ & 1.00 \\
\hline \multirow[t]{2}{*}{ Tx-1959 } & Unit $88,85-92 \mathrm{~cm}$ & $1180 \pm 220$ & -- & $1180 \pm 224$ & AD $648-1045$ & .97 \\
\hline & & & & & AD 1100-1114 & .02 \\
\hline \multicolumn{7}{|c|}{ Delta Bone Quarry 5 (41DT86) } \\
\hline \multirow[t]{2}{*}{ SM-532 } & Possible hearth in & $9550 \pm 375$ & -- & $9550 \pm 377$ & BC $9170-8082$ & .97 \\
\hline & $\begin{array}{l}\text { Late Pleistocene } \\
\text { alluvium }\end{array}$ & & & & BC 9260-9227 & .02 \\
\hline \multicolumn{7}{|c|}{ Doctors Creek (41DT124) } \\
\hline \multirow[t]{2}{*}{ SMU-1936 } & Unit 65 , lv. 4 & -. & $-25.4 \% 0$ & $1090 \pm 190$ & AD $774-1068$ & .81 \\
\hline & & & & & AD $1072-1128$ & .13 \\
\hline \multirow[t]{2}{*}{ SMU-1946 } & Unit 66, lv. 9 & -- & $-25.8 \% 0$ & $1510 \pm 200$ & AD $331-715$ & .95 \\
\hline & & & & & AD $743-761$ & .03 \\
\hline SMU-1947 & Fea. 4 & -. & $-25.5 \%$ & $1050 \pm 30$ & $\mathrm{AD} \quad 983-1017$ & 1.00 \\
\hline \multirow[t]{3}{*}{ SMU-1948 } & Fea. 5 & -. & $-25.7 \%$ & $960 \pm 30$ & AD 1084-1121 & .44 \\
\hline & & & & & AD 1025-1053 & .35 \\
\hline & & & & & AD 1139-1156 & .21 \\
\hline SMU-1957 & Fea. 9 & -- & $-25.7 \%$ & $1020 \pm 30$ & AD $997-1028$ & 1.00 \\
\hline SMU-2009 & Fea. 2 & -- & -- & $860 \pm 30$ & $\mathrm{AD} 1166-1227$ & 1.00 \\
\hline SMU-2026 & Fea. 14 & -- & -- & $860 \pm 30$ & AD 1166-1227 & 1.00 \\
\hline \multicolumn{7}{|l|}{ 41DT141 } \\
\hline Beta-17399 & $\begin{array}{l}\mathrm{BHT} 15,2 \mathrm{AB} \\
\text { horizon, humates }\end{array}$ & $1100 \pm 70$ & -- & $1100 \pm 81$ & $\mathrm{AD} \quad 867-1024$ & 1.00 \\
\hline Beta- 17400 & $\begin{array}{l}\text { BHT 15, 4Ab1 } \\
\text { horizon, humates }\end{array}$ & $2100 \pm 70$ & -- & $2100 \pm 81$ & 199 BC-AD 6 & 1.00 \\
\hline \multirow[t]{3}{*}{ Beta-17401 } & Profile $20,4 \mathrm{Ab} 2$ & $2350 \pm 70$ & -- & $2350 \pm 81$ & $533-356 \mathrm{BC}$ & .73 \\
\hline & horizon, humates & & & & $753-696 \mathrm{BC}$ & .15 \\
\hline & & & & & $289-245$ вC & .12 \\
\hline Beta-41774 & $\begin{array}{l}\text { Profile 1, 3Ab1 } \\
\text { horizon, humates }\end{array}$ & $1110 \pm 80$ & $-21.8 \% 0$ & $1160 \pm 80$ & $\mathrm{AD} \quad 696-1015$ & $1.00 \S$ \\
\hline Beta-41776 & Unit 1, lv. 14 & $1560 \pm 130$ & $-24.5 \% 0$ & $1570 \pm 130$ & $\mathrm{AD} \quad 382-635$ & 1.00 \\
\hline \multicolumn{7}{|c|}{ Bazette (41HE57) } \\
\hline \multirow[t]{2}{*}{ SMU-516 } & Unit $\mathrm{E}$, hearth 1 & $423 \pm 58$ & -- & $423 \pm 71$ & AD $1430-1518$ & .71 \\
\hline & & & & & AD $1579-1624$ & .29 \\
\hline \multicolumn{7}{|c|}{ Woldert (41HE80) } \\
\hline \multirow[t]{2}{*}{ Tx-1279 } & Fea. $1(?)$, & $640 \pm 70$ & -- & $640 \pm 81$ & AD 1331-1396 & .68 \\
\hline & $20-30 \mathrm{~cm}$ & & & & AD 1297-1329 & .32 \\
\hline \multirow[t]{2}{*}{$\mathrm{Tx}-1280$} & Fea. $4(?)$, & $1590 \pm 450$ & -- & $1590 \pm 452$ & $37 \mathrm{BC}-\mathrm{AD} 894$ & .98 \\
\hline & $30-40 \mathrm{~cm}$ & & & & $\mathrm{AD} \quad 926-944$ & .02 \\
\hline \multicolumn{7}{|c|}{ Tomato Patch (41HE188) } \\
\hline \multirow[t]{2}{*}{$\mathrm{Tx}-1273$} & Fea. 11 & $120 \pm 140$ & -- & $120 \pm 146$ & AD 1799-1942 & .59 \\
\hline & & & & & AD 1676-1775 & .41 \\
\hline \multicolumn{7}{|c|}{ Winston (41HE245) } \\
\hline \multirow[t]{3}{*}{ SMU-624 } & Unit 1 , lens 1 & $216 \pm 104$ & -- & $216 \pm 111$ & AD 1711-1822 & .41 \\
\hline & & & & & AD 1634-1709 & .27 \\
\hline & & & & & AD 1834-1881 & .13 \\
\hline \multirow[t]{2}{*}{ SMU-625 } & Unit 1 , lens 1 & $456 \pm 91$ & -- & $456 \pm 99$ & $A D$ 1402-1521 & .73 \\
\hline & & & & & AD $1568-1627$ & .27 \\
\hline
\end{tabular}


TABLE $1 .{ }^{14} \mathrm{C}$ Assays from Prehistoric Archaeological Sites in Eastern Texas (Continued)

\begin{tabular}{|c|c|c|c|c|c|c|}
\hline Assay no. & Provenience & Raw age & $\delta^{13} \mathrm{C}$ & $\begin{array}{l}\text { Corrected } \\
{ }^{14} \mathrm{C} \text { age }\end{array}$ & $\begin{array}{l}\text { Calibrated } \\
\text { age range* }\end{array}$ & RA $\dagger$ \\
\hline SMU-656 & Unit 2, lens 10 & $2635 \pm 49$ & -- & $2635 \pm 63$ & $\begin{array}{l}862-766 \mathrm{BC} \\
896-873 \mathrm{BC}\end{array}$ & $\begin{array}{l}.90 \\
.10\end{array}$ \\
\hline SMU-657 & Unit 2, lens 10 & $2669 \pm 50$ & -- & $2669 \pm 64$ & $\begin{array}{l}862-795 \text { BC } \\
896-873 \text { BC }\end{array}$ & $\begin{array}{l}.80 \\
.20\end{array}$ \\
\hline SMU-660 & Unit 2, lens 10 & $2853 \pm 57$ & -- & $2853 \pm 70$ & $\begin{array}{l}1084-917 \text { вC } \\
1114-1092 \text { BC }\end{array}$ & $\begin{array}{l}.91 \\
.09\end{array}$ \\
\hline SMU-684 & Unit 2, lens 10 & $2821 \pm 59$ & -- & $2821 \pm 71$ & $\begin{array}{l}1045-894 \text { BC } \\
880-849 \text { BC }\end{array}$ & $\begin{array}{l}.88 \\
.12\end{array}$ \\
\hline SMU-686 & Unit 1 , lens 1 & $1205 \pm 56$ & -- & $1205 \pm 69$ & 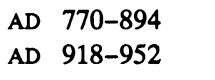 & $\begin{array}{l}.80 \\
.15\end{array}$ \\
\hline \multicolumn{7}{|c|}{ Lawson (41HP78) } \\
\hline SMU-1954 & Posthole 1 & -- & $-27.3 \%$ & $990 \pm 40$ & $\begin{array}{l}\text { AD } 1007-1050 \\
\text { AD } 1088-1119 \\
\text { AD } 1140-1155\end{array}$ & $\begin{array}{l}.57 \\
.29 \\
.14\end{array}$ \\
\hline SMU-1958 & Posthole 3 & -- & $-26.7 \%$ & $960 \pm 40$ & $\begin{array}{l}\text { AD } 1080-1124 \\
\text { AD } 1024-1058 \\
\text { AD } 1136-1157\end{array}$ & $\begin{array}{l}.44 \\
.35 \\
.21\end{array}$ \\
\hline SMU-1978 & Fea. 1 & -- & $-26.4 \% 0$ & $1810 \pm 110$ & 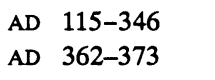 & $\begin{array}{l}.94 \\
.04\end{array}$ \\
\hline Tx-1961 & Hearth No. 2 & $2080 \pm 60$ & -- & $2080 \pm 72$ & $175 \mathrm{BC}-\mathrm{AD} 0$ & 1.00 \\
\hline \multicolumn{7}{|c|}{ Arnold (41HP102) } \\
\hline SMU-310 & $\begin{array}{l}\text { Fea. } 112 \mathrm{~A}, 30-35 \\
\mathrm{~cm} \text { in feature zone }\end{array}$ & $870 \pm 50$ & -- & $870 \pm 64$ & $\begin{array}{l}\text { AD } 1155-1246 \\
\text { AD } 1050-1087 \\
\text { AD } 1120-1140\end{array}$ & $\begin{array}{l}.67 \\
.21 \\
.12\end{array}$ \\
\hline SMU-316 & $\begin{array}{l}\text { Fea. } 112 \mathrm{~A}, \\
\text { basal zone }\end{array}$ & $950 \pm 60$ & -- & $950 \pm 72$ & AD 1023-1164 & 1.00 \\
\hline SMU-325 & $\begin{array}{l}\text { Fea. } 97 \mathrm{~A}, 41 \mathrm{~cm} \text {, } \\
\text { basal zone }\end{array}$ & $950 \pm 50$ & -- & $950 \pm 64$ & $\begin{array}{l}\text { AD } 1070-1129 \\
\text { AD } 1027-1070 \\
\text { AD } 1131-1160\end{array}$ & $\begin{array}{l}.45 \\
.32 \\
.23\end{array}$ \\
\hline SMU-328 & $\begin{array}{l}\text { Fea. } 112 \mathrm{~A}, 49 \mathrm{~cm} \\
\text { in feature zone }\end{array}$ & $850 \pm 60$ & -- & $850 \pm 72$ & $\begin{array}{l}\text { AD } 1158-1276 \\
\text { AD } 1060-1078\end{array}$ & $\begin{array}{l}.85 \\
.09\end{array}$ \\
\hline SMU-335 & $\begin{array}{l}\text { Unit } 52,40-45 \mathrm{~cm} \text {, } \\
\text { basal zone }\end{array}$ & $1360 \pm 140$ & -- & $1360 \pm 146$ & $\begin{array}{ll}\mathrm{AD} & 560-826 \\
\mathrm{AD} & 835-864\end{array}$ & $\begin{array}{l}.92 \\
.08\end{array}$ \\
\hline SMU-338 & $\begin{array}{l}\text { Unit } 109,40-45 \\
\mathrm{~cm} \text {, feature zone }\end{array}$ & $1070 \pm 160$ & -- & $1070 \pm 165$ & $\begin{array}{l}\text { AD } 1062-1077 \\
\text { AD } 1125-1134\end{array}$ & $\begin{array}{l}.53 \\
.32\end{array}$ \\
\hline SMU-339 & $\begin{array}{l}\text { Unit } 155,61 \mathrm{~cm} \text {, } \\
\text { basal zone }\end{array}$ & $1410 \pm 120$ & -- & $1410 \pm 127$ & AD $532-782$ & .98 \\
\hline SMU-341 & $\begin{array}{l}\text { Unit } 127,35-40 \\
\mathrm{~cm} \text {, basal zone }\end{array}$ & $860 \pm 60$ & -- & $860 \pm 72$ & $\begin{array}{l}\text { AD 1156-1261 } \\
\text { AD 1053-1084 }\end{array}$ & $\begin{array}{l}.74 \\
.17\end{array}$ \\
\hline SMU-346 & $\begin{array}{l}\text { Unit } 113,54-56 \\
\mathrm{~cm} \text {, basal zone }\end{array}$ & $1090 \pm 100$ & -- & $1090 \pm 108$ & AD 791-1036 & 1.00 \\
\hline Tx-2041 & $\begin{array}{l}\text { Unit } 130,43 \mathrm{~cm} \text {, } \\
\text { basal zone }\end{array}$ & $970 \pm 90$ & -- & $970 \pm 99$ & $A D \quad 993-1184$ & 1.00 \\
\hline Tx-2042 & $\begin{array}{l}\text { Unit } 161,31 \mathrm{~cm} \text {, } \\
\text { feature zone }\end{array}$ & $1410 \pm 920$ & -- & $1410 \pm 921$ & $370 \mathrm{BC}-\mathrm{AD} 1406$ & 1.00 \\
\hline Tx-2043 & $\begin{array}{l}\text { Fea. } 115 \mathrm{~B}, 50 \mathrm{~cm} \text {, } \\
\text { basal zone }\end{array}$ & $1010 \pm 90$ & -- & $1010 \pm 99$ & $\begin{array}{l}\text { AD } \\
961-1165 \\
\text { AD } 898-906\end{array}$ & $\begin{array}{l}.97 \\
.03\end{array}$ \\
\hline Tx-2044 & $\begin{array}{l}\text { Unit } 219,27 \mathrm{~cm} \text {, } \\
\text { near burial, feature } \\
\text { zone }\end{array}$ & $680 \pm 100$ & -- & $680 \pm 108$ & $\mathrm{AD} 1261-1403$ & 1.00 \\
\hline
\end{tabular}


TABLE $1 .{ }^{14} \mathrm{C}$ Assays from Prehistoric Archaeological Sites in Eastern Texas (Continued)

\begin{tabular}{|c|c|c|c|c|c|c|}
\hline Assay no. & Provenience & Raw age & $\delta^{13} \mathrm{C}$ & $\begin{array}{l}\text { Corrected } \\
{ }^{14} \mathrm{C} \text { age }\end{array}$ & $\begin{array}{l}\text { Calibrated } \\
\text { age range* }\end{array}$ & RAt \\
\hline Tx-2045 & $\begin{array}{l}\text { Unit 177, 20-25 } \\
\mathrm{cm} \text {, near Fea. } \\
177 \mathrm{~A}\end{array}$ & $730 \pm 210$ & $-\cdot$ & $730 \pm 214$ & $\begin{array}{l}\text { AD } 1152-1422 \\
\text { AD } 1045-1100 \\
\text { AD } 1114-1146\end{array}$ & $\begin{array}{l}.81 \\
.12 \\
.07\end{array}$ \\
\hline Tx-2046 & $\begin{array}{l}\text { Unit } 72,24 \mathrm{~cm} \text {, } \\
\text { feature zone }\end{array}$ & $1690 \pm 160$ & -- & $1690 \pm 165$ & $\begin{array}{ll}\text { AD } & 204-547 \\
\text { AD } & 148-164\end{array}$ & $\begin{array}{l}.97 \\
.03\end{array}$ \\
\hline Tx-2047 & $\begin{array}{l}\text { Unit } 145 \text {, } \\
52 \mathrm{~cm} \text {, basal zone }\end{array}$ & $1040 \pm 360$ & -- & $1040 \pm 362$ & $\mathrm{AD} \quad 662-1290$ & 1.00 \\
\hline Tx-2048 & $\begin{array}{l}\text { Unit } 177 \text {, } \\
26 \mathrm{~cm} \text {, feature } \\
\text { zone }\end{array}$ & $830 \pm 110$ & -- & $830 \pm 117$ & $\begin{array}{l}\text { AD } 1154-1287 \\
\text { AD } 1048-1091 \\
\text { AD } 1118-1142\end{array}$ & $\begin{array}{l}.71 \\
.18 \\
.11\end{array}$ \\
\hline Tx-2049 & $\begin{array}{l}\text { Unit } 129,35 \mathrm{~cm} \text {, } \\
\text { feature zone }\end{array}$ & $510 \pm 90$ & -- & $510 \pm 99$ & $\begin{array}{l}\text { AD } 1376-1485 \\
\text { AD } 1306-1364\end{array}$ & $\begin{array}{l}.71 \\
.29\end{array}$ \\
\hline \multicolumn{7}{|c|}{ Cox (41HP105) } \\
\hline Tx-1962 & $\begin{array}{l}\text { Unit } 145 \\
12-19 \mathrm{~cm}\end{array}$ & $1110 \pm 120$ & -- & $1110 \pm 127$ & $\mathrm{AD} \quad 774-1039$ & 1.00 \\
\hline \multicolumn{7}{|c|}{ Hurricane Hill (41HP106) } \\
\hline Beta-82909 & Fea. 83B & $630 \pm 50$ & $-26.4 \% 0$ & $610 \pm 50$ & $\begin{array}{l}\text { AD } 1307-1360 \\
\text { AD } 1379-1400\end{array}$ & $\begin{array}{l}.71 \\
.29\end{array}$ \\
\hline Beta-82910 & Fea. 89 & $620 \pm 70$ & $-25.7 \%$ & $610 \pm 70$ & $\begin{array}{l}\text { AD } 1306-1365 \\
\text { AD } 1374-1402\end{array}$ & $\begin{array}{l}.69 \\
.31\end{array}$ \\
\hline Beta-82911‡ & Fea. 2 & $1050 \pm 50$ & $-25.4 \% 0$ & $1050 \pm 50$ & $\begin{array}{ll}\text { AD } & 959-1029 \\
\text { AD } & 897-909\end{array}$ & $\begin{array}{l}.91 \\
.09\end{array}$ \\
\hline Beta-82912 & Fea. 36 & $750 \pm 80$ & $-27.6 \%$ & $710 \pm 80$ & $\begin{array}{l}\text { AD } 1248-1319 \\
\text { AD } 1342-1392\end{array}$ & $\begin{array}{l}.62 \\
.38\end{array}$ \\
\hline Beta-82913 & U. 75, lv. $6 \mathrm{~A}-6 \mathrm{~B}$ & $1730 \pm 100$ & $-27.6 \%$ & $1710 \pm 100$ & $\begin{array}{ll}\text { AD } & 218-449 \\
\text { AD } & 488-493\end{array}$ & $\begin{array}{l}.99 \\
.01\end{array}$ \\
\hline Beta-82914 & U. 87, lv. 3B-4A & $1820 \pm 90$ & $-25.4 \% 0$ & $1810 \pm 90$ & $\begin{array}{ll}\text { AD } & 123-269 \\
\text { AD } & 272-337\end{array}$ & $\begin{array}{l}.72 \\
.28\end{array}$ \\
\hline Beta-82915 & U. 94, lv. 4A & $1820 \pm 50$ & $-24.1 \% 0$ & $1840 \pm 50$ & $\mathrm{AD} \quad 127-242$ & 1.00 \\
\hline Beta-82916 & $\begin{array}{l}\text { U. } 247 / 259 \\
\text { lv. } 4 \mathrm{~B}-5 \mathrm{~A}\end{array}$ & $930 \pm 50$ & $-26.5 \%$ & $900 \pm 50$ & $\begin{array}{l}\text { AD } 1154-1213 \\
\text { AD } 1048-1093 \\
\text { AD } 1117-1143\end{array}$ & $\begin{array}{l}.45 \\
.35 \\
.20\end{array}$ \\
\hline Beta-82917 & U. 242 , lv. 4B-5A & $1880 \pm 90$ & $-25.9 \%$ & $1870 \pm 90$ & $\begin{array}{lr}\mathrm{AD} & 59-253 \\
\mathrm{AD} & 303-314\end{array}$ & $\begin{array}{l}.96 \\
.04\end{array}$ \\
\hline Beta-82918 & U. 257, lv. $4 \mathrm{~A}$ & $1070 \pm 80$ & $-25.4 \%$ & $1070 \pm 80$ & $A D \quad 882-1039$ & 1.00 \\
\hline Beta-82919 & U. $142-145$, lv. $3 \mathrm{~A}$ & $620 \pm 60$ & $-25.4 \% 0$ & $610 \pm 60$ & $\begin{array}{l}\text { AD } 1306-1363 \\
\text { AD } 1376-1401\end{array}$ & $\begin{array}{l}.70 \\
.30\end{array}$ \\
\hline Beta- 82920 & U. 68, lv. $3 \mathrm{~A}-3 \mathrm{~B}$ & $690 \pm 80$ & $-25.6 \% 0$ & $680 \pm 80$ & $\begin{array}{l}\text { AD } 1335-1394 \\
\text { AD } 1280-1325\end{array}$ & $\begin{array}{l}.56 \\
.44\end{array}$ \\
\hline Beta-82921 & U. 187 , lv. $4 \mathrm{~A}$ & $870 \pm 60$ & $-25.9 \% 0$ & $850 \pm 60$ & $\begin{array}{l}\text { AD } 1159-1275 \\
\text { AD } 1065-1074 \\
\text { AD } 1127-1133\end{array}$ & $\begin{array}{l}.93 \\
.04 \\
.03\end{array}$ \\
\hline Beta-82922 & U. 57, lv. 3B & $940 \pm 100$ & $-25.4 \% 0$ & $930 \pm 100$ & AD 1024-1205 & 1.00 \\
\hline Beta-83089 & Fea. 64 & $2830 \pm 70$ & $-27.2 \% 0$ & $2800 \pm 70$ & $\begin{array}{r}1007-890 \text { BC } \\
889-845 \text { вC }\end{array}$ & $\begin{array}{l}.77 \\
.23\end{array}$ \\
\hline Beta-85866‡ & Fea. 91 & $1860 \pm 50$ & $-24.6 \%$ & $1860 \pm 50$ & AD $118-232$ & 1.00 \\
\hline Beta-85867 & Fea. 71 & $2270 \pm 50$ & $-26.7 \%$ & $2250 \pm 50$ & $\begin{array}{l}307-207 \text { BC } \\
377-352 \text { BC }\end{array}$ & $\begin{array}{l}.79 \\
.21\end{array}$ \\
\hline
\end{tabular}


TABLE $1 .{ }^{14} \mathrm{C}$ Assays from Prehistoric Archaeological Sites in Eastern Texas (Continued)

\begin{tabular}{|c|c|c|c|c|c|c|}
\hline Assay no. & Provenience & Raw age & $\delta^{13} \mathrm{C}$ & $\begin{array}{l}\text { Corrected } \\
{ }^{14} \mathrm{C} \text { age }\end{array}$ & $\begin{array}{l}\text { Calibrated } \\
\text { age range* }\end{array}$ & RA $\dagger$ \\
\hline Beta-85868 $\ddagger$ & Fea. 62 & $1910 \pm 50$ & $-26.2 \% 0$ & $1890 \pm 50$ & $\begin{array}{rr}\mathrm{AD} & 78-148 \\
\mathrm{AD} & 161-210\end{array}$ & $\begin{array}{l}.64 \\
.36\end{array}$ \\
\hline $\begin{array}{l}\text { 41HP116 } \\
\text { Beta-18512 }\end{array}$ & $\begin{array}{l}\text { Zone III, 28-56 } \\
\mathrm{cm} \text {, humates }\end{array}$ & $520 \pm 70$ & -- & $520 \pm 81$ & $\begin{array}{l}\text { AD } 1385-1463 \\
\text { AD } 1310-1354\end{array}$ & $\begin{array}{l}.72 \\
.28\end{array}$ \\
\hline $\begin{array}{l}\text { 41HP118 } \\
\text { SMU-1883 }\end{array}$ & BHT $5 \mathrm{~A}, 220 \mathrm{~cm}$ & -- & $-25 \%$ & $2860 \pm 70$ & $\begin{array}{c}1090-924 \text { BC } \\
1114-1090 \text { вС }\end{array}$ & $\begin{array}{l}.89 \\
.11\end{array}$ \\
\hline SMU-1970 & $\begin{array}{l}\text { BHT 5A, 2A2b } \\
\text { horizon, humates }\end{array}$ & -- & $-21.5 \%$ & $2980 \pm 30$ & $\begin{array}{l}1222-1157 \text { вC } \\
1257-1236 \text { BC } \\
1146-1133 \text { BC }\end{array}$ & $\begin{array}{l}.66 \\
.22 \\
.12\end{array}$ \\
\hline $\begin{array}{l}\text { 41HP137 } \\
\text { SMU-1917 }\end{array}$ & Fea. 2 & -- & $-25.7 \%$ & $2090 \pm 30$ & $\begin{array}{l}122-46 \mathrm{BC} \\
154-142 \mathrm{BC}\end{array}$ & $\begin{array}{l}.90 \\
.10\end{array}$ \\
\hline \multicolumn{6}{|l|}{$41 \mathrm{HP155}$} & 1.00 \\
\hline Beta- 42427 & Unit 1, lv. 13 & $900 \pm 130$ & $-27.7 \%$ & $860 \pm 130$ & $\begin{array}{l}\text { AD } 1152-1276 \\
\text { AD } 1044-1103 \\
\text { AD } 1113-1147\end{array}$ & $\begin{array}{l}.60 \\
.26 \\
.15\end{array}$ \\
\hline \multicolumn{7}{|c|}{ Finley Fan (41HP159) } \\
\hline SMU-2222 & Fea. 1 & -- & $-25.8 \%$ & $4800 \pm 90$ & $\begin{array}{l}3668-3504 \text { BC } \\
3414-3384 \text { BC }\end{array}$ & $\begin{array}{l}.85 \\
.12\end{array}$ \\
\hline GX-15877 & Fea. 4 &.- & -- & $\begin{array}{l}100.5 \pm 2.8 \% \\
\text { of modern }\end{array}$ & N/A & \\
\hline GX-15878 & Fea. 12 & -- & $-24.1 \%$ & $4490 \pm 70$ & $\begin{array}{l}3334-3152 \mathrm{BC} \\
3144-3090 \mathrm{BC}\end{array}$ & $\begin{array}{l}.74 \\
.21\end{array}$ \\
\hline GX-15879 & Unit $31,60-70 \mathrm{~cm}$ & -- & $-26.3 \% 0$ & $530 \pm 50$ & $\begin{array}{l}\text { AD } 1395-1441 \\
\text { AD } 1326-1334\end{array}$ & $\begin{array}{l}.92 \\
.08\end{array}$ \\
\hline GX-15880 & $\begin{array}{l}\text { Unit 43, } \\
170-180 \mathrm{~cm}\end{array}$ & -- & $-26.0 \%$ & $4990 \pm 70$ & $\begin{array}{l}3808-3698 \text { вС } \\
3930-3875 \text { вС }\end{array}$ & $\begin{array}{l}.72 \\
.28\end{array}$ \\
\hline GX-15881‡ & $\begin{array}{l}\text { Unit } 45 \text {, } \\
180-190 \mathrm{~cm}\end{array}$ & -- & $-25.5 \%$ & $5540 \pm 70$ & $\begin{array}{l}4410-4339 \text { BC } \\
4456-4410 \text { BC }\end{array}$ & $\begin{array}{l}.61 \\
.39\end{array}$ \\
\hline \multicolumn{7}{|c|}{ Peerless Bottoms (41HP175) } \\
\hline Beta-51382 & Fea. 1 & $780 \pm 50$ & $-25.1 \% 0$ & $780 \pm 50$ & $A D$ 1227-1285 & 1.00 \\
\hline Beta-51383 & Fea. 3 & $400 \pm 70$ & $-25.7 \%$ & $390 \pm 70$ & $\begin{array}{l}\text { AD } 1446-1521 \\
\text { AD } 1567-1628\end{array}$ & $\begin{array}{l}.57 \\
.43\end{array}$ \\
\hline Beta-51385 & Fea. 8 & $890 \pm 70$ & $-26.8 \%$ & $860 \pm 70$ & $\begin{array}{l}\text { AD } 1156-1261 \\
\text { AD } 1054-1084 \\
\text { AD } 1122-1138\end{array}$ & $\begin{array}{l}.74 \\
.17 \\
.09\end{array}$ \\
\hline Beta-51386 & Unit 22, lv. 2 & $500 \pm 60$ & $-27.2 \% 0$ & $470 \pm 60$ & AD 1404-1486 & 1.00 \\
\hline Beta-51387 & Unit 33, lv. 2 & $560 \pm 70$ & $-26.6 \%$ & $540 \pm 70$ & $\begin{array}{l}\text { AD } 1388-1442 \\
\text { AD } 1312-1350\end{array}$ & $\begin{array}{l}.66 \\
.34\end{array}$ \\
\hline Beta-51388 & Unit 36, lv. 2 & $510 \pm 70$ & $-25.9 \% 0$ & $490 \pm 70$ & $\begin{array}{l}\text { AD } 1393-1487 \\
\text { AD } 1323-1338\end{array}$ & $\begin{array}{l}.93 \\
.07\end{array}$ \\
\hline Beta-51389 & Unit 43, lv. 3 & $400 \pm 70$ & $-26.5 \%$ & $380 \pm 70$ & $\begin{array}{l}\text { AD } 1450-1523 \\
\text { AD } 1563-1630\end{array}$ & $\begin{array}{l}.52 \\
.48\end{array}$ \\
\hline Beta-51390 & Unit 74, lv. 2 & $520 \pm 80$ & $-26.9 \% 0$ & $490 \pm 80$ & $\begin{array}{l}\text { AD } 1391-1497 \\
\text { AD } 1318-1344\end{array}$ & $\begin{array}{l}.85 \\
.11\end{array}$ \\
\hline
\end{tabular}


TABLE $1 .{ }^{14} \mathrm{C}$ Assays from Prehistoric Archaeological Sites in Eastern Texas (Continued)

\begin{tabular}{|c|c|c|c|c|c|c|}
\hline Assay no. & Provenience & Raw age & $\delta^{13} \mathrm{C}$ & $\begin{array}{l}\text { Corrected } \\
{ }^{14} \mathrm{C} \text { age }\end{array}$ & $\begin{array}{l}\text { Calibrated } \\
\text { age range* }\end{array}$ & RA $\dagger$ \\
\hline Beta-51391 & Unit 70, lv. 2 & $410 \pm 80$ & $-26.4 \% 0$ & $390 \pm 80$ & $\begin{array}{l}\text { AD } 1444-1524 \\
\text { AD } 1562-1630\end{array}$ & $\begin{array}{l}.55 \\
.45\end{array}$ \\
\hline Beta-51392 & Unit 83 , lv. 3 & $480 \pm 70$ & $-26.2 \% 0$ & $470 \pm 70$ & $\begin{array}{l}\text { AD 1401-1505 } \\
\text { AD 1603-1614 }\end{array}$ & $\begin{array}{l}.94 \\
.06\end{array}$ \\
\hline Beta-52246 & Fea. 1 & $640 \pm 80$ & $-25.8 \%$ & $630 \pm 80$ & $\begin{array}{l}\text { AD } 1330-1396 \\
\text { AD } 1302-1330\end{array}$ & $\begin{array}{l}.70 \\
.30\end{array}$ \\
\hline SMU-2326 & $\begin{array}{l}\text { Trackhoe Trench, } \\
\text { backdirt }\end{array}$ & -- & $-26.8 \%$ & $210 \pm 60$ & $\begin{array}{l}\text { AD } 1730-1814 \\
\text { AD } 1646-1690 \\
\text { AD } 1924-1955^{*}\end{array}$ & $\begin{array}{l}.53 \\
.28\end{array}$ \\
\hline \multicolumn{7}{|c|}{ Resch (41HS16) } \\
\hline $\mathrm{Tx}-481$ & $\begin{array}{l}\text { Level 6, various } \\
\text { squares }\end{array}$ & $2150 \pm 100$ & -- & $2150 \pm 108$ & $\begin{array}{l}250-49 \mathrm{BC} \\
357-288 \mathrm{BC}\end{array}$ & $\begin{array}{l}.75 \\
.25\end{array}$ \\
\hline$T x-482$ & $\begin{array}{l}\text { Levels } 3 \& 4 \text {, vari- } \\
\text { ous squares }\end{array}$ & $2250 \pm 140$ & -- & $2250 \pm 146$ & $419-51 \mathrm{BC}$ & .97 \\
\hline $\mathrm{Tx}-483$ & $\begin{array}{l}\text { Levels } 7 \& 8 \text {, vari- } \\
\text { ous squares }\end{array}$ & $1850 \pm 90$ & -- & $1850 \pm 99$ & $\begin{array}{lr}\text { AD } & 71-261 \\
\text { AD } & 287-325\end{array}$ & $\begin{array}{l}.87 \\
.13\end{array}$ \\
\hline$T x-484$ & $\begin{array}{l}\text { Level } 5 \text {, various } \\
\text { squares }\end{array}$ & $2360 \pm 130$ & -- & $2360 \pm 136$ & $\begin{array}{l}555-354 \text { вС } \\
760-674 \text { вС } \\
299-208 \text { вС }\end{array}$ & $\begin{array}{l}.55 \\
.20 \\
.19\end{array}$ \\
\hline 41HS74 & & & & & & \\
\hline $\mathrm{Tx}-5618$ & Burial 1 & $630 \pm 240$ & -- & $630 \pm 243$ & AD $1159-1520$ & .87 \\
\hline \multicolumn{7}{|c|}{ Gray's Pasture (41HS524) } \\
\hline Beta-92922 & $\begin{array}{l}\text { Fea. 2, Unit 10, } \\
50-70 \mathrm{~cm}\end{array}$ & $2570 \pm 50$ & $-29.1 \% 0$ & $2510 \pm 50$ & $\begin{array}{l}703-531 \mathrm{BC} \\
780-752 \mathrm{BC}\end{array}$ & $\begin{array}{l}.87 \\
.13\end{array}$ \\
\hline \multicolumn{7}{|l|}{ 41JP50 } \\
\hline Beta-61644 & $\begin{array}{l}\text { Stratum 3, central } \\
\text { test unit, } 37-40 \\
\text { cm bs }\end{array}$ & $1020 \pm 60$ & $-26.4 \%$ & $1000 \pm 60$ & $\begin{array}{l}\text { AD } 987-1056 \\
\text { AD } 1082-1123 \\
\text { AD } 1137-1157\end{array}$ & $\begin{array}{l}.58 \\
.28 \\
.14\end{array}$ \\
\hline Beta-61645 & $\begin{array}{l}\text { Profile 1, } \\
\text { Stratum } 2\end{array}$ & $570 \pm 90$ & $-26.3 \% 0$ & $550 \pm 90$ & $\begin{array}{l}\text { AD } 1378-1441 \\
\text { AD } 1307-1361\end{array}$ & $\begin{array}{l}.57 \\
.43\end{array}$ \\
\hline Beta-61646 & $\begin{array}{l}\text { Profile 1, } \\
\text { Stratum } 3\end{array}$ & $250 \pm 60$ & $-25.6 \%$ & $240 \pm 60$ & $\begin{array}{l}\text { AD } 1741-1808 \\
\text { AD } 1633-1685 \\
\text { AD 1931-1955* } \\
\text { AD } 1527-1554\end{array}$ & $\begin{array}{l}.39 \\
.36 \\
.15 \\
.10\end{array}$ \\
\hline \multicolumn{7}{|c|}{ Mackin (41LR39) } \\
\hline Tx-2167 & $\begin{array}{l}\text { Md. B, N259E462, } \\
\text { Fea. VIIb }\end{array}$ & $710 \pm 40$ & -- & $710 \pm 57$ & $\begin{array}{l}\text { AD 1259-1310 } \\
\text { AD 1352-1386 }\end{array}$ & $\begin{array}{l}.67 \\
.33\end{array}$ \\
\hline $\mathrm{Tx}-2170$ & $\begin{array}{l}\text { Md. B, } \\
\text { N259E462, } \\
\text { Fea. VIIc }\end{array}$ & $1320 \pm 170$ & -- & $1320 \pm 175$ & $\begin{array}{ll}\mathrm{AD} & 593-894 \\
\mathrm{AD} & 918-952\end{array}$ & $\begin{array}{l}.92 \\
.07\end{array}$ \\
\hline Tx-2171 & $\begin{array}{l}\text { Md. A, Trench 1, } \\
\text { Units } 2 \text { \& 3, } \\
\text { contact Zones } \\
\text { A-4 \& A-8 }\end{array}$ & $890 \pm 60$ & -. & $890 \pm 72$ & $\begin{array}{l}\text { AD } 1153-1222 \\
\text { AD } 1046-1099 \\
\text { AD } 1114-1145\end{array}$ & $\begin{array}{l}.47 \\
.34 \\
.19\end{array}$ \\
\hline Tx-2172 & $\begin{array}{l}\text { Md. A, Trench 1, } \\
\text { Unit 2, Zone A-8 }\end{array}$ & $1000 \pm 70$ & -- & $1000 \pm 81$ & $\begin{array}{l}\text { AD } 982-1068 \\
\text { AD } 1072-1128 \\
\text { AD } 1131-1160\end{array}$ & $\begin{array}{l}.53 \\
.32 \\
.15\end{array}$ \\
\hline
\end{tabular}


TABLE $1 .{ }^{14} \mathrm{C}$ Assays from Prehistoric Archaeological Sites in Eastern Texas (Continued)

\begin{tabular}{|c|c|c|c|c|c|c|}
\hline Assay no. & Provenience & Raw age & $\delta^{13} \mathrm{C}$ & $\begin{array}{l}\text { Corrected } \\
{ }^{14} \mathrm{C} \text { age }\end{array}$ & $\begin{array}{l}\text { Calibrated } \\
\text { age range* }\end{array}$ & RA $\dagger$ \\
\hline Tx-2173 & $\begin{array}{l}\text { Md. A, Trench 1, } \\
\text { Unit 6, Zone 3, } \\
\text { premound humus }\end{array}$ & $740 \pm 340$ & -- & $740 \pm 342$ & AD $953-1516$ & .93 \\
\hline Tx-2174 & $\begin{array}{l}\text { Md. A, Trench 1, } \\
\text { Fea. 1, } \\
\text { Component 5, } \\
\text { Unit 2, pre-mound }\end{array}$ & $1100 \pm 70$ & -- & $1100 \pm 81$ & AD $867-1024$ & 1.00 \\
\hline $\mathrm{Tx}-2175$ & $\begin{array}{l}\text { Md. A, Trench 1, } \\
\text { Unit 2, below } \\
\text { Component } 6 \\
\text { of Fea. } 1\end{array}$ & $940 \pm 40$ & -- & $940 \pm 57$ & $\begin{array}{l}\text { AD 1070-1129 } \\
\text { AD 1035-1070 } \\
\text { AD 1131-1160 }\end{array}$ & $\begin{array}{l}.48 \\
.28 \\
.24\end{array}$ \\
\hline Tx-2176 & $\begin{array}{l}\text { Md. A., } \\
\text { Trench 1, } \\
\text { Unit 2, Fea. } 1\end{array}$ & $970 \pm 40$ & -- & $970 \pm 57$ & $\begin{array}{l}\text { AD } 1076-1126 \\
\text { AD } 1017-1063 \\
\text { AD } 1134-1159\end{array}$ & $\begin{array}{l}.41 \\
.39 \\
.20\end{array}$ \\
\hline Tx-2177 & $\begin{array}{l}\text { Md. A, Trench 1, } \\
\text { Unit 1, Fea. IIIa }\end{array}$ & $770 \pm 180$ & -- & $770 \pm 184$ & $\begin{array}{l}\text { AD 1335-1395 } \\
\text { AD 1047-1093 } \\
\text { AD 1117-1143 }\end{array}$ & $\begin{array}{l}.44 \\
.31 \\
.18\end{array}$ \\
\hline Tx-2178 & $\begin{array}{l}\text { Md. B, N255E463, } \\
\text { Zone B-4, pre- } \\
\text { mound }\end{array}$ & $1410 \pm 150$ & -. & $1410 \pm 155$ & $\begin{array}{ll}\mathrm{AD} & 497-784 \\
\mathrm{AD} & 449-486\end{array}$ & $\begin{array}{l}.92 \\
.08\end{array}$ \\
\hline Tx-2179 & $\begin{array}{l}\text { Md. A, Trench 1, } \\
\text { Unit 4, Fea. IIIe, } \\
\text { component D-6 }\end{array}$ & $1010 \pm 80$ & -. & $1010 \pm 90$ & $\mathrm{AD} \quad 967-1162$ & 1.00 \\
\hline \multicolumn{7}{|c|}{ Ray (41LR135) } \\
\hline Beta-46264 & Fea. 1 & $1210 \pm 90$ & $-25.0 \%$ & $1210 \pm 90$ & $\begin{array}{ll}\text { AD } & 759-895 \\
\text { AD } & 917-953 \\
\text { AD } & 714-744\end{array}$ & $\begin{array}{l}.73 \\
.14 \\
.13\end{array}$ \\
\hline Beta-46265 & Level 4 , lot 46 & $1070 \pm 70$ & $-25.6 \%$ & $1060 \pm 70$ & $\mathrm{AD} \quad 893-1028$ & 1.00 \\
\hline Beta-46266 & $\begin{array}{l}\text { Level 4, } \\
\text { lots } 52 \text { \& } 113\end{array}$ & $850 \pm 60$ & $-27.9 \%$ & $800 \pm 60$ & AD $1198-1286$ & 1.00 \\
\hline Beta- $88418 \ddagger$ & Fea. 2 (maize) & $780 \pm 50$ & $-11.8 \%$ & $1000 \pm 50$ & $\begin{array}{l}\text { AD } 990-1050 \\
\text { AD } 1087-1120 \\
\text { AD } 1140-1156\end{array}$ & $\begin{array}{l}.63 \\
.25 \\
.12\end{array}$ \\
\hline Beta- $88419 \ddagger$ & Fea. 2 (maize) & $700 \pm 50$ & $-12.1 \%$ & $910 \pm 50$ & $\begin{array}{l}\text { AD 1044-1104 } \\
\text { AD 1112-1147 } \\
\text { AD 1151-1184 }\end{array}$ & $\begin{array}{l}.48 \\
.27 \\
.25\end{array}$ \\
\hline Beta- 88420 & Fea. $1,40-50 \mathrm{~cm}$ & $890 \pm 80$ & $-27.9 \%$ & $850 \pm 80$ & $\begin{array}{l}\text { AD } 1157-1277 \\
A D 1057-1081\end{array}$ & $\begin{array}{l}.80 \\
.13\end{array}$ \\
\hline Beta- 88421 & Fea. $1,40-50 \mathrm{~cm}$ & $1250 \pm 80$ & $-26.1 \% 0$ & $1230 \pm 80$ & $\begin{array}{ll}\mathrm{AD} & 752-886 \\
\mathrm{AD} & 705-749\end{array}$ & $\begin{array}{l}.78 \\
.22\end{array}$ \\
\hline Beta- 88422 & Fea. 60 & $760 \pm 80$ & $-26.6 \%$ & $740 \pm 80$ & $\begin{array}{l}\text { AD } 1217-1310 \\
A D 1352-1386\end{array}$ & $\begin{array}{l}.81 \\
.19\end{array}$ \\
\hline Beta-88423 & Fea. 37 (maize) & $670 \pm 50$ & $-11.6 \%$ & $890 \pm 50$ & $\begin{array}{l}\text { AD } 1154-1220 \\
\text { AD } 1049-1090 \\
\text { AD } 1118-1142\end{array}$ & $\begin{array}{l}.53 \\
.30 \\
.17\end{array}$ \\
\hline \multicolumn{7}{|l|}{$41 \mathrm{MX5}$} \\
\hline Beta-52709 & W32N0, level 3 & $1790 \pm 90$ & -. & $1790 \pm 99$ & $\begin{array}{ll}\text { AD } & 134-348 \\
\text { AD } & 358-375\end{array}$ & $\begin{array}{l}.94 \\
.06\end{array}$ \\
\hline
\end{tabular}


TABLE 1. ${ }^{14} \mathrm{C}$ Assays from Prehistoric Archaeological Sites in Eastern Texas (Continued)

\begin{tabular}{|c|c|c|c|c|c|c|}
\hline Assay no. & Provenience & Raw age & $\delta^{13} \mathrm{C}$ & $\begin{array}{l}\text { Corrected } \\
{ }^{14} \mathrm{C} \text { age }\end{array}$ & $\begin{array}{l}\text { Calibrated } \\
\text { age range* }\end{array}$ & RA $\dagger$ \\
\hline Beta-52710 & $\begin{array}{l}\text { Unit 2, level 4, } \\
\text { Burial } 2\end{array}$ & $990 \pm 100$ & -- & $990 \pm 108$ & AD $969-1188$ & 1.00 \\
\hline Beta-55922 $\ddagger$ & Burial 3, Vessel E & $240 \pm 70$ & -- & $240 \pm 70$ & $\begin{array}{l}\text { AD } 1734-1812 \\
\text { AD } 1628-1688 \\
\text { AD } 1522-1566\end{array}$ & $\begin{array}{l}.38 \\
.33 \\
.15\end{array}$ \\
\hline Beta- 62513 & $\begin{array}{l}\text { Lot } 24-\mathrm{D} \text {, possible } \\
\text { posthole fill }\end{array}$ & $470 \pm 100$ & $?$ & $470 \pm 100$ & $\begin{array}{l}\text { AD } 1396-1520 \\
\text { AD } 1571-1626\end{array}$ & $\begin{array}{l}.75 \\
.23\end{array}$ \\
\hline Beta-62514 $\ddagger$ & $\begin{array}{l}\text { Lot 24-D, possible } \\
\text { posthole fill }\end{array}$ & $450 \pm 60$ & $?$ & $450 \pm 60$ & $\begin{array}{l}\text { AD 1411-1502 } \\
\text { AD 1603-1614 }\end{array}$ & $\begin{array}{l}.93 \\
.07\end{array}$ \\
\hline \multicolumn{7}{|c|}{ Etoile (41NA11) } \\
\hline Beta-97894 & $\begin{array}{l}\text { N450 Profile, } \\
\text { Pit Sample }\end{array}$ & $380 \pm 70$ & $-28.7 \%$ & $320 \pm 70$ & $\begin{array}{l}\text { AD 1492-1605 } \\
\text { AD 1613-1649 }\end{array}$ & $\begin{array}{l}.76 \\
.24\end{array}$ \\
\hline \multicolumn{7}{|c|}{ Chayah (41NA44) } \\
\hline Tx-2639 & $\begin{array}{l}\text { N62-W197, } \\
30-40 \mathrm{~cm}\end{array}$ & $1110 \pm 70$ & -. & $1110 \pm 81$ & $\begin{array}{ll}A D & 865-1018 \\
A D & 827-833\end{array}$ & $\begin{array}{l}.98 \\
.02\end{array}$ \\
\hline$T x-2640$ & $\begin{array}{l}\text { N62-W195, } \\
30-40 \mathrm{~cm}\end{array}$ & $420 \pm 80$ & -- & $420 \pm 90$ & $\begin{array}{l}\text { AD } 1429-1522 \\
\text { AD } 1564-1629\end{array}$ & $\begin{array}{l}.62 \\
.38\end{array}$ \\
\hline Tx-2799 & $\begin{array}{l}\text { N60-W195, } \\
40-50 \mathrm{~cm}\end{array}$ & $630 \pm 50$ & -- & $630 \pm 64$ & $\begin{array}{l}\text { AD } 1335-1395 \\
\text { AD } 1303-1326\end{array}$ & $\begin{array}{l}.72 \\
.28\end{array}$ \\
\hline$T x-2800$ & $\begin{array}{l}\text { N62-W197, } \\
30-40 \mathrm{~cm}\end{array}$ & $670 \pm 140$ & -- & $670 \pm 146$ & $A D 1222-1430$ & 1.00 \\
\hline \multicolumn{7}{|c|}{ Washington Square (41NA49) } \\
\hline Tx-3943 & Fea. 18 & $710 \pm 70$ & -- & $710 \pm 81$ & $\begin{array}{l}\text { AD } 1248-1319 \\
\text { AD 1342-1392 }\end{array}$ & $\begin{array}{l}.62 \\
.38\end{array}$ \\
\hline Tx-3944 & Fea. 30 & $1150 \pm 140$ & -- & $1150 \pm 146$ & $\begin{array}{ll}\mathrm{AD} & 761-1018 \\
\mathrm{AD} & 715-743\end{array}$ & $\begin{array}{l}.93 \\
.07\end{array}$ \\
\hline Tx-3945 & Fea. 9 & $790 \pm 200$ & -- & $790 \pm 204$ & $\begin{array}{l}\text { AD 1034-1319 } \\
\text { AD 1342-1392 }\end{array}$ & $\begin{array}{l}.87 \\
.13\end{array}$ \\
\hline$T x-4257$ & Fea. 75 & $620 \pm 70$ & -- & $620 \pm 81$ & AD 1304-1399 & 1.00 \\
\hline $\mathrm{Tx}-4258$ & Fea. 30, maize & $360 \pm 70$ & -- & $601 \pm 81$ & $\begin{array}{l}\text { AD } 1305-1367 \\
\text { AD 1373-1407 }\end{array}$ & $\begin{array}{l}.65 \\
.35\end{array}$ \\
\hline Tx-4872 & $\begin{array}{l}\text { Fea. } 75 \text {, maize, } \\
\text { charcoal \& } \\
\text { nutshells }\end{array}$ & $830 \pm 110$ & -- & $1071 \pm 117$ & $\begin{array}{l}\text { AD } 858-1051 \\
\text { AD } 1086-1120 \\
\text { AD } 820-842\end{array}$ & $\begin{array}{l}.80 \\
.10 \\
.06\end{array}$ \\
\hline Tx-4873 & Fea. 199, maize & $840 \pm 50$ & -- & $1081 \pm 64$ & $\begin{array}{ll}\text { AD } & 942-1016 \\
\text { AD } & 893-933\end{array}$ & $\begin{array}{l}.68 \\
.32\end{array}$ \\
\hline Tx-4874 & Fea. 199 & $980 \pm 60$ & -- & $980 \pm 72$ & $\begin{array}{l}\text { AD 1009-1069 } \\
\text { AD 1071-1129 }\end{array}$ & $\begin{array}{l}.42 \\
.39\end{array}$ \\
\hline $\mathrm{Tx}-4875$ & Fea. 9, maize & $630 \pm 60$ & -. & $871 \pm 72$ & $\begin{array}{l}\text { AD } 1131-1160 \\
\text { AD } 1155-1246 \\
\text { AD } 1049-1089 \\
\text { AD } 1119-1141\end{array}$ & $\begin{array}{l}.19 \\
.63 \\
.23 \\
.13\end{array}$ \\
\hline $\begin{array}{l}\text { Tx-4876 } \\
\text { Hudnall-Pirtle }\end{array}$ & $\begin{array}{l}\text { Fea. } 80 \\
\text { (RK4) }\end{array}$ & $1280 \pm 100$ & -- & $1280 \pm 108$ & Hudnall-Pirtle (41RK4) & 1.00 \\
\hline Beta-43539 & $\begin{array}{l}\text { Md. F, Unit } 11 \text {, } \\
\text { lv. } 12 / 13\end{array}$ & $890 \pm 70$ & -. & $890 \pm 81$ & $\begin{array}{l}\text { AD } 1152-1223 \\
\text { AD } 1045-1102 \\
\text { AD } 1113-1146\end{array}$ & $\begin{array}{l}.45 \\
.35 \\
.20\end{array}$ \\
\hline
\end{tabular}


TABLE $1 .{ }^{14} \mathrm{C}$ Assays from Prehistoric Archaeological Sites in Eastern Texas (Continued)

\begin{tabular}{|c|c|c|c|c|c|c|}
\hline Assay no. & Provenience & Raw age & $\delta^{13} \mathrm{C}$ & $\begin{array}{l}\text { Corrected } \\
{ }^{14} \mathrm{C} \text { age }\end{array}$ & $\begin{array}{l}\text { Calibrated } \\
\text { age range* }\end{array}$ & RAt \\
\hline Beta-43540 & $\begin{array}{l}\text { Md. F, Unit 3, } \\
\text { lv. 13A }\end{array}$ & $870 \pm 70$ & -- & $870 \pm 81$ & $\begin{array}{l}\text { AD } 1154-1250 \\
\text { AD } 1048-1092 \\
\text { AD } 1117-1142\end{array}$ & $\begin{array}{l}.61 \\
.25 \\
.14\end{array}$ \\
\hline \multicolumn{7}{|c|}{ Oak Hill Village (41RK214) } \\
\hline Beta- 60088 & N455E466, lv. 5 & $570 \pm 80$ & $-20.8 \%$ & $640 \pm 80$ & $\begin{array}{l}\text { AD } 1332-1396 \\
\text { AD } 1297-1328\end{array}$ & $\begin{array}{l}.68 \\
.32\end{array}$ \\
\hline Beta-73936 & Fea. 65, Midden A & $610 \pm 60$ & $-27.9 \%$ & $560 \pm 60$ & $\begin{array}{l}\text { AD } 1388-1432 \\
\text { AD } 1312-1350\end{array}$ & $\begin{array}{l}.57 \\
.43\end{array}$ \\
\hline Beta-73938 & $\begin{array}{l}\text { Fea. 81, N469.9 } \\
\text { E494.3 }\end{array}$ & $620 \pm 140$ & $-28.3 \% 0$ & $570 \pm 140$ & $\mathrm{AD} 1280-1481$ & 1.00 \\
\hline Beta-73939 & $\begin{array}{l}\text { Fea. } 85, \text { Structure } \\
2 \text { (maize) }\end{array}$ & $610 \pm 100$ & $-12.8 \%$ & $810 \pm 100$ & $\begin{array}{l}\text { AD } 1157-1294 \\
\text { AD } 1057-1081\end{array}$ & $\begin{array}{l}.85 \\
.10\end{array}$ \\
\hline Beta-73940 & $\begin{array}{l}\text { Fea. } 86, \text { Structure } \\
2 \text { (maize) }\end{array}$ & $400 \pm 80$ & $-12.3 \% 0$ & $610 \pm 80$ & $\begin{array}{l}\text { AD } 1305-1368 \\
\text { AD } 1372-1403\end{array}$ & $\begin{array}{l}.68 \\
.32\end{array}$ \\
\hline Beta-73941 & $\begin{array}{l}\text { Fea. } 95 \\
\text { Structure } 1\end{array}$ & $570 \pm 60$ & $-26.1 \% 0$ & $550 \pm 60$ & $\begin{array}{l}\text { AD } 1390-1436 \\
\text { AD } 1314-1348\end{array}$ & $\begin{array}{l}.65 \\
.35\end{array}$ \\
\hline Beta-81486 & Structure 39, PM 3 & $820 \pm 60$ & $-26.2 \%$ & $800 \pm 60$ & AD 1198-1286 & 1.00 \\
\hline Beta-81680 & $\begin{array}{l}\text { Structure 37, } \\
\text { PM } 11\end{array}$ & $1810 \pm 60$ & $-23.4 \% 0$ & $1830 \pm 60$ & $\begin{array}{ll}\mathrm{AD} & 123-254 \\
\mathrm{AD} & 302-315\end{array}$ & $\begin{array}{l}.93 \\
.07\end{array}$ \\
\hline Beta-81681 & Structure 39, PM 1 & $900 \pm 60$ & $-25.8 \%$ & $880 \pm 60$ & $\begin{array}{l}\text { AD } 1154-1228 \\
\text { AD } 1048-1092 \\
\text { AD } 1117-1142\end{array}$ & $\begin{array}{l}.56 \\
.28 \\
.16\end{array}$ \\
\hline \multicolumn{7}{|l|}{ 41RK215 } \\
\hline Beta-60089 & $\begin{array}{l}\text { Unit N465 E481, } \\
\text { lv. } 6 \text {, humates }\end{array}$ & $3100 \pm 90$ & $-26.0 \%$ & $3090 \pm 90$ & $\begin{array}{l}1440-1252 \mathrm{BC} \\
1246-1208 \mathrm{BC}\end{array}$ & $\begin{array}{l}.88 \\
.12\end{array}$ \\
\hline Beta-60090 & $\begin{array}{l}\text { Unit } 465 \text {, E481, } \\
\text { lv. } 8 \text {, humates }\end{array}$ & $3560 \pm 90$ & $-25.3 \%$ & $3560 \pm 90$ & $\begin{array}{l}1978-1750 \text { вС } \\
2014-2006 \text { вС }\end{array}$ & $\begin{array}{l}.97 \\
.03\end{array}$ \\
\hline \multicolumn{7}{|l|}{ 41RK222 } \\
\hline Beta-60093 & $\begin{array}{l}\text { Unit N486, E510, } \\
\text { lv. } 5 \text {, humates }\end{array}$ & $1400 \pm 70$ & $-24.3 \%$ & $1410 \pm 70$ & $\mathrm{AD} \quad 591-685$ & .89 \\
\hline Beta-60094 & $\begin{array}{l}\text { Unit } 486, \text { E510, lv. } \\
7, \text { humates }\end{array}$ & $1840 \pm 100$ & $-24.8 \%$ & $1840 \pm 100$ & $\begin{array}{lr}\text { AD } & 77-263 \\
\text { AD } & 283-327\end{array}$ & $\begin{array}{l}.84 \\
.16\end{array}$ \\
\hline \multicolumn{7}{|c|}{ Holdeman (41RR11) } \\
\hline Beta-75059 & Burial 11 & $330 \pm 50$ & $-16.9 \%$ & $460 \pm 50$ & AD 1415-1478 & 1.00 \\
\hline Beta-75060 & Burial 14 & $310 \pm 60$ & $-14.5 \%$ & $480 \pm 60$ & AD $1402-1478$ & 1.00 \\
\hline Beta-75061 & Burial 23 & $790 \pm 60$ & $-20.2 \% 0$ & $870 \pm 60$ & $\begin{array}{l}\text { AD } 1156-1245 \\
\text { AD } 1052-1085 \\
\text { AD } 1121-1139\end{array}$ & $\begin{array}{l}.69 \\
.20 \\
.11\end{array}$ \\
\hline Beta-79446 & Burial 21 & $350 \pm 70$ & $-15.5 \%$ & $510 \pm 70$ & $\begin{array}{l}\text { AD } 1392-1469 \\
\text { AD } 1319-1343\end{array}$ & $\begin{array}{l}.85 \\
.15\end{array}$ \\
\hline \multicolumn{7}{|c|}{ Fasken (41RR14) } \\
\hline Beta-91234 $\ddagger$ & $\begin{array}{l}\text { N692E451, } \\
\text { lv. } 4 \text { (lot 369) }\end{array}$ & $850 \pm 50$ & $-24.0 \% 0$ & $870 \pm 50$ & $\begin{array}{l}\text { AD } 1157-1242 \\
\text { AD } 1055-1083 \\
\text { AD } 1122-1138\end{array}$ & $\begin{array}{l}.74 \\
.17 \\
.09\end{array}$ \\
\hline Beta-91235 $\ddagger$ & $\begin{array}{l}\text { N693E451 } \\
\text { lv. } 7 \text { (lot 539) }\end{array}$ & $850 \pm 60$ & $-21.5 \%$ & $910 \pm 60$ & $\begin{array}{l}\text { AD } 1043-1107 \\
\text { AD } 1111-1148 \\
\text { AD } 1151-1188\end{array}$ & $\begin{array}{l}.47 \\
.27 \\
.26\end{array}$ \\
\hline
\end{tabular}


TABLE 1. ${ }^{14} \mathrm{C}$ Assays from Prehistoric Archaeological Sites in Eastern Texas (Continued)

\begin{tabular}{|c|c|c|c|c|c|c|}
\hline Assay no. & Provenience & Raw age & $\delta^{13} \mathrm{C}$ & $\begin{array}{l}\text { Corrected } \\
{ }^{14} \mathrm{C} \text { age }\end{array}$ & $\begin{array}{l}\text { Calibrated } \\
\text { age range* }\end{array}$ & RA $†$ \\
\hline \multicolumn{7}{|c|}{ Roitsch/Sam Kaufman (41RR16) } \\
\hline Beta-46267 $\ddagger$ & Fea. 101, level 9 & $705 \pm 45$ & -- & $705 \pm 45$ & $\begin{array}{l}\text { AD } 1275-1309 \\
\text { AD } 1355-1383\end{array}$ & $\begin{array}{l}.67 \\
.33\end{array}$ \\
\hline Beta-46957 & Fea. 601 & $840 \pm 120$ & $-26.8 \%$ & $810 \pm 120$ & $\begin{array}{l}\text { AD } 1154-1296 \\
\text { AD } 1048-1091 \\
\text { AD } 1118-1142\end{array}$ & $\begin{array}{l}.75 \\
.16 \\
.09\end{array}$ \\
\hline $\mathrm{Tx}-882$ & House 3 & $870 \pm 70$ & -- & $870 \pm 81$ & $\begin{array}{l}\text { AD } 1154-1250 \\
\text { AD } 1048-1092 \\
\text { AD } 1117-1142\end{array}$ & $\begin{array}{l}.61 \\
.25 \\
.14\end{array}$ \\
\hline $\mathrm{Tx}-883$ & House 3 & $1000 \pm 70$ & -- & $1000 \pm 81$ & $\begin{array}{l}\text { AD } 982-1068 \\
\text { AD } 1072-1128 \\
\text { AD } 1131-1160\end{array}$ & $\begin{array}{l}.53 \\
.32 \\
.15\end{array}$ \\
\hline $\mathrm{Tx}-884$ & House 3 & $910 \pm 70$ & -- & $910 \pm 81$ & AD 1040-1200 & 1.00 \\
\hline$T x-885$ & House 3 & $900 \pm 70$ & -- & $900 \pm 81$ & $\begin{array}{l}\text { AD } 1151-1216 \\
\text { AD } 1044-1105 \\
\text { AD } 1112-1147\end{array}$ & $\begin{array}{l}.40 \\
.38 \\
.22\end{array}$ \\
\hline $\mathrm{Tx}-8074$ & $\begin{array}{l}\text { Burial } 15 \text { (SMU), } \\
\text { Shaft tomb }\end{array}$ & $\begin{array}{l}170 \pm 63 \\
\text { (apatite) }\end{array}$ & $-8.0 \%$ & $448 \pm 65$ & $\begin{array}{l}\text { AD } 1412-1511 \\
\text { AD } 1600-1616\end{array}$ & $\begin{array}{l}.91 \\
.09\end{array}$ \\
\hline Tx-8075 & Burial 17 (SMU) & $\begin{array}{l}151 \pm 53 \\
\text { (apatite) }\end{array}$ & $-8.2 \%$ & $426 \pm 55$ & $\begin{array}{l}\text { AD 1431-1513 } \\
\text { AD 1596-1619 }\end{array}$ & $\begin{array}{l}.83 \\
.17\end{array}$ \\
\hline Tx-8076 & Burial 19 (TAS) & $\begin{array}{l}404 \pm 84 \\
\text { (apatite) }\end{array}$ & $-8.2 \%$ & $679 \pm 86$ & $\begin{array}{l}\text { AD } 1332-1396 \\
A D 1280-1328\end{array}$ & $\begin{array}{l}.56 \\
.44\end{array}$ \\
\hline $\mathrm{Tx}-8077$ & Burial 20 (TAS) & $\begin{array}{l}220 \pm 273 \\
\text { (apatite) }\end{array}$ & $-8.0 \% 0$ & $497 \pm 282$ & $\begin{array}{l}\text { AD } 1231-1678 \\
\text { AD } 1770-1802\end{array}$ & $\begin{array}{l}.93 \\
.04\end{array}$ \\
\hline \multicolumn{7}{|c|}{ Rowland Clark (41RR77) } \\
\hline Beta-75053 & Burial 2 & $150 \pm 70$ & $-17.0 \%$ & $280 \pm 70$ & $\begin{array}{l}\text { AD } 1502-1603 \\
\text { AD } 1614-1673 \\
\text { AD } 1780-1796\end{array}$ & $\begin{array}{l}.53 \\
.35 \\
.08\end{array}$ \\
\hline Beta-79447 & Burial 7 & $410 \pm 60$ & $-14.5 \%$ & $580 \pm 60$ & $\begin{array}{l}\text { AD } 1309-1357 \\
\text { AD } 1382-1418\end{array}$ & $\begin{array}{l}.58 \\
.42\end{array}$ \\
\hline Beta-79448 & Burial 21 & $80 \pm 70$ & $-14.0 \%$ & $260 \pm 70$ & $\begin{array}{l}\text { AD } 1515-1591 \\
\text { AD } 1621-1680 \\
\text { AD } 1752-1804\end{array}$ & $\begin{array}{l}.34 \\
.34 \\
.23\end{array}$ \\
\hline Beta-79449 & Burial 33 & $320 \pm 60$ & $-11.5 \%$ & $540 \pm 60$ & $\begin{array}{l}\text { AD } 1391-1440 \\
\text { AD } 1317-1345\end{array}$ & $\begin{array}{l}.72 \\
.28\end{array}$ \\
\hline \multicolumn{7}{|c|}{ Saltwell Slough (41RR204) } \\
\hline Beta-46269 & N116E90, level 3 & $640 \pm 100$ & $-27.4 \%$ & $600 \pm 100$ & AD $1300-1415$ & 1.00 \\
\hline Beta-46958 & Fea. 11 & $780 \pm 160$ & $-25.6 \%$ & $770 \pm 160$ & $\begin{array}{l}\text { AD } 1156-1322 \\
\text { AD } 1339-1393 \\
\text { AD } 1052-1085\end{array}$ & $\begin{array}{l}.67 \\
.17 \\
.10\end{array}$ \\
\hline Beta-92199 $\ddagger$ & $\begin{array}{l}\text { N116E90, } \\
\text { lv. } 3 \text { (lot 98) }\end{array}$ & $380 \pm 60$ & $-24.3 \% 0$ & $390 \pm 60$ & $\begin{array}{l}\text { AD } 1447-1519 \\
\text { AD } 1572-1626\end{array}$ & $\begin{array}{l}.60 \\
.40\end{array}$ \\
\hline \multicolumn{7}{|c|}{ Sawmill (41SA89) } \\
\hline Beta-97892 & $\begin{array}{l}\text { N180E4, } \\
\text { coll 10-15-57 }\end{array}$ & $950 \pm 70$ & $-27.3 \%$ & $920 \pm 70$ & AD 1035-1181 & 1.00 \\
\hline \multicolumn{7}{|c|}{ Blount (41SA123) } \\
\hline Beta-97893 & $\begin{array}{l}\text { N495E560, } \\
0.5-1.0 \text { foot level }\end{array}$ & $480 \pm 70$ & $-26.3 \%$ & $460 \pm 70$ & $\begin{array}{l}\text { AD } 1405-1510 \\
\text { AD } 1601-1615\end{array}$ & $\begin{array}{l}.92 \\
.08\end{array}$ \\
\hline
\end{tabular}


TABLE $1 .{ }^{14} \mathrm{C}$ Assays from Prehistoric Archaeological Sites in Eastern Texas (Continued)

\begin{tabular}{|c|c|c|c|c|c|c|}
\hline Assay no. & Provenience & Raw age & $\delta^{13} \mathrm{C}$ & $\begin{array}{l}\text { Corrected } \\
{ }^{14} \mathrm{C} \text { age }\end{array}$ & $\begin{array}{l}\text { Calibrated } \\
\text { age range* }\end{array}$ & RA $†$ \\
\hline \multicolumn{7}{|c|}{ Redwine (41SM193) } \\
\hline Beta-91341 & Unit $2,20-30 \mathrm{~cm}$ & $570 \pm 50$ & $-25.0 \%$ & $570 \pm 50$ & $\begin{array}{l}\text { AD 1312-1350 } \\
\text { AD 1388-1423 }\end{array}$ & $\begin{array}{l}.49 \\
.51\end{array}$ \\
\hline \multicolumn{7}{|c|}{ Robert Griffin (41SY41) } \\
\hline Beta-97897 & $\begin{array}{l}\text { Burial 3, } \\
\text { mussel shell }\end{array}$ & $960 \pm 70$ & $-6.0 \%$ & $1270 \pm 70$ & $\begin{array}{ll}\text { AD } & 677-818 \\
\text { AD } & 844-856\end{array}$ & $\begin{array}{l}.94 \\
.06\end{array}$ \\
\hline \multicolumn{7}{|c|}{ Buddy Hancock (41SY45) } \\
\hline Beta-97896 & $\begin{array}{l}\text { Trash pit, } \\
\text { mussel shells }\end{array}$ & $650 \pm 60$ & $-6.0 \%$ & $960 \pm 60$ & $\begin{array}{l}\text { AD } 1073-1127 \\
\text { AD } 1022-1066 \\
\text { AD } 1132-1159\end{array}$ & $\begin{array}{l}.43 \\
.35 \\
.21\end{array}$ \\
\hline \multicolumn{7}{|c|}{ Tyson (41SY92) } \\
\hline Tx-7612 & Fea. $3,15-30 \mathrm{~cm}$ & $490 \pm 60$ & $-24.0 \% 0$ & $510 \pm 60$ & $\begin{array}{l}\text { AD } 1390-1442 \\
\text { AD } 1327-1351\end{array}$ & $\begin{array}{l}.73 \\
.27\end{array}$ \\
\hline Tx-7625 & Fea. $3,16.5-20 \mathrm{~cm}$ & $500 \pm 60$ & -- & $500 \pm 60$ & $\begin{array}{l}\text { AD 1394-1441 } \\
\text { AD 1332-1342 }\end{array}$ & $\begin{array}{l}.87 \\
.13\end{array}$ \\
\hline Tx-7626 & Fea. $3,20-70 \mathrm{~cm}$ & $440 \pm 60$ & $-24.0 \%$ & $460 \pm 60$ & $\begin{array}{l}\text { AD } 1403-1490 \\
\text { AD } 1334-1338\end{array}$ & $\begin{array}{l}.97 \\
.03\end{array}$ \\
\hline Beta-97895 & $\begin{array}{l}\text { Fea. 14, } \\
\text { mussel shells }\end{array}$ & $320 \pm 60$ & $-6.0 \% 0$ & $630 \pm 60$ & $\begin{array}{l}\text { AD } 1336-1394 \\
\text { AD } 1303-1325\end{array}$ & $\begin{array}{l}.73 \\
.27\end{array}$ \\
\hline \multicolumn{7}{|c|}{ Keith (41TT11) } \\
\hline$T x-1306$ & $\begin{array}{l}\text { Mound fill, ca. } \\
102.6-106 \mathrm{~m} \\
\text { elevation }\end{array}$ & $540 \pm 70$ & -- & $540 \pm 81$ & $\begin{array}{l}\text { AD 1383-1445 } \\
\text { AD 1309-1356 }\end{array}$ & $\begin{array}{l}.62 \\
.38\end{array}$ \\
\hline \multicolumn{7}{|l|}{ 41TT154 } \\
\hline Beta-48880 & $\begin{array}{l}\text { Trench } 7 \text {, } \\
\text { lv. } 6 \text {, humates }\end{array}$ & $840 \pm 80$ & -- & $840 \pm 80$ & $\begin{array}{l}\text { AD } 1158-1280 \\
\text { AD } 1060-1078 \\
\text { AD } 1125-1135\end{array}$ & $\begin{array}{l}.86 \\
.09 \\
.05\end{array}$ \\
\hline \multicolumn{7}{|l|}{ 41TT182 } \\
\hline Beta-44786 & Fea. C1 & $220 \pm 80$ & -- & $220 \pm 80$ & $\begin{array}{l}\text { AD } 1717-1819 \\
\text { AD } 1634-1703 \\
\text { AD } 1529-1543 \\
\text { AD } 1851-1863\end{array}$ & $\begin{array}{l}.46 \\
.30 \\
.03 \\
.03\end{array}$ \\
\hline Beta-44787 & Fea. C5 & $290 \pm 120$ & -- & $290 \pm 120$ & $\begin{array}{l}\mathrm{AD} 1465-1680 \\
\mathrm{AD} 1759-1803\end{array}$ & $\begin{array}{l}.81 \\
.14\end{array}$ \\
\hline Beta-44789 & Zone 2, humates & $320 \pm 120$ & -- & $320 \pm 70$ & $\begin{array}{l}\text { AD } 1492-1605 \\
\text { AD } 1613-1649\end{array}$ & $\begin{array}{l}.76 \\
.24\end{array}$ \\
\hline \multicolumn{7}{|l|}{$41 T T 370$} \\
\hline Beta-48882 & $\begin{array}{l}\text { N101W93, lv. } 8 \text {, } \\
\text { humates }\end{array}$ & $2140 \pm 100$ & -- & $2140 \pm 100$ & $\begin{array}{l}210-42 \text { вC } \\
356-290 \text { ВC } \\
239-215 \text { BC }\end{array}$ & $\begin{array}{l}.69 \\
.23 \\
.07\end{array}$ \\
\hline \multicolumn{7}{|l|}{ 41TT372 } \\
\hline Beta-70993 & N103W101, lv. 2 & $670 \pm 60$ & $-27.1 \% 0$ & $640 \pm 60$ & $\begin{array}{l}\text { AD } 1337-1394 \\
\text { AD } 1299-1324\end{array}$ & $\begin{array}{l}.70 \\
.30\end{array}$ \\
\hline Beta-70994 $\ddagger$ & N103W101, lv. 3 & $1290 \pm 50$ & $-26.4 \% 0$ & $1270 \pm 50$ & $\begin{array}{ll}\mathrm{AD} & 680-790 \\
\mathrm{AD} & 791-810\end{array}$ & $\begin{array}{l}.89 \\
.11\end{array}$ \\
\hline Beta-70995 $\ddagger$ & N103W101, lv. 4 & $1800 \pm 60$ & $-25.3 \%$ & $1800 \pm 60$ & $\begin{array}{lr}\text { AD } & 143-262 \\
\text { AD } & 285-326\end{array}$ & $\begin{array}{l}.74 \\
.26\end{array}$ \\
\hline
\end{tabular}


TABLE 1. ${ }^{14} \mathrm{C}$ Assays from Prehistoric Archaeological Sites in Eastern Texas (Continued)

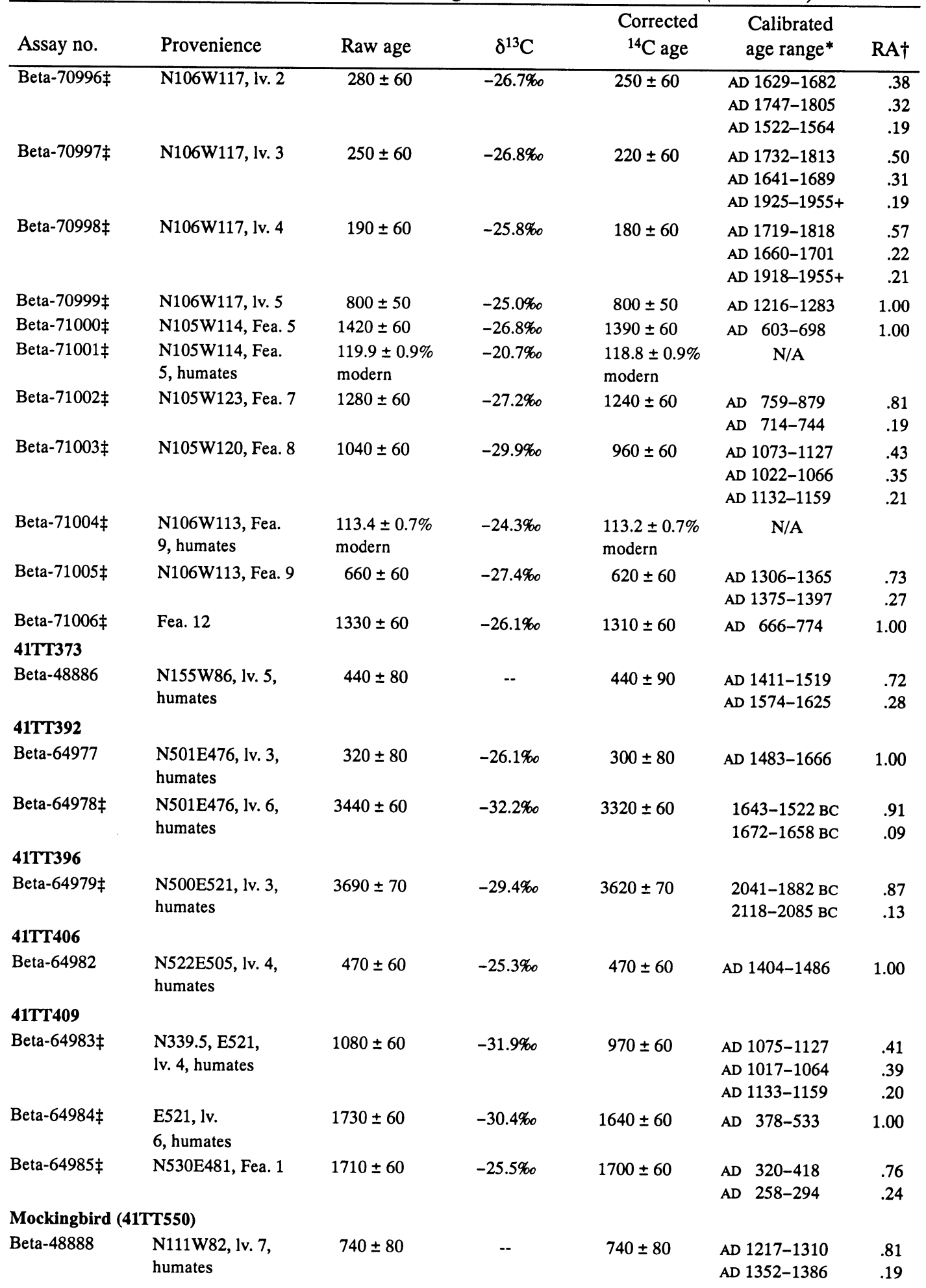


TABLE $1 .{ }^{14} \mathrm{C}$ Assays from Prehistoric Archaeological Sites in Eastern Texas (Continued)

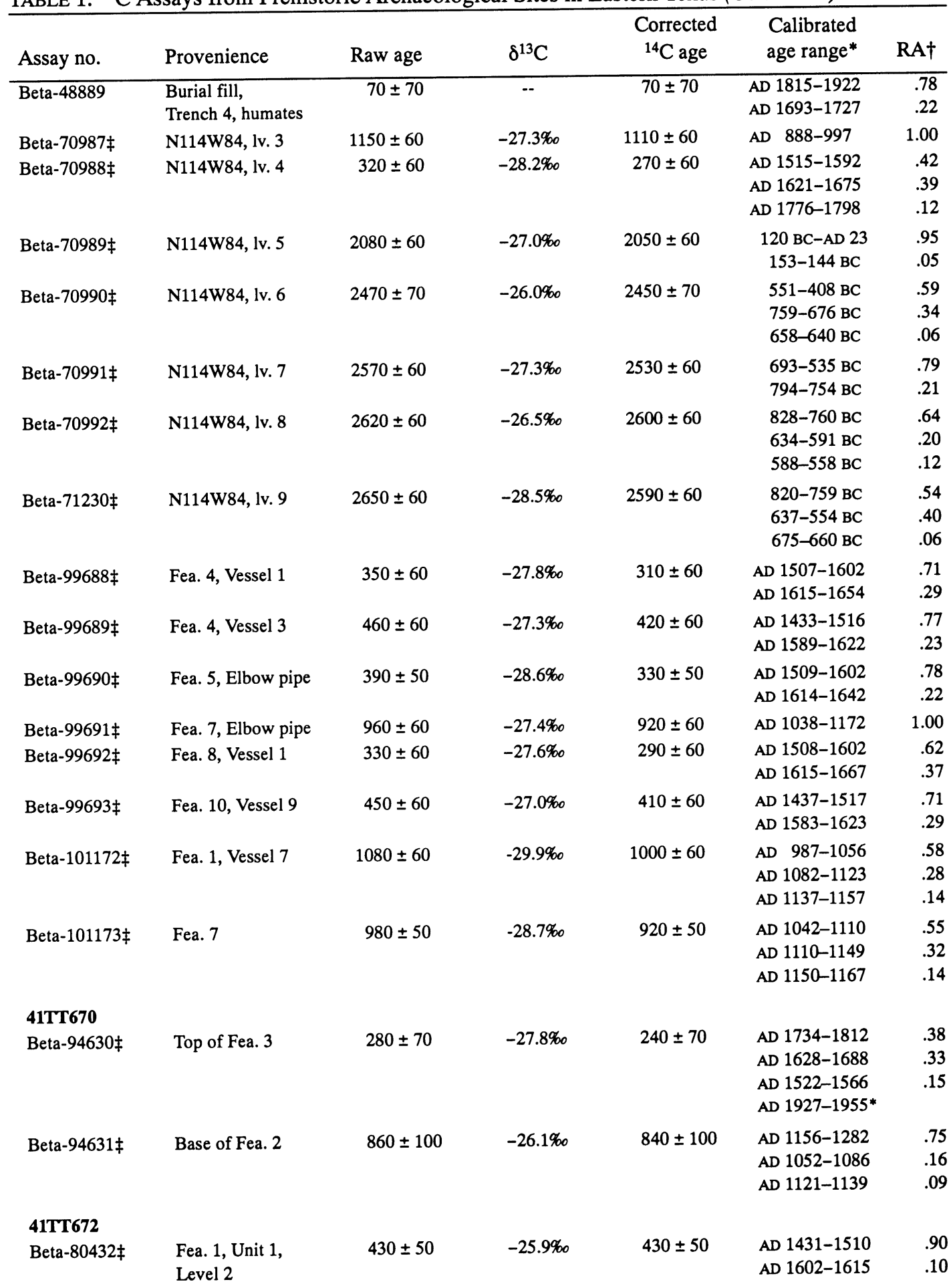


TABLE $1 .{ }^{14} \mathrm{C}$ Assays from Prehistoric Archaeological Sites in Eastern Texas (Continued)

\begin{tabular}{|c|c|c|c|c|c|c|}
\hline Assay no. & Provenience & Raw age & $\delta^{13} \mathrm{C}$ & $\begin{array}{l}\text { Corrected } \\
{ }^{14} \mathrm{C} \text { age }\end{array}$ & $\begin{array}{l}\text { Calibrated } \\
\text { age range* }\end{array}$ & $\mathrm{RA} \dagger$ \\
\hline \multicolumn{7}{|c|}{ Harroun (41UR10) } \\
\hline $\mathrm{Tx}-84$ & $\begin{array}{l}\text { Md. D, structure } \\
\text { under mound }\end{array}$ & $490 \pm 100$ & -- & $490 \pm 108$ & $\begin{array}{l}\text { AD } 1386-1515 \\
A D 1311-1352 \\
A D 1593-1620\end{array}$ & $\begin{array}{l}.72 \\
.17 \\
.10\end{array}$ \\
\hline $\mathrm{T} x-238$ & Md. B & $265 \pm 65$ & -- & $265 \pm 76$ & $\begin{array}{l}\text { AD } 1511-1599 \\
\text { AD } 1616-1680 \\
\text { AD } 1756-1804\end{array}$ & $\begin{array}{l}.39 \\
.34 \\
.20\end{array}$ \\
\hline Tx-239 & Md. C & $330 \pm 110$ & -- & $330 \pm 117$ & AD 1444-1668 & .98 \\
\hline $\mathrm{T} x-240$ & Md. C & $555 \pm 70$ & -- & $555 \pm 81$ & $\begin{array}{l}\text { AD } 1382-1437 \\
\text { AD } 1308-1357\end{array}$ & $\begin{array}{l}.56 \\
.44\end{array}$ \\
\hline $\mathrm{Tx}-241$ & $\begin{array}{l}\text { Md. D, beam } \\
\text { above House } 4 \\
\text { floor }\end{array}$ & $345 \pm 75$ & - & $345 \pm 85$ & AD $1479-1641$ & 1.00 \\
\hline \multicolumn{7}{|c|}{ Dalton Mound (41UR11) } \\
\hline$T x-83$ & $\begin{array}{l}\text { Latest of two } \\
\text { structures under } \\
\text { mound }\end{array}$ & $480 \pm 110$ & -- & $480 \pm 117$ & $\begin{array}{l}\text { AD } 1391-1520 \\
\text { AD } 1571-1626 \\
\text { AD } 1316-1346\end{array}$ & $\begin{array}{l}.68 \\
.21 \\
.11\end{array}$ \\
\hline \multicolumn{7}{|l|}{ 41UR105 } \\
\hline Tx-7991 & $\begin{array}{l}\text { Unit N178- } \\
\text { 179E200, } \\
\text { levels } 7 \& 8\end{array}$ & $1107 \pm 51$ & $-22.1 \%$ & $1154 \pm 51$ & $\begin{array}{ll}\mathrm{AD} & 862-973 \\
\mathrm{AD} & 823-838\end{array}$ & $\begin{array}{l}.92 \\
.08\end{array}$ \\
\hline \multicolumn{7}{|l|}{ 41UR118 } \\
\hline Beta-72372 $\ddagger$ & $\begin{array}{l}\text { BHT } 46 \text {, organic } \\
\text { material on } \\
\text { pottery sherd }\end{array}$ & $300 \pm 60$ & $-27.3 \%$ & $260 \pm 60$ & $\begin{array}{l}\text { AD } 1624-1679 \\
\text { AD } 1518-1591 \\
\text { AD } 1766-1803\end{array}$ & $\begin{array}{l}.40 \\
.32 \\
.20\end{array}$ \\
\hline Beta-90532 & $\begin{array}{l}\text { N123/E143 } \\
\text { N118/E131 }\end{array}$ & $440 \pm 40$ & $-25.0 \%$ & $440 \pm 40$ & AD $1430-1483$ & 1.00 \\
\hline \multicolumn{7}{|l|}{ 41UR129 } \\
\hline Tx-7990 & $\begin{array}{l}\text { N198E211, } \\
\text { soil humate }\end{array}$ & $403 \pm 41$ & $-21.6 \% 0$ & $458 \pm 41$ & $\mathrm{AD} 1425-1470$ & 1.00 \\
\hline Beta-90533 & $\begin{array}{l}\text { Lots } 1294 \text {, } \\
1121-\mathrm{A}-, 1121-\mathrm{C} \\
\text { and } 1121-4\end{array}$ & $1220 \pm 60$ & $-25.0 \%$ & $1220 \pm 60$ & 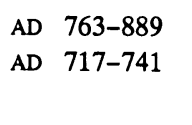 & $\begin{array}{l}.88 \\
.12\end{array}$ \\
\hline \multicolumn{7}{|l|}{ 41UR133 } \\
\hline Tx-7989 & N184E402, lv. 4 & $578 \pm 118$ & $-26.5 \%$ & $554 \pm 118$ & $\mathrm{AD} 1295-1455$ & 1.00 \\
\hline Tx-7994 & $\begin{array}{l}\text { BHT } 21 \text {, Zone } 3 \text {, } \\
\text { soil humate }\end{array}$ & $266 \pm 42$ & $-23.6 \%$ & $243 \pm 42$ & AD 1638-1679 & .52 \\
\hline Beta-90534 & $\begin{array}{l}\text { BS6, Lots 2162, } \\
2158 \text { \& Sample 3; } \\
\text { BS 7, Lots 2146- } \\
2147\end{array}$ & $360 \pm 40$ & $-25.0 \%$ & $360 \pm 40$ & $\begin{array}{l}\text { AD } 1562-1630 \\
A D 1480-1523\end{array}$ & $\begin{array}{l}.61 \\
.39\end{array}$ \\
\hline \multicolumn{7}{|c|}{ Griffin Mound (41UR142) } \\
\hline Beta-65018 & $\begin{array}{l}\text { Fea. 1, } \\
110-130 \mathrm{~cm}\end{array}$ & $820 \pm 80$ & $-25.5 \% 0$ & $810 \pm 80$ & AD $1160-1292$ & .98 \\
\hline \multicolumn{7}{|c|}{ Camp Joy (41UR144) } \\
\hline Beta- 84435 & $\begin{array}{l}\text { Fea. 1, top } \\
\text { charcoal lens }\end{array}$ & $390 \pm 60$ & $-28.3 \%$ & $340 \pm 60$ & $\begin{array}{l}A D 1495-1605 \\
A D 1613-1636\end{array}$ & $\begin{array}{l}.83 \\
.17\end{array}$ \\
\hline
\end{tabular}


TABLE $1 .{ }^{14} \mathrm{C}$ Assays from Prehistoric Archaeological Sites in Eastern Texas (Continued)

\begin{tabular}{|c|c|c|c|c|c|c|}
\hline Assay no. & Provenience & Raw age & $\delta^{13} \mathrm{C}$ & $\begin{array}{l}\text { Corrected } \\
{ }^{14} \mathrm{C} \text { age }\end{array}$ & $\begin{array}{l}\text { Calibrated } \\
\text { age range* }\end{array}$ & RAt \\
\hline Beta-84436 & $\begin{array}{l}\text { Fea. 1, } \\
\text { top charcoal lens }\end{array}$ & $310 \pm 60$ & $-27.4 \%$ & $270 \pm 60$ & $\begin{array}{l}\text { AD } 1515-1592 \\
\text { AD } 1621-1675 \\
\text { AD } 1776-1798\end{array}$ & $\begin{array}{l}.42 \\
.39 \\
.12\end{array}$ \\
\hline \multicolumn{7}{|c|}{ Carlisle (41WD46) } \\
\hline Beta-17494 & $\begin{array}{l}\text { Midden, Fea. 1, } \\
25-35 \mathrm{~cm}\end{array}$ & $540 \pm 60$ & -- & $540 \pm 72$ & $\begin{array}{l}\text { AD } 1387-1443 \\
\text { AD } 1311-1351\end{array}$ & $\begin{array}{l}.65 \\
.35\end{array}$ \\
\hline \multicolumn{7}{|c|}{ McKenzie (41WD55) } \\
\hline Tx-4096 & $\begin{array}{l}\text { Unit A-2NE, } \\
1.30 \mathrm{~m} \text { bd; } \\
\text { structure covered } \\
\text { by low md. }\end{array}$ & $660 \pm 80$ & -- & $660 \pm 90$ & $\begin{array}{l}\text { AD } 1331-1396 \\
\text { AD } 1288-1329\end{array}$ & $\begin{array}{l}.61 \\
.39\end{array}$ \\
\hline Tx-4097 & $\begin{array}{l}\text { Unit A-2NE, } \\
1.22 \mathrm{~m} \text { bd; struc- } \\
\text { ture capped by } \\
\text { low md. }\end{array}$ & $630 \pm 80$ & -- & $630 \pm 90$ & AD 1298-1400 & 1.00 \\
\hline Tx-4098 & $\begin{array}{l}\text { Unit A-2SE, } \\
1.19 \mathrm{~m} \text { bd }\end{array}$ & $630 \pm 80$ & -- & $630 \pm 90$ & AD 1298-1400 & 1.00 \\
\hline Tx-4099 & $\begin{array}{l}\text { Unit A-3 (?), } \\
\text { SE, } 1.37 \mathrm{~m} \text { bd }\end{array}$ & $520 \pm 80$ & -- & $520 \pm 90$ & $\begin{array}{l}\text { AD 1381-1470 } \\
\text { AD 1308-1358 }\end{array}$ & $\begin{array}{l}.70 \\
.30\end{array}$ \\
\hline Tx-4956 & $\begin{array}{l}\text { Structure covered } \\
\text { by low md. }\end{array}$ & $680 \pm 40$ & -- & $680 \pm 57$ & $\begin{array}{l}\text { AD } 1346-1391 \\
A D 1284-1316\end{array}$ & $\begin{array}{l}.56 \\
.44\end{array}$ \\
\hline Tx-4957 & $\begin{array}{l}\text { Structure associ- } \\
\text { ated (under?) low } \\
\text { md. }\end{array}$ & $560 \pm 60$ & -- & $560 \pm 72$ & $\begin{array}{l}\text { AD } 1384-1433 \\
A D 1310-1354\end{array}$ & $\begin{array}{l}.55 \\
.45\end{array}$ \\
\hline $\mathrm{Tx}-4958$ & $\begin{array}{l}\text { Structure associ- } \\
\text { ated (under?) low } \\
\text { md. }\end{array}$ & $570 \pm 50$ & -- & $570 \pm 64$ & $\begin{array}{l}\text { AD } 1310-1354 \\
\text { AD } 1385-1426\end{array}$ & $\begin{array}{l}.50 \\
.50\end{array}$ \\
\hline Tx-4959 & $\begin{array}{l}\text { Structure associ- } \\
\text { ated with low md. }\end{array}$ & $670 \pm 70$ & -- & $670 \pm 81$ & $\begin{array}{l}\text { AD 1335-1395 } \\
\text { AD 1285-1326 }\end{array}$ & $\begin{array}{l}.59 \\
.41\end{array}$ \\
\hline \multicolumn{7}{|c|}{ Osborn (41WD73) } \\
\hline Tx-3049 & Fea. 4 & $1190 \pm 50$ & -- & $1190 \pm 64$ & $\begin{array}{ll}\mathrm{AD} & 779-895 \\
\mathrm{AD} & 915-955\end{array}$ & $\begin{array}{l}.79 \\
.21\end{array}$ \\
\hline \multicolumn{7}{|c|}{ Spoonbill (41WD109) } \\
\hline $\mathrm{Tx}-3570$ & Fea. 1 & $1010 \pm 80$ & -- & $1010 \pm 90$ & $\mathrm{AD} \quad 967-1162$ & 1.00 \\
\hline $\mathrm{Tx}-3571$ & $\begin{array}{l}\text { Fea. 2, } \\
\text { upper layer }\end{array}$ & $950 \pm 50$ & -- & $950 \pm 64$ & $\begin{array}{l}\text { AD } 1070-1129 \\
\text { AD } 1027-1070 \\
\text { AD } 1131-1160\end{array}$ & $\begin{array}{l}.45 \\
.32 \\
.23\end{array}$ \\
\hline Tx-3572 & $\begin{array}{l}\text { Fea. } 2 \text {, } \\
\text { middle layer }\end{array}$ & $720 \pm 80$ & -- & $720 \pm 90$ & $\begin{array}{l}\text { AD } 1228-1318 \\
\text { AD } 1344-1391\end{array}$ & $\begin{array}{l}.68 \\
.32\end{array}$ \\
\hline Tx-3573 & Fea. 5 & $690 \pm 70$ & -- & $690 \pm 81$ & $\begin{array}{l}\text { AD 1334-1395 } \\
\text { AD 1276-1326 }\end{array}$ & $\begin{array}{l}.53 \\
.47\end{array}$ \\
\hline Tx-3574 & Fea. 9 & $690 \pm 60$ & -- & $690 \pm 72$ & $\begin{array}{l}\text { AD } 1339-1393 \\
\text { AD } 1277-1322\end{array}$ & $\begin{array}{l}.53 \\
.47\end{array}$ \\
\hline $\begin{array}{l}\text { 41WD382 } \\
\text { Beta-96373 }\end{array}$ & ST 65 & $770 \pm 50$ & $-22.8 \%$ & $810 \pm 50$ & AD 1206-1281 & 1.00 \\
\hline \multicolumn{7}{|c|}{ Hines (41WD450) } \\
\hline$T x-3043$ & $\begin{array}{l}\text { Fea. 1, large } \\
\text { rectangular } \\
\text { structure }\end{array}$ & $910 \pm 50$ & -- & $910 \pm 64$ & $\begin{array}{l}\text { AD } 1042-1109 \\
\text { AD } 1111-1149 \\
\text { AD } 1151-1189\end{array}$ & $\begin{array}{l}.42 \\
.27 \\
.27\end{array}$ \\
\hline
\end{tabular}


$\underline{\text { TABLE } 1 .{ }^{14} \mathrm{C} \text { Assays from Prehistoric Archaeological Sites in Eastern Texas (Continued) }}$

\begin{tabular}{|c|c|c|c|c|c|c|}
\hline Assay no. & Provenience & Raw age & $\delta^{13} \mathrm{C}$ & $\begin{array}{l}\text { Corrected } \\
{ }^{14} \mathrm{C} \text { age }\end{array}$ & $\begin{array}{l}\text { Calibrated } \\
\text { age range* }\end{array}$ & RA $\dagger$ \\
\hline \multicolumn{7}{|c|}{ Taddlock (41WD482) } \\
\hline Tx-3046 & $\begin{array}{l}\text { Midden A, } \\
\text { Unit } 25,30-40 \mathrm{~cm}\end{array}$ & $950 \pm 50$ & -- & $950 \pm 64$ & $\begin{array}{l}\text { AD } 1070-1129 \\
\text { AD } 1027-1070 \\
\text { AD } 1131-1160\end{array}$ & $\begin{array}{l}.45 \\
.32 \\
.23\end{array}$ \\
\hline Tx-3047 & $\begin{array}{l}\text { Midden A, } \\
\text { Unit } 25,30-40 \mathrm{~cm}\end{array}$ & $970 \pm 40$ & -- & $970 \pm 57$ & $\begin{array}{l}\text { AD } 1076-1126 \\
\text { AD } 1017-1063 \\
\text { AD } 1134-1159\end{array}$ & $\begin{array}{l}.41 \\
.39 \\
.20\end{array}$ \\
\hline Tx-3048 & $\begin{array}{l}\text { Midden A, } \\
\text { Unit } 31,20-30 \mathrm{~cm}\end{array}$ & $1010 \pm 60$ & -- & $1010 \pm 72$ & $\begin{array}{l}\text { AD } 974-1061 \\
\text { AD } 1078-1125 \\
\text { AD } 1135-1158\end{array}$ & $\begin{array}{l}.60 \\
.26 \\
.13\end{array}$ \\
\hline Tx-3050 & $\begin{array}{l}\text { Midden A, Unit } \\
18,40-50 \mathrm{~cm} \text {, } \\
\text { same context as } \\
\text { Tx-3047 }\end{array}$ & $490 \pm 60$ & -- & $490 \pm 72$ & $\begin{array}{l}\text { AD } 1393-1488 \\
\text { AD } 1321-1340\end{array}$ & $\begin{array}{l}.91 \\
.08\end{array}$ \\
\hline \multicolumn{7}{|c|}{ Killabrew (41WD495) } \\
\hline Tx-3045 & Fea. 3 & $1760 \pm 50$ & -- & $1760 \pm 64$ & AD $\quad 228-384$ & 1.00 \\
\hline \multicolumn{7}{|c|}{ Steck (41WD529) } \\
\hline Tx-3473 & $\begin{array}{l}\text { Trash } \\
\text { Midden }\end{array}$ & $480 \pm 80$ & -- & $480 \pm 90$ & $\begin{array}{l}\text { AD } 1393-1515 \\
\text { AD } 1592-1621 \\
\text { AD } 1322-1339\end{array}$ & $\begin{array}{l}.82 \\
.12 \\
.06\end{array}$ \\
\hline
\end{tabular}

${ }^{*}$ Calibrated dates ending in $1955^{*}$ denote the influence of atomic bomb ${ }^{14} \mathrm{C}$.

$\dagger \mathrm{RA}=$ relative area under probability distribution

$\ddagger$ AMS assays

$\S 2-\sigma$ calibrated ages

Note: ${ }^{14} \mathrm{C}$ assays with $\delta^{13} \mathrm{C}$ are corrected (for isotopic fractionation) and calibrated at a 20 -yr interval scale for calendric dates using CALIB 3.03c, Test 10 (Stuiver and Reimer 1993a, 1993b). One assay (SM-532) from 41DT86 was calibrated using Kromer and Becker (1993). Assays on nutshell and wood charcoal lacking $\delta^{13} \mathrm{C}$ values use the value estimates for fractionation correction suggested by Stuiver and Reimer (1993b: Table 1), namely $-25 \%$ for nutshells and charcoal, and $-10 \%$ for charred maize. These assays have standard deviations that include an error in the estimated ${ }^{13} \mathrm{C}$. In the case of ${ }^{14} \mathrm{C}$ assays from the George C. Davis site (41CE19), an average $\delta^{13} \mathrm{C}$ value of $-26.48 \%$ was employed (Story 1998: Table 1), except for those on maize, or on the four assays where the isotopic values were known (Tx-3271, Tx-3272, Tx-3273 and Tx-3308). 
TABLE 2. Oxidizable Carbon Ratio Dates from East Texas Sites

\begin{tabular}{|c|c|c|c|c|}
\hline Assay no. & Provenience & $\begin{array}{l}\text { Calculated } \\
\text { OCR date* }\end{array}$ & $\begin{array}{c}\text { Confidence } \\
\text { interval }\end{array}$ & $\begin{array}{l}\text { Rounded date } \\
\text { (AD) }\end{array}$ \\
\hline \multicolumn{5}{|l|}{$41 \mathrm{BW553}$} \\
\hline ACT 1981 & Unit $69,34-36 \mathrm{~cm}, 2 \mathrm{~A}$ horizon & 411 & \pm 12 & $1540 \pm 10$ \\
\hline ACT 1982 & Unit 69, Fea. $5,44-46 \mathrm{~cm}$ & 596 & \pm 17 & $1350 \pm 20$ \\
\hline ACT 1983 & $\begin{array}{l}\text { Unit } 67 \text {, Fea. } 6,10-11 \mathrm{~cm} \text {, } \\
\text { A1 horizon midden }\end{array}$ & 276 & \pm 8 & $1670 \pm 10$ \\
\hline ACT 1984 & $\begin{array}{l}\text { Unit } 67 \text {, Fea. } 6,20-21 \mathrm{~cm} \text {, } \\
\text { A1 horizon midden }\end{array}$ & 299 & \pm 8 & $1650 \pm 10$ \\
\hline ACT 1985 & $\begin{array}{l}\text { Unit } 67, \text { Fea. } 6,30-31 \mathrm{~cm} \text {, } \\
\text { A1 horizon midden }\end{array}$ & 383 & \pm 11 & $1570 \pm 10$ \\
\hline ACT 1986 & Unit $67,48-50 \mathrm{~cm}$, below midden & 537 & \pm 16 & $1410 \pm 20$ \\
\hline ACT 1987 & Unit 67 , above Fea. 7 burial, $59-61 \mathrm{~cm}$ & 907 & \pm 27 & $1040 \pm 30$ \\
\hline ACT 1988 & Unit 30, Fea. 3, 70-80 cm & 1009 & \pm 30 & $940 \pm 30$ \\
\hline ACT 1989 & Unit 24, Fea. $1,30-40 \mathrm{~cm}$ & 759 & \pm 22 & $1190 \pm 20$ \\
\hline \multicolumn{5}{|c|}{ Knight's Bluff (41CS14) } \\
\hline ACT 2618 & ST $22,31 \mathrm{~cm}$ bs & 1700 & \pm 50 & $250 \pm 50$ \\
\hline ACT 2619 & ST $33,26 \mathrm{~cm}$ bs & 1649 & \pm 49 & $300 \pm 50$ \\
\hline ACT 2716 & Near ST $22,15 \mathrm{~cm}$ bs & 1158 & -- & 790 \\
\hline \multicolumn{5}{|c|}{ Tom Moore (41PN149) } \\
\hline АCТ 2669 & OCR 1 & 1502 & \pm 45 & $450 \pm 50$ \\
\hline ACT 2670 & OCR 2 & 1570 & \pm 47 & $380 \pm 50$ \\
\hline \multicolumn{5}{|l|}{$41 T T 670$} \\
\hline ACT 1974 & Unit $20,7-10 \mathrm{~cm}$ & 687 & \pm 20 & $1260 \pm 20$ \\
\hline ACT 1975 & Unit $20,17-20 \mathrm{~cm}$, Area A midden & 713 & \pm 21 & $1240 \pm 20$ \\
\hline ACT 1976 & Unit $20,25-28 \mathrm{~cm}$, Area A midden & 762 & \pm 22 & $1190 \pm 20$ \\
\hline ACT 1977 & $\begin{array}{l}\text { Unit } 20 \text {, Fea. } 2,35-38 \mathrm{~cm} \text {, } \\
\text { base of midden }\end{array}$ & 746 & \pm 22 & $1200 \pm 20$ \\
\hline ACT 1978 & $\begin{array}{l}\text { Unit } 20 \text {, Fea. } 2,40-43 \mathrm{~cm} \text {, bottom of } \\
\text { feature hearth }\end{array}$ & 788 & \pm 23 & $1160 \pm 20$ \\
\hline ACT 1979 & Unit $20,49-51 \mathrm{~cm}$, below midden & 1005 & \pm 30 & $940 \pm 30$ \\
\hline ACT 1980 & Unit $20,63-66 \mathrm{~cm}$, below midden & 898 & \pm 26 & $1050 \pm 30$ \\
\hline \multicolumn{5}{|c|}{ Camp Joy Mound (41UR144) } \\
\hline ACT 2218 & South Trench, Fea. 1, $57 \mathrm{~cm}$ & 296 & \pm 8 & $1650 \pm 10$ \\
\hline АCT 2219 & Northwest wall, Fea. 1 & 420 & \pm 12 & $1530 \pm 10$ \\
\hline
\end{tabular}

*In years before present, defined as 1950 , to correspond to ${ }^{14} \mathrm{C}$ data 